\title{
Regulation of the anaphase promoting complex (APC/C) in the mitotic and meiotic cell cycle of Saccharomyces cerevisiae
}

\author{
Dissertation \\ zur Erlangung des Doktorgrades \\ der Mathematisch-Naturwissenschaftlichen Fakultäten \\ der Georg-August-Universität zu Göttingen
}

\author{
vorgelegt von \\ Melanie Bolte \\ aus \\ Hann. Münden
}

Göttingen 2003 
Die vorliegende Arbeit wurde von Februar 2001 bis Dezember 2003 in der Arbeitsgruppe von Dr. Stefan Irniger in der Abteilung Molekulare Mikrobiologie und Genetik von Prof. Dr. Gerhard H. Braus am Institut für Mikrobiologie und Genetik der Georg-AugustUniversität Göttingen angefertigt.

Teile dieser Arbeit wurden veröffentlicht in:

Bolte M, Steigemann P, Braus GH, Irniger S. (2002) Inhibition of APC-mediated proteolysis by the meiosis-specific protein kinase Ime2. Proc Natl Acad Sci U S A., 99, 4385-4390.

Bolte M, Dieckhoff P, Krause C, Braus GH, Irniger S. (2003) Synergistic inhibition of APC/C by glucose and activated Ras proteins can be mediated by each of the Tpk1-3 proteins in Saccharomyces cerevisiae. Microbiology, 149, 1205-1216.

D7

Referent: Prof. Dr. G.H. Braus

Korreferent: Prof. Dr. H.-U. Mösch

Tag der mündlichen Prüfung: 22. 01. 2004 


\section{Contents}

Summary

Zusammenfassung.

\section{Chapter 1}

\section{Introduction}

1. The eukaryotic cell cycle

1.1 The life cycle of Saccharomyces cerevisiae ................................................... 4

1.2 The role of cyclin dependent kinases ............................................................ 5

2. Ubiquitin-dependent proteolysis ............................................................................. 7

3. The anaphase promoting complex/cyclosome (APC/C) …........................................ 9

3.1 Composition of the APC/C .......................................................................... 9

3.2 Roles of APC/C during the cell cycle........................................................ 10

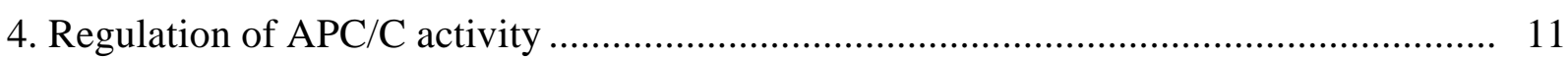

4.1 Phosphorylation regulates APC/C activity ................................................. 11

4.2 Control of APC/C activity by checkpoints ................................................... 12

4.2.1 Spindle assembly checkpoint......................................................... 12

4.2.2 Spindle orientation checkpoint ...................................................... 13

4.2.3 DNA damage checkpoint ............................................................ 14

5. The meiotic cell cycle of Saccharomyces cerevisiae ..................................................... 15

5.1 Differences between the mitotic and meiotic cell cycle ................................... 15

5.2 Regulation cascade governs initiation of sporulation..................................... 17

5.3 Role of the Ime2 protein kinase in meiosis..................................................... 19

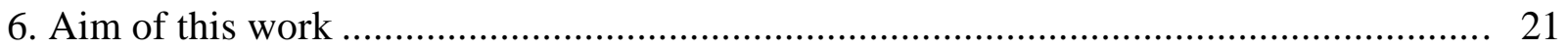

Chapter 2 ...................................................................................... 28

Synergistic inhibition of APC/C by glucose and activated Ras proteins can be mediated by each of the three Tpk1-3 proteins in Saccharomyces cerevisiae

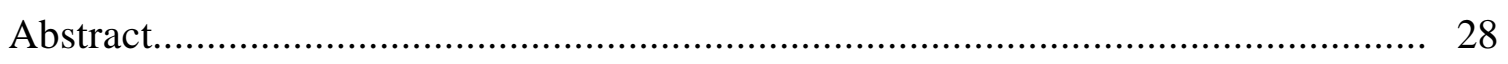

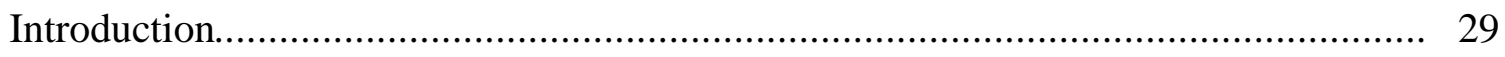

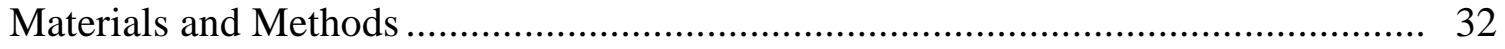




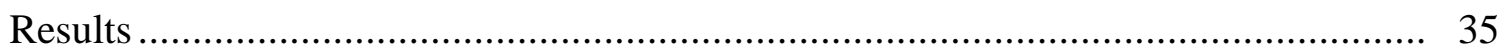

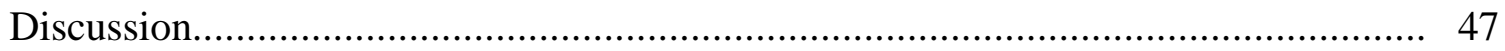

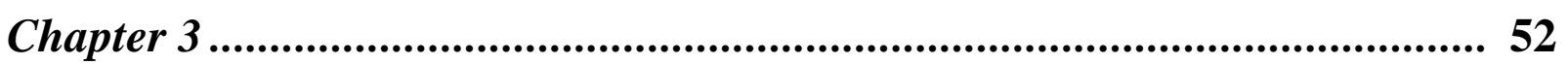

Inhibition of APC-mediated proteolysis by the meiosis-specific protein kinase Ime2

Abstract

Chapter 4 ............................................................................................... 73

Ime2 protein stability depends on an intact $\mathrm{C}$-terminal domain and is required for yeast sporulation

Abstract

Chapter 5 ................................................................................ 95

Conclusions and outlook

Curriculum Vitae ........................................................................................... 111 


\section{Summary}

Ubiquitin-dependent proteolysis is a crucial process in the eukaryotic cell cycle. A key player of this system is a large complex termed the anaphase promoting complex/cyclosome (APC/C). The APC/C is an ubiquitin ligase, which is essential for the progression through mitosis. The APC/C ligates chains of ubiquitin molecules to lysine residues of its substrate proteins and thereby marks them for degradation by the $26 \mathrm{~S}$ proteasome. The activity of the APC/C is precisely regulated during the cell cycle. The aim of this work was the characterisation of protein kinases involved in $\mathrm{APC} / \mathrm{C}$ regulation in the mitotic and meiotic cell cycle of the yeast Saccharomyces cerevisiae.

In the first part of this work, control of the APC/C by the protein kinase A (PKA) pathway was analysed. Glucose and activated Ras2 protein both induce PKA activity. Experimental data imply that these two signals are able to affect the APC/C synergistically. PKA of $S$. cerevisiae is encoded by three different genes, TPK1-3. This work revealed that all three genes have redundant functions in $\mathrm{APC} / \mathrm{C}$ regulation.

In the second part of this work, Ime2, a meiosis-specific protein kinase, was characterised. Ime 2 was identified in a screen for negative regulators of the APC/C. Further experiments demonstrate, that Ime 2 phosphorylates the APC/C regulator Cdh1 and thereby leads to inhibition of the APC/C. Ectopic expression of IME2 causes stabilisation of cyclins and other APC/C substrates. Furthermore IME2 expression in vegetative cells was shown to arrest cells in mitosis and to inhibit bud formation. These results suggest that Ime 2 represents a meiosis-specific regulator of the APC/C.

Finally, this work focused on the regulation of Ime 2 stability. Ime 2 protein levels were shown to fluctuate during meiosis. By the construction and analysis of an IME2 deletion set, the N-terminal region was identified as the part of the protein responsible for kinase activity, whereas the C-terminal 241 amino acids were shown to be essential for Ime2 instability. Smaller deletions did not show a distinct effect on stability of the resulting truncated proteins suggesting that two or more degradation signals are located in the Cterminal region. Deletions resulting in proteins with a truncated C-terminus led to a stabilised and active version of the kinase, which causes cells to form abnormal asci. This result indicates that the instability of Ime2 is important for proper progression through meiosis. 


\section{Zusammenfassung}

Die Ubiquitin-abhängige Proteolyse ist ein kritischer Prozess im eukaryontischen Zellzyklus. Ein Schlüsselfaktor dieses Systems ist der Anaphase-promoting Komplex/ Cyclosom (APC/C). Der APC/C ist eine Ubiquitinligase, die essentiell für den Ablauf der Mitose ist. Der APC/C ligiert Ketten von Ubiquitinmolekülen an die Lysinreste seiner Substrate, um diese Proteine für den Abbau durch das 26S Proteasom zu markieren. Die Aktivität des APC/C ist im Verlauf des Zellzyklus präzise reguliert. Das Ziel dieser Arbeit war die Charakterisierung von Proteinkinasen, die in die Regulation des APC/C im mitotischen und meiotischen Zellzyklus der Hefe Saccharomyces cerevisiae involviert sind. Im ersten Teil dieser Arbeit wurde die Kontrolle des APC/C durch den Proteinkinase A (PKA)-Signalweg analysiert. Glucose und aktiviertes Ras2 Protein sind in der Lage die PKA zu aktivieren. Die experimentellen Daten zeigten, dass diese beiden Signale den APC/C synergistisch beeinflussen können. Die PKA von S. cerevisiae wird von drei verschiedenen Genen, TPK1-3, kodiert. Diese Arbeit offenbarte, dass diese drei Gene eine redundante Funktion in Bezug auf die Regulation des APC/C besitzten.

Im zweiten Teil der Arbeit wurde die meiosespezifische Kinase Ime2 charakterisiert. Ime2 wurde bei der Suche nach negativen Regulatoren des APC/C identifiziert. Weitere Untersuchungen demonstrierten, dass Ime 2 den APC/C-Regulator Cdh1 phosphorylieren kann und dadurch zur Inhibierung des APC/C führt. Ektopische Expression von IME2 verursacht die Stabilisierung von Cyclinen und weiteren APC/C Substraten. Außerdem führt die Expression von IME2 zu einem Zellzyklusarrest in der Mitose und verhindert die Sprossung. Diese Ergebnisse weisen darauf hin, dass Ime2 ein meiosespezifischer Regulator des APC/C ist. Schließlich befasste sich diese Arbeit mit der Regulation der Stabilität des Ime2 Proteins. Während der Meiose schwankt die Ime2 Proteinmenge. Durch die Konstruktion und Analyse einer Reihe von IME2-Deletionen konnte die Kinaseaktivität von Ime2 der N-terminalen Region des Proteins zugeordnet werden, wohingegen den letzten 241 Aminosäuren am C-Terminus eine Funktion in der Proteininstabilität zukommt. Kleinere Deletionen zeigten keinen ausgeprägten Effekt auf die Stabilität. Dies legt die Vermutung nahe, dass in der C-terminalen Region mindestens zwei Degradationssignale vorhanden sind. Deletionen, die zu Proteinen mit verkürtztem C-Terminus führten, ergaben eine stabilisierten und aktiven Form der Kinase, die zur Bildung von ungewöhnlichen Asci führt. Dieses Ergebnis weist darauf hin, dass die Instabilität von Ime2 wichtig für den korrekten Ablauf der Meiose ist. 


\section{Chapter1}

\section{Introduction}

\section{The eukaryotic cell cycle}

The central function of the eukaryotic cell cycle is the production of exact replicas of the parent cell. Therefore, the chromosomes have to be duplicated and segregated equally to both mother and daughter cell. In order to conserve the genetic information, the cell has to ensure that all steps of duplication and segregation take place in the correct order.

The eukaryotic cell cycle can be divided into four phases: G1-, S-, G2- and M-phase. During S-phase (synthesis-phase) chromosomes and cell components are duplicated. In mitosis or M-phase the duplicated chromosomes are distributed equally between mother and daughter cell and cytokinesis takes place, resulting in two identical cells (Murray and Hunt 1993). S- and M-phase are interrupted by "gap"-phases termed G1 and G2 as shown for the budding yeast Saccharomyces cerevisiae in Figure 1.

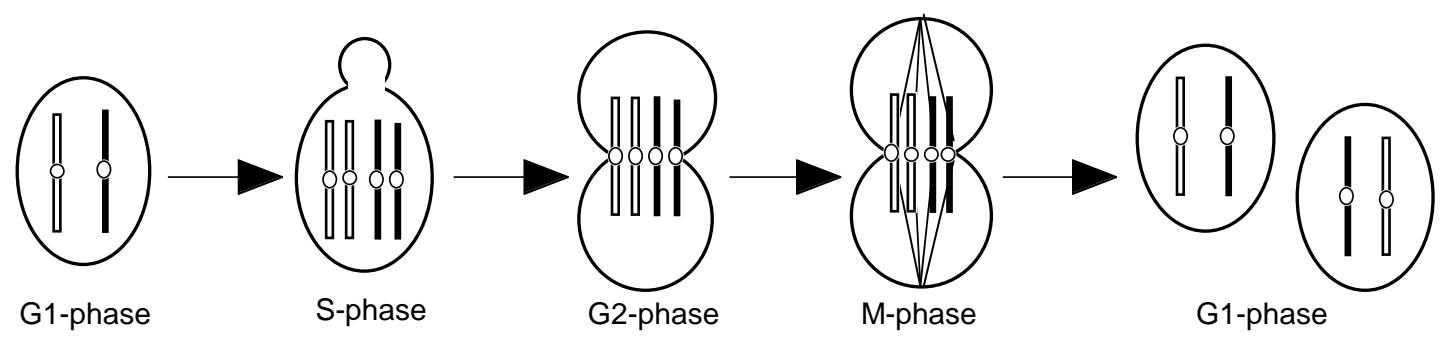

Fig. 1 Cell cycle of budding yeast

The cell cycle can be divided into four phases. During S-phase DNA is duplicated and bud formation occurs. S-phase is followed by the G2-phase, in which the yeast cell grows. During mitosis the duplicated DNA is segregated between mother and daughter cell and cell division takes place. In the subsequent G1-phase the cell prepares for a new round of cell division.

M-phase can be subdivided into four stages. In prophase, chromatin condensation occurs, centriols migrate to the cell poles and the spindle apparatus is built. In metaphase, chromosomes arrange at the equatorial plain of the spindle apparatus. Sister chromatides are separated and transported to the opposite cell poles during anaphase. In the final telophase chromosomes are decondensed and a new cell wall between mother and daughter cell is built. 
The central question of cell cycle control is: how does the cell manage to trigger cell cycle progression and, in case of a defect, how to stop the process instantly?

\subsection{The life cycle of Saccharomyces cerevisiae}

The baker's yeast $S$. cerevisiae serves as a model system for investigation of cell cycle control of eukaryotic organisms. The ascomycete $S$. cerevisiae can persist in a haploid or diploid form and propagates in an asexual and a sexual manner (Fig. 2). Dependent on the nutritional conditions baker's yeast exhibits a number of morphological and genetic developmental programms. Under good nutrient conditions diploid as well as haploid cells grow vegetatively in the unicellular yeast form, undergoing mitotic cell division. Thereby a genetically identical daughter cell emerges as a bud at the cell pole. When cells are starved for an essential nutrient, both haploids and diploids arrest in G1-phase and enter a stationary growth phase. The lack of nutrients decides which differentiation process is initiated: Under nitrogen starvation in the presence of a fermentable carbon source diploid cells start to grow in form of filamentous pseudohyphae (Gimeno et al. 1992). In this stage cells show a unipolar budding pattern, in which mother and daughter do not separate completely from each other, and the shape of the cell is longer and thinner as in the yeast form. Under the same nutrient conditions, haploid yeast cells undergo invasive growth. Then cells are elongated, bud formation occurs on both cell poles and, like in the pseudohyphae form, mother and daughter do not separate completely after cell division.

The absence of glucose in combination with nitrogen starvation and the presence of a nonfermentable carbon source triggers sporulation in diploid cells. During this meiotic reproduction one round of DNA-replication is followed by two rounds of chromosome segregation, resulting in four haploid ascospores that form a tetrade as ascus (Pringle and Saba 1981). In this process recombination between the homologous chromosomes takes place allowing the exchange of genetic material between parental chromosomes. Spores germinate under good nutrient conditions. In the haploid form two different mating types, MATa and MAT $\boldsymbol{\alpha}$, can be distinguished. Cells of opposite mating type can conjugate and form a diploid zygote. This sexual reproduction cycle ensures genetic variance among the resulting haploid offsprings. 


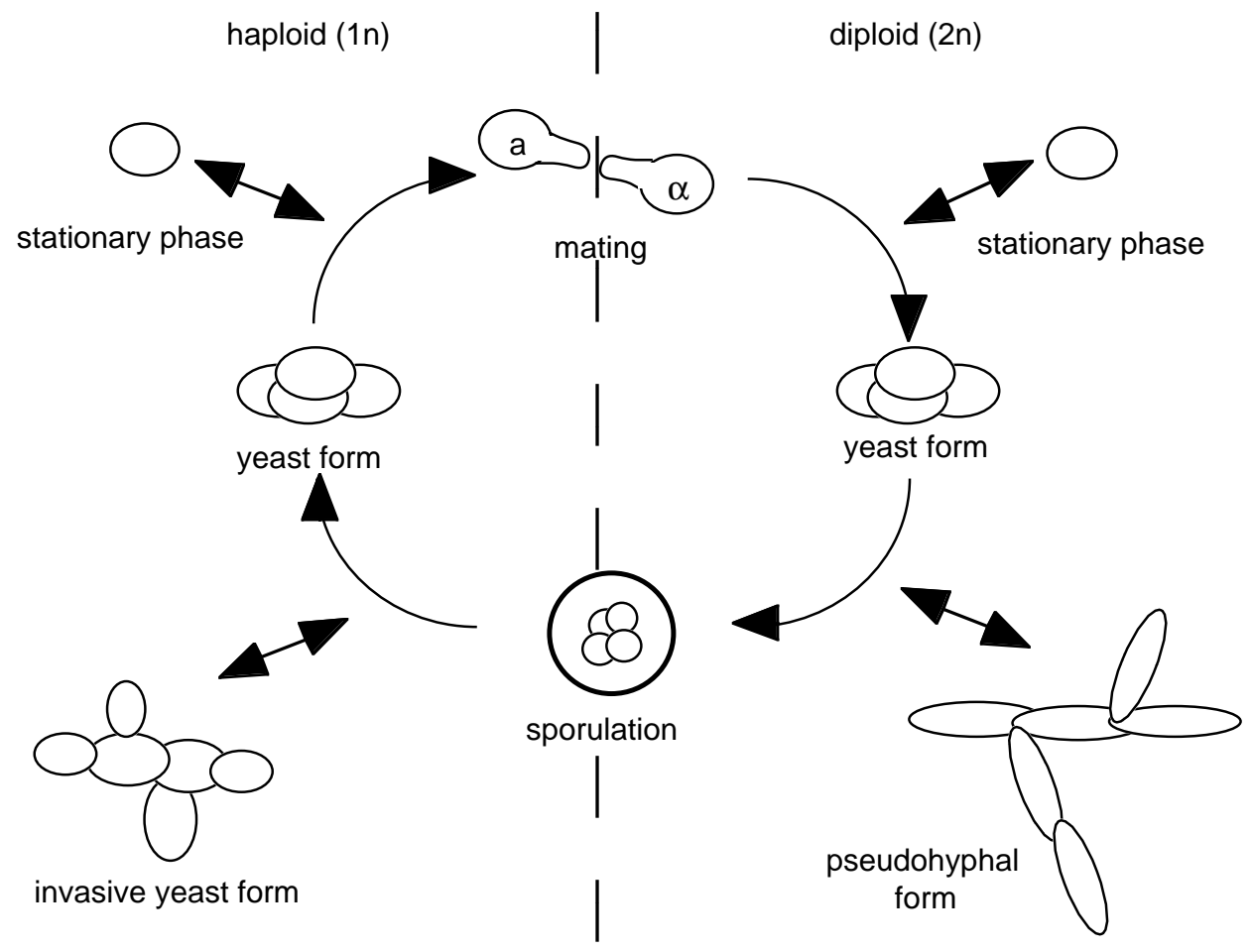

Fig. 2 The life cycle of Saccharomyces cerevisiae

Dependent on nutrient supply the yeast Saccharomyces cerevisiae can undergo different morphological and genetical differentiations. Under good nutrient conditions haploid and diploid cells grow in the vegetative yeast form. Nutrient starvation leads to a G1 arrest in the stationary growth phase. Haploid yeast cells of opposite mating type can conjugate in the presence of rich medium to form diploids. These diploids can sporulate to form haploids.

\subsection{The role of cyclin dependent kinases}

Key factors in the regulation of the mitotic cell cycle are cyclin dependent kinases (CDKs). They are present in all eukaryotic organisms and are highly conserved from yeast to humans (Beach et al. 1982; Lee and Nurse 1987). CDKs are proline-directed kinases that phosphorylate serine or threonine in S/T-P motifs (Langan et al. 1989). The activity of these kinases is regulated by the periodic association with different cyclins. Binding to the kinase is mediated by a conserved region in the cyclin called "cyclin box" (Morgan 1995). The kind of cyclin bound to the kinase determines the substrate specificity. S. cerevisiae possesses five cyclin dependent kinases: Cdc28, Pho85, Kin28, Ssn3, and Ctk1 (Toh and Nishizawa 2001). Cdc28 is the central coordinator of the yeast cell cycle. The CDC28 gene is transcribed and translated at constitutive levels in all phases of the cell cycle, but its kinase activity is subject to complex control. 
The Cdc28 activity cycle is linked to the chromosome cycle. Two major states of cyclin dependent kinase activity exist during the cell cycle, a state of high activity and a state of low activity (Amon 1997). The switch from low to high activity is critical for proper control of DNA replication. For the initiation of DNA replication first the pre-replication complex has to be built and this can only occur under low Cdc28 activity conditions. In contrast, the following activation of DNA-unwinding and polymerase function is promoted by high kinase activity (Dahmann and Futcher 1995; Diffley 1996; Piatti et al. 1996; Noton and Diffley 2000; Diffley 2001). Because high Cdc28 activity inhibits the formation of pre-replication complexes, reinitiation cannot occur until cells reduce their Cdc 28 activity by passing through mitosis. Thereby, the activity of cyclin dependent kinase ensures the accurate order of DNA replication and segregation during the mitotic cell cycle.

The periodicity of Cdc28 activity is achieved by cell cycle dependent binding and degradation of cyclins. Cdc28 cyclins are grouped into two categories: G1-cyclins and Btype cyclins. As the name implies the three G1-cyclins $\mathrm{Cln} 1, \mathrm{Cln} 2$, and $\mathrm{Cln} 3$, regulate events between the end of mitosis and the start of a new round of DNA replication. ClnCdc28 complexes stimulate DNA synthesis by accelerating the proteolysis of the ClbCdc28 inhibitor Sic1. Besides, Cln-Cdc28 complexes trigger bud formation and spindle pole body duplication. The other category includes six B-type cyclins, $\mathrm{Clb} 1$ to Clb6. They are expressed from S- to M-phase. Initiation of S-phase requires Cdc28 complexed with the S-phase cyclins Clb5 and Clb6. Formation of a mitotic spindle, spindle elongation and nuclear division rely on kinase complexes containing the B-type cyclins $\mathrm{Clb} 1$ to $\mathrm{Clb5}$ (Nasmyth 1993). Activity of the different Cdc28 complexes is restricted to distinct stages of the cell cycle. This cell cycle dependent activity is achieved by transcriptional and posttranslational control of cyclins. Proteolysis is the main post-translational control mechanism. G1-cyclin accumulation peaks at the end of G1-phase, whereas in G2-phase the amount of Cln1-3 declines due to their degradation (Schneider et al. 1998). B-type cyclins are stable during S-phase and mitosis but are degraded rapidly at the end of mitosis (Evans et al. 1983).

Cell cycle dependent degradation of cyclins is mediated by ubiquitin-dependent proteolysis. Ubiquitin is a 76 amino acid protein, which exhibits regulatory functions when covalently bound to proteins (Hershko and Ciechanover 1998). Mono-ubiquitination 
affects protein function in different ways (Stelter and Ulrich 2003), whereas ligation of chains of ubiquitin molecules marks proteins for rapid degradation by the $26 \mathrm{~S}$ proteasome.

\section{Ubiquitin-dependent proteolysis}

The transfer of ubiquitin to any substrate occurs in three steps (Hershko and Ciechanover 1998) (Fig. 3). First, an ubiquitin-activating enzyme (E1) uses ATP to generate a thiol ester between its activation site cysteine and the C-terminal glycine residue of ubiquitin. Second, the ubiquitin is transferred to an ubiquitin-conjugating enzyme (E2). Third, the E2 assembles with an ubiquitin-ligase (E3), and finally ubiquitin is ligated to lysine residues of a substrate protein. In $S$. cerevisiae a single gene, $U B A l$ encodes the E1 enzyme, whereas 13 different genes encoding E2 enzymes were identified (Peters 2002). E3 ligases are part of a large ubiquitin-ligase complex. E3 complexes facilitate the ubiquitination reaction indirectly by bringing substrate and ubiquitin-conjugating enzyme into close proximity. For general cell cycle progression two ubiquitin-ligase complexes are essential:

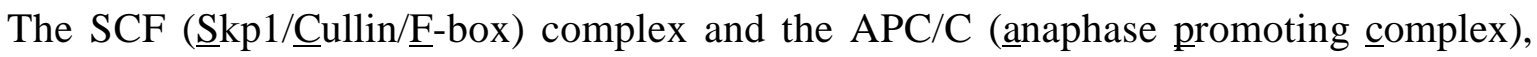
also called cyclosome.

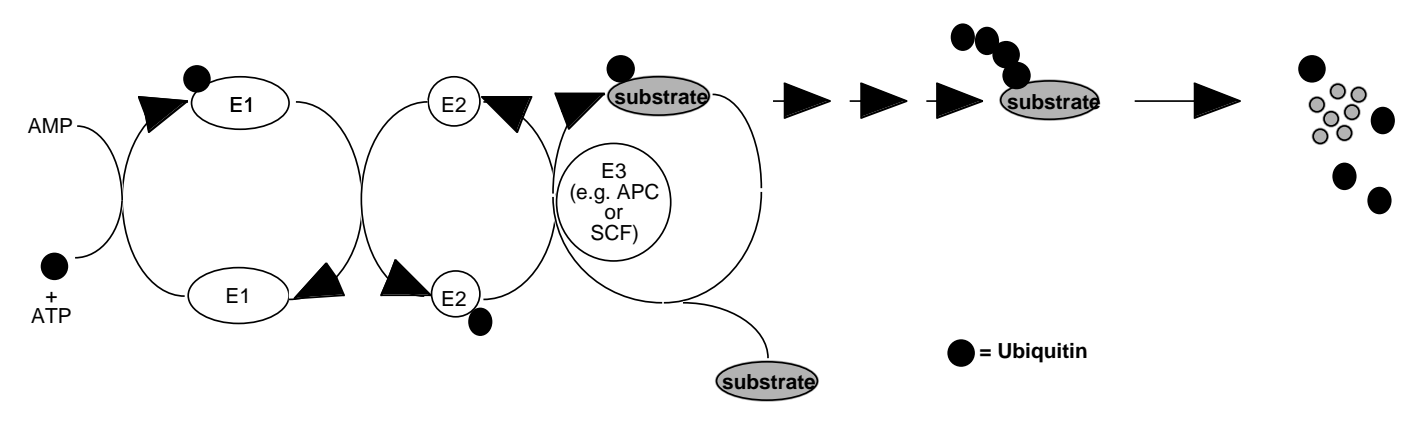

Fig. 3 The ubiquitination system

The covalent binding of chains of small ubiquitin molecules marks proteins for their rapid degradation by the $26 \mathrm{~S}$ proteasome. Ubiquitination is initiated by the binding of a ubiquitin molecule to a ubiquitin-activating enzyme (E1), this initial step is ATP-dependent. An ubiquitin-conjugating enzyme (E2) transfers ubiquitin to the ubiquitin-ligase (E3), which covalently attaches ubiquitin to the substrate protein. After several rounds of ubiquitination the multi-ubiquitinated protein is degraded by the $26 \mathrm{~S}$ proteasome.

The SCF is responsible for degradation of proteins involved in cell cycle regulation like the Cdc28 inhibitor Sic1 and the G1-cyclins. In addition, SCF-dependent proteolysis plays a role besides the cell cycle. Degradation of the transcription activator Gcn4, necessary for the general control of amino acid biosynthesis, is also mediated by the SCF complex 
(Irniger and Braus 2003). The F-box proteins Cdc4, Grr1, and Met30 can associate to the complex and determine its substrate specificity. $\mathrm{SCF}^{\mathrm{Cdc} 4}$ ubiquitinates $\mathrm{Sic} 1$ and $\mathrm{Gcn} 4$, whereas $\mathrm{SCF}^{\mathrm{Grrl}}$ marks G1-cyclins for degradation. The SCF complex is active throughout the cell cycle, but degradation of its substrates is regulated by phosphorylation of the substrates (Feldman et al. 1997).

In contrast to SCF, the activity of the APC/C complex is tightly cell cycle regulated. Its activation occurs at the metaphase/anaphase transition and persists until the end of G1phase. The function of the APC/C complex during mitosis is ubiquitination of B-type cyclins and other proteins involved in cell cycle regulation, like the securin Pds1, which has to be degraded to enable sister chromatid separation.

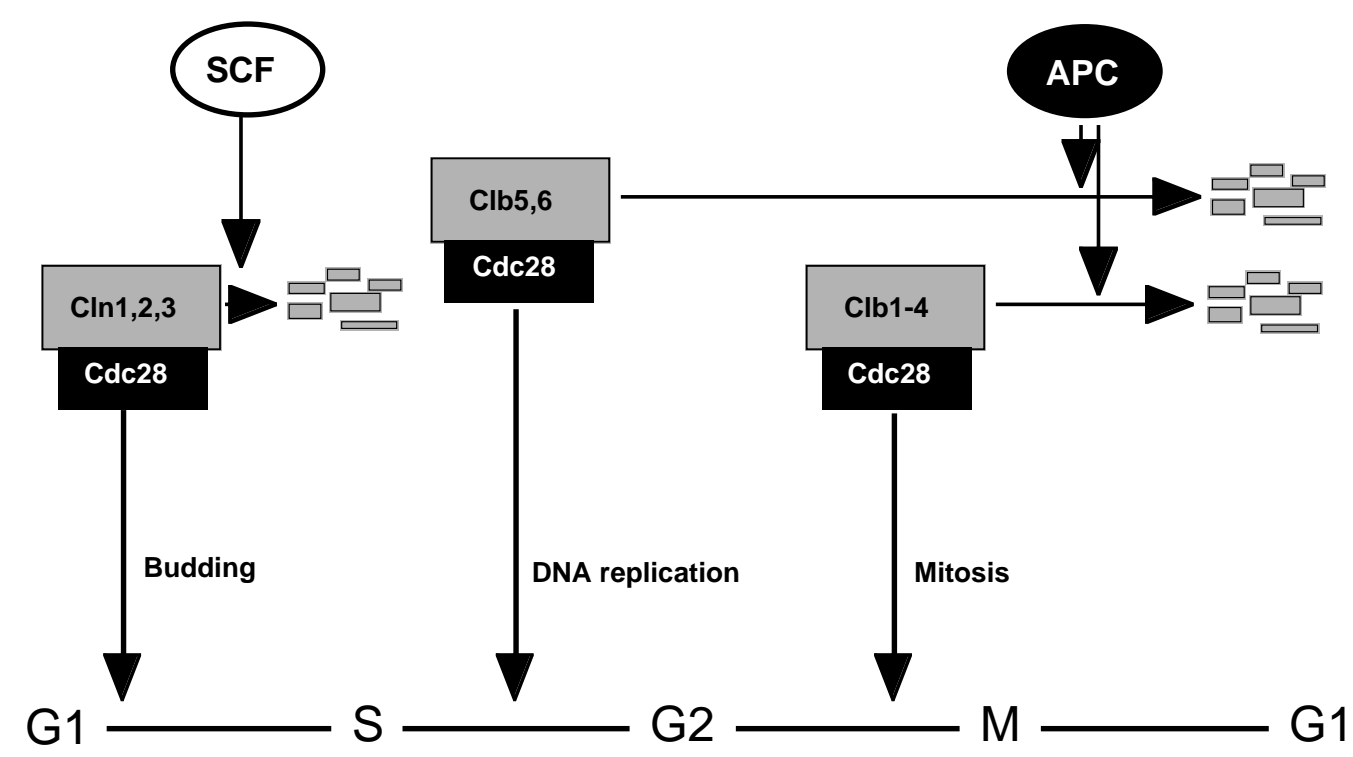

Fig.4 Progression through the eukaryotic cell cycle depends on Cdc28/Cyclin complexes and their destruction triggered by ubiquitin-ligases

Critical steps in the yeast mitotic cell cycle like budding, DNA replication, and mitosis itself are triggered by the cyclin dependent kinase $\mathrm{Cdc} 28$ in association with its cyclins. For proper progression through the cell cycle Cdc28 complexes have to be inactivated by destruction of the activating cyclin. Cyclin destruction is mediated by two ubiquitin-ligase complexes the $\underline{\operatorname{S} k p 1 / \underline{C} u l l i n / \underline{F}-b o x}$ complex (SCF) and the anaphase promoting complex, also called cyclosome (APC/C). 


\section{The anaphase promoting complex/cyclosome (APC/C)}

\subsection{Composition of the $\mathrm{APC} / \mathrm{C}$}

The composition of the APC/C complex has been investigated in many organisms. The Xenopus and human complexes contain at least 10 subunits, whereas the yeast APC/C consists of at least 12 subunits. Most yeast subunits have counterparts in vertebrates suggesting that the APC/C is highly conserved in the eukaryotic kingdom (Peters et al. 1996; Yu et al. 1998; Zachariae et al. 1998b). The core complex of the $S$. cerevisiae APC/C consists of the eleven subunits Apc1, Apc2, Apc4, Apc5, Apc9, Apc10, Apc11, Cdc16, Cdc23, Cdc26, and Cdc27. These proteins are bound together throughout the cell cycle. The association of additional regulatory subunits is cell cycle regulated. In yeast the three activators Cdh1 (also termed Hct1), Cdc20 and Ama1 had been identified (Zachariae and Nasmyth 1999). Little is known about the biochemical roles played by the individual subunits. Some of them, such as $\mathrm{Cdc} 16, \mathrm{Cdc} 23$ and $\mathrm{Cdc} 27$, are phosphorylated and therefore could be targets for regulatory information. Some subunits could be responsible for localisation of the whole complex in a distinct cell compartment or be involved in binding of the regulators Cdh1, Cdc20 and Ama1. The cullin-related subunit Apc2 and the RING-finger protein Apc11 function as the catalytic centre. In combination with the ubiquitin-conjugating enzyme Ubc4, ubiquitin transfer to the substrate is mediated by these two subunits (Leverson et al. 2000; Harper et al. 2002). First impressions of the morphology of the human APC/C complex were obtained from a low-resolution structure determined by cryo-electron microscopy (Gieffers et al. 2001). An outer protein wall surrounding an inner cave dominates the complex. This structure suggests that the APC/C possesses a reaction chamber in which ubiquitination could take place without the influence of the environment. Apc10 is the only subunit of which the crystal structure could be determined at the present (Au et al. 2002). Apc10 is characterised by a so-called Doc1 domain, which is also found in other ubiquitin-ligases, but its function in the ubiquitination process is not understood up to now. Maybe this domain is involved in protein protein interaction as the structure formed by the Doc1 domain is related to proteins mediating bio-molecular interactions (Au et al. 2002). Recently published data show a role for Apc10 in substrate recognition (Passmore et al. 2003).

During mitosis Cdc20 and Cdh1 are substrate-specific activators of the APC/C. They associate with the APC/C in a cell cycle dependent manner and target a distinct set of proteins for degradation by the $26 \mathrm{~S}$ proteasome. These two proteins are characterised by 
WD40 repeat motifs, consisting of repeated sequences of approximately 40 amino acids ending with tryptophan (W) and aspartate (D) (Li and Roberts 2001). The 3D structure resulting from these sequence motifs seems to be important for protein protein interactions. In addition to their role as activator proteins, $\mathrm{Cdh} 1$ and $\mathrm{Cdc} 20$ are also responsible for recruitment of substrates to the APC/C. They can bind to APC/C substrates like securin or B-type cyclins via their N-termini (Pfleger et al. 2001). Some substrates are recognised by both WD proteins, like the cyclin $\mathrm{Clb} 2$, and some are recognised specifically by only one of them like Pds1.

\subsection{Roles of APC/C during the cell cycle}

The initiation of anaphase and the exit from mitosis depends on the activity of the APC/C. The APC/C ubiquitinates proteins such as the securin Pds1 in budding yeast, whose subsequent degradation is essential for the initiation of sister chromatid separation at the metaphase/anaphase transition. Sister chromatids are bound together by a cohesin complex. Upon initiation of anaphase this complex has to be destroyed by the separase Esp1. Most time of the cell cycle Pds1 binds to the separase Esp1, thereby inhibiting its protease activity. At the metaphase/anaphase transition Pds1 is degraded in a APC/C dependent manner, resulting in activation of the separase and allowing cleavage of the cohesin complex accompanied by sister chromatid separation (Salah and Nasmyth 2000).

Later in anaphase and telophase the APC/C promotes the inactivation of the cyclin dependent kinase Cdc28 by destruction of its activating cyclin subunits. The APC/C also mediates the ubiquitin-dependent proteolysis of other mitotic regulators like the polo-like kinase $\mathrm{Cdc5}$, the spindle-associated protein Ase1, the kinesin-like motor proteins Cin8 and Kip1, the APC/C activator Cdc20, and inhibitors of DNA replication (Harper et al. 2002).

All substrates ubiquitinated by the APC/C contain either one of two specific degradation signals, the cyclin destruction box (D-box) or the KEN-box (Glotzer et al. 1991; Pfleger and Kirschner 2000). The destruction box consists of a degenerated nine amino acids motif, KxxLxxxxN. The KEN-box was identified to be KENxxxN, but also some other amino acids seem to be allowed at the terminal position. Both elements are found either alone or in combination in all APC/C substrates known up to now. APC/C $\mathrm{C}^{\text {Cdh1 }}$ recognises both D-box and KEN-box proteins, including Cdc20 and mitotic cyclins, whereas $\mathrm{APC} / \mathrm{C}^{\mathrm{Cdc} 20}$ recognises only D-box proteins.

During the mitotic cell cycle the APC/C is activated by two different activator proteins, $\mathrm{Cdh} 1$ and $\mathrm{Cdc} 20$. Cdc20 binds to APC/C at metaphase. Activation of $\mathrm{APC} / \mathrm{C}^{\mathrm{Cdc} 20}$ leads to 
the degradation of the anaphase inhibitor securin Pds1, resulting in sister chromatid separation. The binding of $\mathrm{Cdc} 20$ to the APC/C is dependent on high Cdc28 activity. Therefore, cyclin provides its own destruction by activating Cdc28 in prophase.

Cdc20 protein levels fluctuate during the cell cycle (Weinstein 1997; Prinz et al. 1998). The Cdc20 level rises in G2, peaks in mitosis, and declines as cells exit mitosis and enter G1. The rapid loss of $\mathrm{Cdc} 20$ at the end of mitosis is due to protein degradation targeted by APC/C ${ }^{\text {Cdh1 }}$ (Fang et al. 1998; Prinz et al. 1998). At the end of mitosis Cdc20 becomes replaced by Cdh1, which keeps the APC/C active until the end of the subsequent G1-phase. In late mitosis Cdh1 triggers the APC/C to degrade mitotic cyclins, which leads to exit of mitosis (Wan and Kirschner 2001).

Cdh1 is produced at constant levels all over the cell cycle, but the association of Cdh1 to the APC/C is strictly regulated during the cell cycle. Cdh1 becomes phosphorylated by Cdc28 and this modification inhibits its association with the APC/C. Activation of $\mathrm{APC} / \mathrm{C}^{\mathrm{Cdh} 1}$ in late mitosis depends on dephosphorylation of $\mathrm{Cdh} 1$. This process is triggered by the phosphatase Cdc14 (Visintin et al. 1998). After its dephosphorylation, Cdh1 can bind and subsequently activate the APC/C.

\section{Regulation of APC/C activity}

$\mathrm{APC} / \mathrm{C}$ activity is regulated at multiple levels. This includes association with substrateselective WD40-repeat activator proteins Cdc20 and Cdh1, phosphorylation of these regulatory proteins and core subunits, and different checkpoints like the spindle assembly checkpoint, which ensures that duplicated chromosomes are properly aligned and attached to spindles before being separated at anaphase.

\subsection{Phosphorylation regulates $\mathrm{APC} / \mathrm{C}$ activity}

In yeast, only the non-phosphorylated form of $\mathrm{Cdh} 1$ can bind to and activate APC/C (Zachariae et al. 1998a; Jaspersen et al. 1999), indicating that low kinase levels in G1 allow Cdh1 to activate APC/C. In contrast, binding of Cdc20 requires phosphorylation of the APC/C in Xenopus and human (Kramer et al. 2000). Two kinases, Cdc28 and the pololike kinase $\mathrm{Cdc5}$, are both required for complete activation of the APC/C (Golan et al. 2002). In mammalian cells Cdk1 (the mammalian homologue of Cdc28) phosphorylates Cdc16 and Cdc23, whereas Apc1 and Cdc27 are substrates of Cdc5.

In contrast to phosphorylation by $\mathrm{Cdc} 5$ and $\mathrm{Cdc} 28$, which activates $\mathrm{APC} / \mathrm{C}^{\mathrm{Cdc} 20}$, phosphorylation mediated by the cAMP-dependent protein kinase A (PKA) inhibits APC/C 
activity. For the human APC/C (Kotani et al. 1998) showed that PKA phosphorylates Apc1 and $\mathrm{Cdc} 27$ directly, and these phosphorylations counteract the polo kinase. Some genetic experiments suggest that this negative regulation of the APC/C is conserved in eukaryotes (Yamashita et al. 1996; Yamada et al. 1997; Anghileri et al. 1999; Irniger et al. 2000). Reducing cAMP levels or PKA activity was shown to suppress different yeast mutants defective in APC/C subunit genes. Addition of cAMP leads to a cell cycle arrest in mitosis at the meta/anaphase transition as well as in telophase (Anghileri et al. 1999).

Glucose or activation of the Ras proteins mediates activation of the cAMP/PKA pathway. Glucose is sensed by a G-protein-coupled receptor system consisting of the receptor Gpr1 and the G $\alpha$ protein Gpa2 (Colombo et al. 1998). Gpa2 can directly stimulate the adenylate cyclase. Activation of Ras1 and Ras2, two small GTP-binding proteins, is catalysed by the product of the $C D C 25$ gene, a protein that promotes removal of GDP bound to Ras and its replacement with free GTP (Broek et al. 1987; Robinson et al. 1987). Ras-GTP is capable of stimulating adenylate cyclase Cyr1, the key player of the cAMP/PKA pathway, which catalyses the formation of cAMP. High levels of cAMP in yeast cells lead to activation of the cAMP-dependent protein kinase (protein kinase A, PKA). This kinase is a heterotetramer comprising two regulatory subunits encoded by the $B C Y 1$ locus and two catalytic subunits redundantly encoded by three separate genes: TPK1, TPK2 and TPK3 (Toda et al. 1987). In the presence of cAMP the inhibitor Bcy 1 releases the catalytic subunits, which are then able to phosphorylate different target proteins. High protein kinase A activity induces breakdown of stored carbohydrates, activation of the glycolytic pathway, induction of transcription of a large number of growth-specific genes and down modulation of the Ras/cAMP-pathway (reviewed by (Broach 1991).

Glucose, Ras2 and cAMP levels can influence APC/C activity. Addition of glucose to yeast cells growing on poor medium as well as expression of a constitutive active Ras2 protein lower the viability of apc mutants significantly (Irniger et al. 2000). Reduction of the cAMP level leads to suppression of the lethality of mutants carrying a defective APC/C in Schizosaccharomyces pombe (Yamashita et al. 1996) and S. cerevisiae (Anghileri et al. 1999; Irniger et al. 2000).

\subsection{Control of APC/C activity by checkpoints}

\subsubsection{Spindle assembly checkpoint}

The main function of the spindle checkpoint is to ensure that all chromosomes are properly attached to the mitotic spindle at the kinetochore before sister chromatids are separated. 
After DNA duplication a cohesin protein complex connects sister chromatids to each other. For equal distribution of the DNA between mother and daughter it is necessary that sister chromatids are attached to microtubules, which originate from the opposite poles of the mitotic spindle and thereby establish tension across the two kinetochores of a sister chromatid pair (Nasmyth et al. 2000; Tanaka 2002). The spindle checkpoint senses the microtubule occupancy and tension at the kinetochores (Hoffman et al. 2001). The sensing mechanism of the checkpoint is unknown. Lack of tension at the kinetochores as well as unattached kinetochores per se can activate the spindle checkpoint. A number of proteins including Mad2, Mad3, Bub3, and Cdc20 were identified as signal transducers of the spindle checkpoint pathway (Amon 1999). These proteins form the mitotic checkpoint complex (MCC). It is unclear whether this inhibitory complex is only formed in the presence of unattached kinetochores or if it is present throughout the cell cycle. The target of the spindle checkpoint is the $\mathrm{APC} / \mathrm{C}^{\mathrm{Cd} 20}$. The mechanism by which $\mathrm{MCC}$ inhibits the APC/C is still unclear. It was shown that Mad2 and Mad3 can bind directly to Cdc20, but this does not block the ability of Cdc20 to recruit substrates, especially Pds1, to the APC/C. Rather the MCC seems to block the release of the substrate from Cdc20 in vitro (Pfleger et al. 2001). Therefore, the spindle checkpoint and the MCC may interfere with the ability of the APC/C to interact with its substrates in a productive way (Yu 2002).

When spindle defects are repaired and all kinetochores achieve bipolar attachment to the mitotic spindle, the checkpoint is inactivated and the active $\mathrm{APC} / \mathrm{C}^{\mathrm{Cdc} 20}$ mediates ubiquitination and destruction of the securin Pds1. Degradation of Pds1 activates the separase, which then cleaves Scc1, a component of the cohesin complex. The loss of cohesion between the sister chromatids initiates anaphase and allows sister chromatid separation.

\subsubsection{Spindle orientation checkpoint}

As mentioned before, exit from mitosis requires inactivation of the cyclin dependent kinase Cdc28. The highly conserved phosphatase Cdc14 plays an essentiell role in promoting inactivation of mitotic kinases and thus for the exit from mitosis (Visintin et al. 1998; Jaspersen et al. 1999). Cdc14 dephosphorylates Cdh1, thereby allowing its association with the $\mathrm{APC} / \mathrm{C}$ and proteolysis of mitotic cyclins. By dephosphorylating the $\mathrm{Cdc} 28$ inhibitor Sic1 and its transcription factor Swi5, Cdc14 induces expression and stabilisation of Sic1. Cdc14 activity is regulated by Cfi1/Net1 (Visintin et al. 1998; Shou et al. 1999; Straight et al. 1999), which localises Cdc14 to the nucleolus during G1-, S-phase and early mitosis. 
At the end of mitosis, when sister chromatids are separated, but prior to the exit from mitosis, a checkpoint consisting of two networks monitors the orientation of the mitotic spindle and decides whether Cdc14 is released from the nucleolus or not. The first component of the checkpoint is the FEAR (Cdc fourteen early anaphase release) network, consisting of the polo kinase Cdc5, the separase Esp1 and the regulator proteins Slk19 and Spo12 (Stegmeier et al. 2002). In early anaphase FEAR promotes the release of Cdc14 from the nucleolus by an unknown mechanism. The signal sensed by the second network of this checkpoint is the localisation of a progeny spindle pole body in the bud. The mitotic exit network (MEN) (Hoyt 2000) includes the Ras-like GTP binding protein Tem1, the exchange factor Lte1, the two component GTPase activating enzyme Bub2-Byr4, and the protein kinases $\mathrm{Cdc} 5, \mathrm{Cdc} 15$, and Dbf2. Tem1 is solely localised at the spindle pole body that migrates into the bud (Bardin et al. 2000). Its's exchange factor Lte1 is present throughout the cell during G1 but localizes to the bud as soon as it forms. Thus, Tem1 and Lte1 are present at the same compartement only when the new nucleus has entered the bud. In this case the exchange of GDP to GTP bound to Tem1 can be mediated by Lte1. Tem1GTP activates the protein kinases Cdc5 and Dfb2, which provide release of phosphatase Cdc14 from Net1/Cfi1 in the nucleolus. It was proposed that dissociation of Cdc14 from Net1/Cfi1 is mediated by Cdc5, which was shown to be able to phosphorylate Cdc14 (Yoshida and Toh-e 2002). Once released, Cdc14 can reach the target proteins in the nucleus (Cdh1 and Sic1) and in the cyctoplasm (Swi5). Dephosphorylation of Cdh1 results in activation of $\mathrm{APC} / \mathrm{C}^{\mathrm{Cdh} 1}$, degradation of mitotic cyclins, inactivation of $\mathrm{Cdc} 28$, and finally exit from mitosis. This spindle orientation checkpoint guarantees that exit from mitosis and cell division can not proceed before the DNA is partitioned between mother and daughter cell.

\subsubsection{DNA damage checkpoint}

In budding yeast, the DNA damage checkpoint induces a mitotic arrest by inhibiting the metaphase-anaphase transition. In the case of damaged DNA the Mec1 kinase is activated, which in turn activates two downstream kinases, Chk1 and Rad53 (Agarwal et al. 2003). Both kinases are required for a complete metaphase arrest. The downstream target of Rad53 needed for mitotic arrest is unknown, but it was shown that the Rad53 pathway inhibits the Pds1-Cdc20 interaction (Schwab et al. 2001). The target of Chk1 is Pds1, which is directly phosphorylated by Chk1 (Wang et al. 2001). Phosphorylation of Pds1 inhibits the ubiquitination reaction. Therefore both kinases prevent the degradation of Pds1 
by inhibiting the APC/C $\mathrm{C}^{\mathrm{Cdc} 20}$ activity (Agarwal et al. 2003). Once damaged DNA is repaired, Pds1 dephosphorylation is involved in the recovery from the checkpoint- induced cell cycle arrest.

\section{The meiotic cell cycle of Saccharomyces cerevisiae}

\subsection{Differences between the mitotic and meiotic cell cycle}

Meiosis can be considered as a specialised form of the mitotic cell cycle: in mitosis each round of DNA replication is followed by one round of chromosome segregation; in meiosis, replication is followed by two sequential rounds of chromosome segregation. In the first meiotic division, homologous chromosomes segregate to opposite poles; during the second meiotic division, which is similar to the mitotic division, sister chromatids separate from each other, thereby generating haploid ascospores to form a tetrade (Fig. 5; Petronczki et al. 2003).

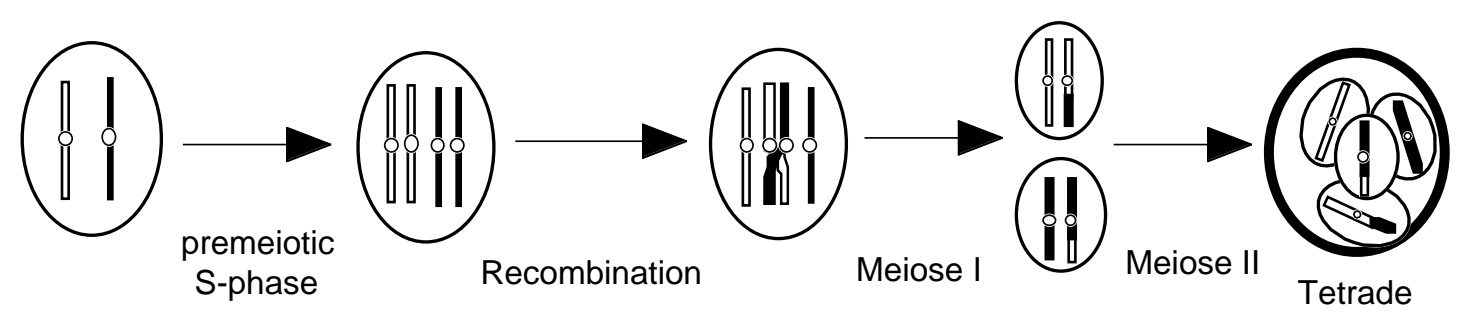

Fig. 5 The meiotic cell cycle

During the pre-meiotic S-phase the DNA is replicated, afterwards meiotic recombination between homologous chromosomes occurs. In meiosis I homologous chromosomes are segregated, while in meiosis II sister chromatids are separated, resulting in four haploid ascospores that form a tetrade.

During the mitotic cell cycle the G1-cyclins Cln1, 2, and 3 associate with cyclin dependent kinase Cdc28 in order to trigger bud formation, spindle pole body duplication and DNA replication. Since cells can undergo mitosis and meiosis as well, it is necessary to prevent initiation of both cell cycles at the same time. During mitosis the G1-cyclins prevent entry into meiosis by inhibiting the expression of the meiotic key transcription factor IME1. In contrast, after entry into sporulation Cln-Cdc28 complexes are inactivated by down regulation of G1-cyclin transcription (Colomina et al. 1999). Initiation of DNA replication during meiosis is performed by the kinase Ime2 instead of Cln-Cdc28. The core replication machinery seems to be the same in mitosis and meiosis. Cdc28 is critical for meiotic S- 
phase. Cells lacking Clb5,6 fail to undergo DNA replication (Stuart and Wittenberg 1998), suggesting that the early activity of Cdc28 in meiosis is executed in partnership with Clb5 and Clb6.

Due to the fact that during meiosis I homologous chromosomes and not sister chromatids are segregated, a linkage between homologous chromosomes has to be established to resist the forces of the meiosis I spindle. This linkage is provided by chiasmatas, which are the result of the recombination event between homologous chromosomes. During anaphase I cohesin along the chromosome arms is cleaved whereas the centromeric cohesin is retained. Loss of the arm cohesin is required for the resolution of chiasmatas and thus meiosis I chromosome segregation, but the maintenance of the cohesin at centromers ensures that sister chromatids segregate together. In meiosis II the cohesin is removed completely and sister chromatids are separated (Miyazaki and Orr-Weaver 1994; Lee and Amon 2001). The composition of the cohesin complex, which binds chromosomes together, differs between meiosis and mitosis. The mitotic cohesin subunit Scc1 is replaced by the meiosis-specific cohesin subunit Rec8 (Klein et al. 1999). Both proteins can be cleaved by the separase Esp1, which is under control of the securin Pds1. Like in mitosis in yeast the $\mathrm{APC} / \mathrm{C}^{\mathrm{Cdc} 20}$ is responsible for destruction of the securin Pds1 in metaphase I as well as in metaphase II (Salah and Nasmyth 2000).

The cyclin dependent kinase Cdc28 in combination with its activating B-type cyclins plays an important role in meiosis, similar to mitosis. In budding yeast $\mathrm{Clb} 1, \mathrm{Clb} 3$, and $\mathrm{Clb} 4$ are important for progression into the first meiotic division and for progression from meiosis I to meiosis II (Dahmann and Futcher 1995). Expression of five of the six B-type cyclins is controlled by the meiosis-specific transcription activator $\mathrm{Ndt} 80 \mathrm{Clb} 2$, the most important cyclin in mitosis, does not contain a Ndt80 binding site and is not expressed during meiosis (Grandin and Reed 1993; Chu et al. 1998). The APC/C is essential for progression through meiosis, but little is known about its meiotic function and regulation.

In budding yeast it was shown that during both meiotic divisions chromosome segregation is initiated by degradation of the securin Pds1 mediated by the $\mathrm{APC} / \mathrm{C}^{\mathrm{Cdc20}}$ complex (Salah and Nasmyth 2000; Harper et al. 2002).

In $S$. cerevisiae a potential meiosis-specific regulator of the APC/C was identified, AMAI. AMA1 codes for a member of the Cdc20 family of proteins and is only transcribed and spliced during meiosis. Ama1 can associate with the $\mathrm{APC} / \mathrm{C}$ in vivo and is required for execution of meiosis I, late meiotic gene expression and spore formation, but not for 
meiosis II chromosome segregation. Destruction of $\mathrm{Clb} 1$ during meiosis is mediated by APC/C in association with its meiosis-specific activator protein Ama1 (Cooper et al. 2000; Rabitsch et al. 2001). Besides $C D C 20$ and $A M A 1, C D H 1$ is transcribed during meiosis, but the role of Cdh1 in cyclin proteolysis and the exit from meiotic divisions is yet unknown. In summary, three different $\mathrm{APC} / \mathrm{C}$ complexes seem to be involved in the regulation of the meiotic cell cycle in budding yeast. Similarly, meiosis-specific WD-repeat proteins were also identified in S. pombe (Blanco et al. 2001) and Drosophila melanogaster (Chu et al. 2001), suggesting that additional meiosis-specific APC/C complexes are widespread in eukaryotes.

Checkpoints also operate in APC/C regulation during meiosis. DNA damage, failure in completion of recombination or failure to complete DNA replication results in a meiotic arrest and a block of spore formation (Lydall et al. 1996; Chu et al. 1998; Hepworth et al. 1998; Stuart and Wittenberg 1998). Some of the mitotic checkpoint network proteins are also involved in the control of APC/C activity during meiosis. The spindle checkpoint is even more important for meiosis than it is for mitosis (Li and Murray 1991; Shonn et al. 2000). Spindle checkpoint is required for proper chromosome segregation in meiosis I. Checkpoint mutants suffer from non-disjunction in meiosis I, resulting in tetrades with two viable and two dead spores. During meiosis spindle elongation and chromosome segregation depends on APC/C activation. The FEAR network regulates meiotic chromosome segregation through activating Cdc14 (Marston et al. 2003). Two FEAR network components, Slk1 and Spo12, promote Cdc14 release from the nucleolus during anaphase I and are necessary for the timely disassembly of the meiosis I spindle. Cdc14 exhibits a localisation pattern similar to that observed during mitosis. Cdc14 is localised in the nucleolus throughout meiotic prophase I and metaphase I. At anaphase Cdc14 is released and spreads to the nucleus and cytoplasm. In metaphase II cells, Cdc14 is transferred back into the nucleolus before being released again in anaphase II. Conclusively, Cdc14 undergoes two cycles of nuclear localisation and release during meiosis.

\subsection{Regulation cascade governs initiation of sporulation}

Three nutritional conditions are required for sporulation. The first is limitation of an essential nutrient, which causes cells to arrest in G1. Nitrogen limitation causes efficient sporulation, however limitation for carbon, sulphate, guanine, methionine and other components can also cause sporulation (Freese et al. 1982; Sumrada and Cooper 1987; 
Mitchell 1994; Honigberg and Purnapatre 2003). A second condition is the presence of a non-fermentable carbon source, which can be metabolised through respiration. Sporulation can take place in the presence of pyruvate or acetate. The third condition is the absence of glucose. Generally, the carbon source governs the decision between pseudohyphal growth and sporulation: N-limitation in the presence of glucose leads to pseudohyphal growth (Gimeno et al. 1992), N-limitation in the absence of glucose leads to sporulation. Glucose inhibits initiation of meiosis even when the first and the second condition are met. In addition, the ability to sporulate requires both mating type loci MATa and MAT $\alpha$ (Herskowitz 1988).

The targets of nutritional regulation are two key regulators of meiosis: IME1, a transcription factor responsible for expression of a number of genes early in meiosis including the second key factor, IME2, which encodes a Ser/Thr protein kinase. Both IME1 and IME2 are required for proper meiotic initiation (reviewed by (Mitchell 1994). Transcription of both genes is regulated by nutrients, but the mechanisms by which the signals are transmitted to these two genes are very different. In the case of IME1 the signal is integrated at its complex promoter (approximately $2 \mathrm{~kb}$ ) consisting of four upstream control regions. For example, glucose can repress IME1 through the IREu site (Ime2 repeat element upsite), whereas acetate activates $I M E 1$ through the UASrm site (upstream activating sequence regulated middle) (Sagee et al. 1998; Honigberg and Purnapatre 2003). Besides, two regions required for cell-type control exist in the promoter region of IME1 (Covitz and Mitchell 1993). Three genes are known to transmit the mating type signal to IME1: RME1, IME4, and RES1. Rme1 is a zinc-finger DNA-binding protein, representing a negative regulator for $I M E 1$ transcription in cells carrying only one of the MAT alleles (Kassir and Simchen 1976). Ime4 is a positive regulator strictly required for IME 1 expression. IME2 possesses only one upstream repression site (URS1). The transcription factor Ume6 binds to this URS in all stages of the cell cycle. When IME2 is repressed Ume6 is bound in addition to the Sin3-Rpd3 complex. Activation of IME2 transcription requires the dissociation of the Sin3-Rpd3 complex from Ume6 and association of Ume6 with the phosphorylated form of Ime1 (Washburn and Esposito 2001). The stability of this Ume6-Ime1 complex determines whether IME2 is transcribed and this is regulated by both starvation and glucose. Starvation activates the kinase Rim11 that can phosphorylate both Ume6 and Ime1, and this phosphorylation stabilises the Ume6-Ime1 complex. The presence of glucose destabilises the complex by repression of another kinase, which is also 
responsible (by an unknown mechanism) for association of Ume6 and Ime1 (Vidan and Mitchell 1997). By this mechanism starvation and glucose can both regulate IME2 transcription by modulating the same transcription factor complex.

Glucose repression of meiosis is regulated by the glucose repression pathway (reviewed in (Carlson 1999). The central component of this pathway is the Snf1 kinase, whose activity is repressed by intracellular glucose. Snf1 kinase activity is generally required for expression of IME1 and IME2 (Honigberg and Lee 1998). Extracellular glucose is sensed by the G-coupled receptor Gpr1, which activates Gpa2, the alpha subunit of a trimeric Gprotein complex. This complex activates protein kinase A (PKA). PKA inhibits transcription of both $I M E 1$ and IME2. Besides Gpa2 can bind directly to Ime2 and thereby inhibits its kinase activity (Donzeau and Bandlow 1999). In summary, many different pathways mediate the glucose signal to control expression of meiotic genes.

\subsection{Role of the Ime2 protein kinase in meiosis}

One key factor in the regulation of the meiotic cell cycle is the Ser/Thr protein kinase Ime2 (Mitchell et al. 1990). Ime2 shares several amino acid motifs with cyclin dependent kinases, like amino acid residues that are involved in nucleotid binding and the formation of a catalytic triad required for transfer of phosphate to protein substrates (Hui et al. 2002). Although the catalytic domain resembles that of CDKs, the protein diverges from CDKs in that it lacks a PSTARIE motif involved in cyclin binding and differs in the T-loop activation domain. Ime2 itself is a highly unstable protein which posseses an extended Cterminal domain that has been proposed to be involved in destabilizing the protein and in interaction with negatively acting factors (Kominami et al. 1993; Donzeau and Bandlow 1999; Guttmann-Raviv et al. 2002). Recombinant Ime2 produced in an eukaryotic expression system displays the ability to phosphorylate histone $\mathrm{H} 1$ and to autophosphorylate itself. Amino acid substitution of lysin 97 (K97) to arginine (R) results in a kinase dead version of the protein (Hui et al. 2002).

Ime 2 is required for many stages of meiosis. First, Ime2 kinase activity is responsible for meiotic DNA replication (Foiani et al. 1996). It controls the G1-S transition by decreasing the level of Sic1, an inhibitor of Cdc28. Ime2 dependent degradation of Sic1 leads to activation of Cdc28 associated with the B-type cyclins Clb5 and Clb6. This complex triggers meiotic DNA replication (Dirick et al. 1998; Stuart and Wittenberg 1998). Ime2 is also required to restrict DNA replication. In the absence of Ime2 a second round of DNA replication occurs. Expression of IME2 is induced by the meiosis-specific transcription 
activator Ime1. Ime2 associates with and phosphorylates Ime1. Phosphorylation leads to destabilization and degradation of Ime 1 by the $26 \mathrm{~S}$ proteasome (Guttmann-Raviv et al. 2002). Together with Ime1, Ime2 leads to the transcription of early meiotic genes, like SPO11 and SPO13. Overexpression of IME2 was shown to bypass the requirement of Ime1 for transcription of early meiotic genes (Mitchell et al. 1990).

The transition from expression of early meiotic genes to expression of middle sporulationspecific genes occures at exit from pachytene. When pre-meiotic replication is completed, the spindle pole body is duplicated but not separated and formation of the meiosis I spindle takes place (G2-M transition). Ime2 kinase activity is necessary for the initiation of the expression of middle sporulation genes, because Ime 2 activates transcription of NDT80. NDT80 encodes the activator of middle meiotic genes (Hepworth et al. 1998). In addition to the transcriptional control of NDT80 by Ime2, Ndt80 activity is posttranslationally regulated by Ime2 (Sopko et al. 2002). Ime2 dependent phosphorylation is required for Ndt80 to interact effectively with middle sporulation element (MSE) sites in the promoter region of middle sporulation genes. Besides other genes, NDT80 promotes the expression and accumulation of the B-type cyclins $\mathrm{Clb} 1,3$, and 4. Accumulation of these cyclins is essential for the next steps in meiosis, because exit from pachytene requires $\mathrm{Cdc} 28$ activity, achieved by the binding of B-type cyclins (Xu et al. 1995).

By using a modified inhibitor sensitive version of Ime2, ime2-as1, (Bishop et al. 2000), it could be shown that Ime 2 kinase possesses also functions in late meiosis especially in both meiotic nuclear division and the maintenance of phosphorylated Ndt80 (Benjamin et al. 2003). The increase of Ime 2 kinase activity in meiotic M-phase is dependent on Ndt80 and Cdc28. ndt80 mutant cells lack the peak of Ime2 kinase activity in late meiosis and Cdc28 is responsible for the hyperphosphorylation of Ime2 in this stage (Benjamin et al. 2003). The late requirement of Ime 2 is partly due to its stimulation of NDT80 transcription throughout M-phase. Additionally, it was suggested that Ime2 dependent phosphorylation of Ndt80 may increase its stability and therefore boost middle gene transcription, or may be needed for a nontranscriptional role of $\mathrm{Ndt} 80$ (Benjamin et al. 2003).

Orthologous of Ime2 have been found in S. pombe, mde3 and pit1. These proteins are important for the timing of meiotic division and spore formation (Abe and Shimoda 2000). In mammals the Mak ("male germ associated kinase") proteins are homologous to Ime2. Their function is unknown, but they were found in primary spermatocytes during late meiotic G2-phase (Jinno et al. 1993; Shinkai et al. 2002). The catalytic domain of the Crk1 
protein of the plant pathogen Ustilago maydis shares $34,8 \%$ identity with Ime2 from $S$. cerevisiae. U. maydis crkl mutants are unable to response properly to environmental stimuli and show defects in morphogenesis and cell cycle adjustment to changing conditions (Garrido and Perez-Martin 2003).

\section{Aim of this work}

The aim of this work is a better understanding of factors and mechanisms involved in the regulation of the cell division cycle. The understanding how critical events during the eukaryotic cell cycle are regulated is a crucial prerequisite for the analysis of cells in which the control of the cell cycle is impaired. Many critical processes of the cell cycle are conserved from unicellular eukaryotic microorganisms to mammalian cells. Due to the well established genetics of $S$. cerevisiae, this organism is an useful tool to identify and characterise important processes in the eukaryotic cell cycle. Findings in this model organisms may facilitate the study of their counterparts in more complex eukaryotic organisms.

Ubiquitin-dependent proteolysis is essential for sister chromatid separation and the exit from mitosis. Key factors in this process are the anaphase promoting complex (APC/C), a multisubunit ubiquitin-ligase, and its activator proteins $\mathrm{Cdc} 20$ and $\mathrm{Cdh} 1$. APC/C activity is tightly cell cycle regulated. This work aims to characterise the regulation of ubiquitindependent protein degradation mediated by the APC/C during the mitotic and the meiotic cell cycle in budding yeast.

The first part of the project focuses on components of the Ras/cAMP/PKA signaling pathway which previously was shown to influence APC/C function. The mechanisms how the protein kinase A proteins Tpk1-3 affect APC/C activity and thereby regulate progression through mitosis was analysed (Chapter 2).

To understand the role of the $\mathrm{APC} / \mathrm{C}$ and its regulation during cellular differentiation processes, in the second part APC/C function in yeast cells which undergo meiosis is described. The meiosis-specific protein kinase Ime 2 was identified as an inhibitor of APC/C-dependent proteolysis of the B-type cyclin Clb2 (Chapter 3). This suggests that Ime 2 acts as a regulator of the APC/C during the meiotic cell cycle. The third part focuses on a further characterisation of the protein kinase Ime2, especially on sequences responsible for the rapid turn over of the protein and the effects of a stabilised Ime 2 on the cell cycle (Chapter 4). 


\section{References}

Abe, H. and C. Shimoda. 2000. Autoregulated expression of Schizosaccharomyces pombe meiosis-specific transcription factor Mei4 and a genome-wide search for its target genes. Genetics 154: 1497-508.

Agarwal, R., Z. Tang, H. Yu, and O. Cohen-Fix. 2003. Two distinct pathways for inhibiting Pds1 ubiquitination in response to DNA damage. J Biol Chem.

Amon, A. 1997. Regulation of B-type cyclin proteolysis by Cdc28-associated kinases in budding yeast. EMBO J 16: 2693-702.

Amon, A. 1999. The spindle checkpoint. Curr Opin Genet Dev 9: 69-75.

Anghileri, P., P. Branduardi, F. Sternieri, P. Monti, R. Visintin, A. Bevilacqua, L. Alberghina, E. Martegani, and M.D. Baroni. 1999. Chromosome separation and exit from mitosis in budding yeast: dependence on growth revealed by cAMPmediated inhibition. Exp Cell Res 250: 510-23.

Au, S.W., X. Leng, J.W. Harper, and D. Barford. 2002. Implications for the Ubiquitination Reaction of the Anaphase-promoting Complex from the Crystal Structure of the Doc1/Apc10 Subunit. J Mol Biol 316: 955-68.

Bardin, A.J., R. Visintin, and A. Amon. 2000. A mechanism for coupling exit from mitosis to partitioning of the nucleus. Cell 102: 21-31.

Beach, D., B. Durkacz, and P. Nurse. 1982. Functionally homologous cell cycle control genes in budding and fission yeast. Nature 300: 706-9.

Benjamin, K.R., C. Zhang, K.M. Shokat, and I. Herskowitz. 2003. Control of landmark events in meiosis by the CDK Cdc28 and the meiosis-specific kinase Ime2. Genes Dev 17: 1524-39.

Bishop, A.C., J.A. Ubersax, D.T. Petsch, D.P. Matheos, N.S. Gray, J. Blethrow, E. Shimizu, J.Z. Tsien, P.G. Schultz, M.D. Rose, J.L. Wood, D.O. Morgan, and K.M. Shokat. 2000. A chemical switch for inhibitor-sensitive alleles of any protein kinase. Nature 407: 395-401.

Blanco, M.A., L. Pelloquin, and S. Moreno. 2001. Fission yeast mfr1 activates APC and coordinates meiotic nuclear division with sporulation. J Cell Sci 114: 2135-43.

Broach, J.R. 1991. RAS genes in Saccharomyces cerevisiae: signal transduction in search of a pathway. Trends Genet 7: 28-33.

Broek, D., T. Toda, T. Michaeli, L. Levin, C. Birchmeier, M. Zoller, S. Powers, and M. Wigler. 1987. The $S$. cerevisiae CDC25 gene product regulates the RAS/adenylate cyclase pathway. Cell 48: 789-99.

Carlson, M. 1999. Glucose repression in yeast. Curr Opin Microbiol 2: 202-7.

Chu, S., J. DeRisi, M. Eisen, J. Mulholland, D. Botstein, P.O. Brown, and I. Herskowitz. 1998. The transcriptional program of sporulation in budding yeast. Science $\mathbf{2 8 2}$ : 699-705.

Chu, T., G. Henrion, V. Haegeli, and S. Strickland. 2001. Cortex, a Drosophila gene required to complete oocyte meiosis, is a member of the Cdc20/fizzy protein family. Genesis 29: 141-52.

Colombo, S., P. Ma, L. Cauwenberg, J. Winderickx, M. Crauwels, A. Teunissen, D. Nauwelaers, J.H. de Winde, M.F. Gorwa, D. Colavizza, and J.M. Thevelein. 1998. Involvement of distinct G-proteins, Gpa2 and Ras, in glucose- and intracellular acidification-induced cAMP signalling in the yeast Saccharomyces cerevisiae. EMBO J 17: 3326-41.

Colomina, N., E. Gari, C. Gallego, E. Herrero, and M. Aldea. 1999. G1 cyclins block the Ime1 pathway to make mitosis and meiosis incompatible in budding yeast. EMBO J 18: $320-9$. 
Cooper, K.F., M.J. Mallory, D.B. Egeland, M. Jarnik, and R. Strich. 2000. Ama1p is a meiosis-specific regulator of the anaphase promoting complex/cyclosome in yeast. Proc Natl Acad Sci U S A 97: 14548-53.

Covitz, P.A. and A.P. Mitchell. 1993. Repression by the yeast meiotic inhibitor RME1. Genes Dev 7: 1598-608.

Dahmann, C. and B. Futcher. 1995. Specialization of B-type cyclins for mitosis or meiosis in S. cerevisiae. Genetics 140: 957-63.

Diffley, J.F. 1996. Once and only once upon a time: specifying and regulating origins of DNA replication in eukaryotic cells. Genes Dev 10: 2819-30.

Diffley, J.F. 2001. DNA replication: building the perfect switch. Curr Biol 11: R367-70.

Dirick, L., L. Goetsch, G. Ammerer, and B. Byers. 1998. Regulation of meiotic S phase by Ime2 and a Clb5,6-associated kinase in Saccharomyces cerevisiae. Science 281: 1854-7.

Donzeau, M. and W. Bandlow. 1999. The yeast trimeric guanine nucleotide-binding protein alpha subunit, Gpa2p, controls the meiosis-specific kinase Ime2p activity in response to nutrients. Mol Cell Biol 19: 6110-9.

Evans, T., E.T. Rosenthal, J. Youngblom, D. Distel, and T. Hunt. 1983. Cyclin: a protein specified by maternal mRNA in sea urchin eggs that is destroyed at each cleavage division. Cell 33: 389-96.

Fang, G., H. Yu, and M.W. Kirschner. 1998. Direct binding of CDC20 protein family members activates the anaphase- promoting complex in mitosis and G1. Mol Cell 2: $163-71$.

Feldman, R.M., C.C. Correll, K.B. Kaplan, and R.J. Deshaies. 1997. A complex of Cdc4p, Skp1p, and Cdc53p/cullin catalyzes ubiquitination of the phosphorylated CDK inhibitor Sic1p. Cell 91: 221-30.

Foiani, M., E. Nadjar-Boger, R. Capone, S. Sagee, T. Hashimshoni, and Y. Kassir. 1996. A meiosis-specific protein kinase, Ime2, is required for the correct timing of DNA replication and for spore formation in yeast meiosis. Mol Gen Genet 253: 278-88.

Freese, E.B., M.I. Chu, and E. Freese. 1982. Initiation of yeast sporulation of partial carbon, nitrogen, or phosphate deprivation. J Bacteriol 149: 840-51.

Garrido, E. and J. Perez-Martin. 2003. The $c r k 1$ gene encodes an Ime2-related protein that is required for morphogenesis in the plant pathogen Ustilago maydis. Mol Microbiol 47: 729-43.

Gieffers, C., P. Dube, J.R. Harris, H. Stark, and J.M. Peters. 2001. Three-dimensional structure of the anaphase-promoting complex. Mol Cell 7: 907-13.

Gimeno, C.J., P.O. Ljungdahl, C.A. Styles, and G.R. Fink. 1992. Unipolar cell divisions in the yeast $S$. cerevisiae lead to filamentous growth: regulation by starvation and RAS. Cell 68: 1077-90.

Glotzer, M., A.W. Murray, and M.W. Kirschner. 1991. Cyclin is degraded by the ubiquitin pathway. Nature 349: 132-8.

Golan, A., Y. Yudkovsky, and A. Hershko. 2002. The cyclin-ubiquitin ligase activity of cyclosome/APC is jointly activated by protein kinases Cdk1/cyclin B and Plk. $J$ Biol Chem 21: 21.

Grandin, N. and S.I. Reed. 1993. Differential function and expression of Saccharomyces cerevisiae B-type cyclins in mitosis and meiosis. Mol Cell Biol 13: 2113-25.

Guttmann-Raviv, N., S. Martin, and Y. Kassir. 2002. Ime2, a meiosis-specific kinase in yeast, is required for destabilization of its transcriptional activator, Ime1. Mol Cell Biol 22: 2047-56.

Harper, J.W., J.L. Burton, and M.J. Solomon. 2002. The anaphase-promoting complex: it's not just for mitosis any more. Genes Dev 16: 2179-206. 
Hepworth, S.R., H. Friesen, and J. Segall. 1998. NDT80 and the meiotic recombination checkpoint regulate expression of middle sporulation-specific genes in Saccharomyces cerevisiae. Mol Cell Biol 18: 5750-61.

Hershko, A. and A. Ciechanover. 1998. The ubiquitin system. Annu Rev Biochem 67: 42579.

Herskowitz, I. 1988. Life cycle of the budding yeast Saccharomyces cerevisiae. Microbiol Rev 52: 536-53.

Hoffman, D.B., C.G. Pearson, T.J. Yen, B.J. Howell, and E.D. Salmon. 2001. Microtubuledependent changes in assembly of microtubule motor proteins and mitotic spindle checkpoint proteins at PtK1 kinetochores. Mol Biol Cell 12: 1995-2009.

Honigberg, S.M. and R.H. Lee. 1998. Snf1 kinase connects nutritional pathways controlling meiosis in Saccharomyces cerevisiae. Mol Cell Biol 18: 4548-55.

Honigberg, S.M. and K. Purnapatre. 2003. Signal pathway integration in the switch from the mitotic cell cycle to meiosis in yeast. J Cell Sci 116: 2137-47.

Hoyt, M.A. 2000. Exit from mitosis: spindle pole power. Cell 102: 267-70.

Hui, C.M., A. Campistrous, and D.T. Stuart. 2002. Purification and some properties of Saccharomyces cerevisiae meiosis-specific protein kinase Ime2. Protein Expr Purif 26: 416-24.

Irniger, S., M. Bäumer, and G.H. Braus. 2000. Glucose and ras activity influence the ubiquitin ligases APC/C and SCF in Saccharomyces cerevisiae. Genetics 154: 1509-21.

Irniger, S. and G.H. Braus. 2003. Controlling transcription by destruction: the regulation of yeast Gen4p stability. Curr Genet 44: 8-18.

Jaspersen, S.L., J.F. Charles, and D.O. Morgan. 1999. Inhibitory phosphorylation of the APC regulator Hct1 is controlled by the kinase Cdc28 and the phosphatase Cdc14. Curr Biol 9: 227-36.

Jinno, A., K. Tanaka, H. Matsushime, T. Haneji, and M. Shibuya. 1993. Testis-specific mak protein kinase is expressed specifically in the meiotic phase in spermatogenesis and is associated with a 210-kilodalton cellular phosphoprotein. Mol Cell Biol 13: 4146-56.

Kassir, Y. and G. Simchen. 1976. Regulation of mating and meiosis in yeast by the matingtype region. Genetics 82: 187-206.

Klein, F., P. Mahr, M. Galova, S.B. Buonomo, C. Michaelis, K. Nairz, and K. Nasmyth. 1999. A central role for cohesins in sister chromatid cohesion, formation of axial elements, and recombination during yeast meiosis. Cell 98: 91-103.

Kominami, K., Y. Sakata, M. Sakai, and I. Yamashita. 1993. Protein kinase activity associated with the IME2 gene product, a meiotic inducer in the yeast Saccharomyces cerevisiae. Biosci Biotechnol Biochem 57: 1731-5.

Kotani, S., S. Tugendreich, M. Fujii, P.M. Jorgensen, N. Watanabe, C. Hoog, P. Hieter, and K. Todokoro. 1998. PKA and MPF-activated polo-like kinase regulate anaphase-promoting complex activity and mitosis progression. Mol Cell 1: 371-80.

Kramer, E.R., N. Scheuringer, A.V. Podtelejnikov, M. Mann, and J.M. Peters. 2000. Mitotic regulation of the APC activator proteins CDC20 and CDH1. Mol Biol Cell 11: $1555-69$.

Langan, T.A., J. Gautier, M. Lohka, R. Hollingsworth, S. Moreno, P. Nurse, J. Maller, and R.A. Sclafani. 1989. Mammalian growth-associated H1 histone kinase: a homolog of $c d c 2+/ C D C 28$ protein kinases controlling mitotic entry in yeast and frog cells. Mol Cell Biol 9: 3860-8.

Lee, B. and A. Amon. 2001. Meiosis: how to create a specialized cell cycle. Curr Opin Cell Biol 13: 770-7. 
Lee, M.G. and P. Nurse. 1987. Complementation used to clone a human homologue of the fission yeast cell cycle control gene cdc2. Nature 327: 31-5.

Leverson, J.D., C.A. Joazeiro, A.M. Page, H. Huang, P. Hieter, and T. Hunter. 2000. The APC11 RING-H2 finger mediates E2-dependent ubiquitination. Mol Biol Cell 11: 2315-25.

Li, D. and R. Roberts. 2001. WD-repeat proteins: structure characteristics, biological function, and their involvement in human diseases. Cell Mol Life Sci 58: 2085-97.

Li, R. and A.W. Murray. 1991. Feedback control of mitosis in budding yeast. Cell 66: 51931.

Lydall, D., Y. Nikolsky, D.K. Bishop, and T. Weinert. 1996. A meiotic recombination checkpoint controlled by mitotic checkpoint genes. Nature 383: 840-3.

Marston, A.L., B.H. Lee, and A. Amon. 2003. The Cdc14 phosphatase and the FEAR network control meiotic spindle disassembly and chromosome segregation. Dev Cell 4: 711-26.

Mitchell, A.P. 1994. Control of meiotic gene expression in Saccharomyces cerevisiae. Microbiol Rev 58: 56-70.

Mitchell, A.P., S.E. Driscoll, and H.E. Smith. 1990. Positive control of sporulation-specific genes by the IME1 and IME2 products in Saccharomyces cerevisiae. Mol Cell Biol 10: $2104-10$.

Miyazaki, W.Y. and T.L. Orr-Weaver. 1994. Sister-chromatid cohesion in mitosis and meiosis. Annu Rev Genet 28: 167-87.

Morgan, D.O. 1995. Principles of CDK regulation. Nature 374: 131-4.

Murray, A. and Hunt, T. 1993. The cell cycle: an introduction. Oxford University Press

Nasmyth, K. 1993. Control of the yeast cell cycle by the Cdc28 protein kinase. Curr Opin Cell Biol 5: 166-79.

Nasmyth, K., J.M. Peters, and F. Uhlmann. 2000. Splitting the chromosome: cutting the ties that bind sister chromatids. Science 288: 1379-85.

Noton, E. and J.F. Diffley. 2000. CDK inactivation is the only essential function of the $\mathrm{APC} / \mathrm{C}$ and the mitotic exit network proteins for origin resetting during mitosis. Mol Cell 5: 85-95.

Passmore, L.A., E.A. McCormack, S.W. Au, A. Paul, K.R. Willison, J.W. Harper, and D. Barford. 2003. Doc1 mediates the activity of the anaphase-promoting complex by contributing to substrate recognition. EMBO J 22: 786-96.

Peters, J.M. 2002. The anaphase-promoting complex: proteolysis in mitosis and beyond. Mol Cell 9: 931-43.

Peters, J.M., R.W. King, C. Hoog, and M.W. Kirschner. 1996. Identification of BIME as a subunit of the anaphase-promoting complex. Science 274: 1199-201.

Petronczki, M., M.F. Siomos, and K. Nasmyth. 2003. Un menage a quatre: the molecular biology of chromosome segregation in meiosis. Cell 112: 423-40.

Pfleger, C.M. and M.W. Kirschner. 2000. The KEN box: an APC recognition signal distinct from the D box targeted by Cdh1. Genes Dev 14: 655-65.

Pfleger, C.M., E. Lee, and M.W. Kirschner. 2001. Substrate recognition by the Cdc20 and Cdh1 components of the anaphase- promoting complex. Genes Dev 15: 2396-407.

Piatti, S., T. Bohm, J.H. Cocker, J.F. Diffley, and K. Nasmyth. 1996. Activation of Sphase-promoting CDKs in late G1 defines a "point of no return" after which Cdc6 synthesis cannot promote DNA replication in yeast. Genes Dev 10: 1516-31.

Pringle, J.K. and S.J. Saba. 1981. [Not Available]. Ann Midi 93: 397-417.

Prinz, S., E.S. Hwang, R. Visintin, and A. Amon. 1998. The regulation of Cdc20 proteolysis reveals a role for APC components Cdc23 and Cdc27 during S phase and early mitosis. Curr Biol 8: 750-60. 
Rabitsch, K.P., A. Toth, M. Galova, A. Schleiffer, G. Schaffner, E. Aigner, C. Rupp, A.M. Penkner, A.C. Moreno-Borchart, M. Primig, R.E. Esposito, F. Klein, M. Knop, and K. Nasmyth. 2001. A screen for genes required for meiosis and spore formation based on whole-genome expression. Curr Biol 11: 1001-9.

Robinson, L.C., J.B. Gibbs, M.S. Marshall, I.S. Sigal, and K. Tatchell. 1987. CDC25: a component of the $R A S$-adenylate cyclase pathway in Saccharomyces cerevisiae. Science 235: 1218-21.

Sagee, S., A. Sherman, G. Shenhar, K. Robzyk, N. Ben-Doy, G. Simchen, and Y. Kassir. 1998. Multiple and distinct activation and repression sequences mediate the regulated transcription of $I M E 1$, a transcriptional activator of meiosis-specific genes in Saccharomyces cerevisiae. Mol Cell Biol 18: 1985-95.

Salah, S.M. and K. Nasmyth. 2000. Destruction of the securin Pds1p occurs at the onset of anaphase during both meiotic divisions in yeast. Chromosoma 109: 27-34.

Schneider, B.L., E.E. Patton, S. Lanker, M.D. Mendenhall, C. Wittenberg, B. Futcher, and M. Tyers. 1998. Yeast G1 cyclins are unstable in G1 phase. Nature 395: 86-9.

Schwab, M., M. Neutzner, D. Mocker, and W. Seufert. 2001. Yeast Hct1 recognizes the mitotic cyclin $\mathrm{Clb} 2$ and other substrates of the ubiquitin ligase APC. EMBO J 20: 5165-75.

Shinkai, Y., H. Satoh, N. Takeda, M. Fukuda, E. Chiba, T. Kato, T. Kuramochi, and Y. Araki. 2002. A testicular germ cell-associated serine-threonine kinase, MAK, is dispensable for sperm formation. Mol Cell Biol 22: 3276-80.

Shonn, M.A., R. McCarroll, and A.W. Murray. 2000. Requirement of the spindle checkpoint for proper chromosome segregation in budding yeast meiosis. Science 289: $300-3$.

Shou, W., J.H. Seol, A. Shevchenko, C. Baskerville, D. Moazed, Z.W. Chen, J. Jang, H. Charbonneau, and R.J. Deshaies. 1999. Exit from mitosis is triggered by Tem1dependent release of the protein phosphatase Cdc14 from nucleolar RENT complex. Cell 97: 233-44.

Sopko, R., S. Raithatha, and D. Stuart. 2002. Phosphorylation and maximal activity of Saccharomyces cerevisiae meiosis-specific transcription factor Ndt80 is dependent on Ime2. Mol Cell Biol 22: 7024-40.

Stegmeier, F., R. Visintin, and A. Amon. 2002. Separase, polo kinase, the kinetochore protein Slk19, and Spo12 function in a network that controls Cdc14 localization during early anaphase. Cell 108: 207-20.

Stelter, P. and H.D. Ulrich. 2003. Control of spontaneous and damage-induced mutagenesis by SUMO and ubiquitin conjugation. Nature 425: 188-91.

Straight, A.F., W. Shou, G.J. Dowd, C.W. Turck, R.J. Deshaies, A.D. Johnson, and D. Moazed. 1999. Net1, a Sir2-associated nucleolar protein required for rDNA silencing and nucleolar integrity. Cell 97: 245-56.

Stuart, D. and C. Wittenberg. 1998. CLB5 and CLB6 are required for premeiotic DNA replication and activation of the meiotic S/M checkpoint. Genes Dev 12: 2698-710.

Sumrada, R.A. and T.G. Cooper. 1987. Ubiquitous upstream repression sequences control activation of the inducible arginase gene in yeast. Proc Natl Acad Sci U S A 84: 3997-4001.

Tanaka, T.U. 2002. Bi-orienting chromosomes on the mitotic spindle. Curr Opin Cell Biol 14: $365-71$.

Toda, T., S. Cameron, P. Sass, M. Zoller, and M. Wigler. 1987. Three different genes in $S$. cerevisiae encode the catalytic subunits of the cAMP-dependent protein kinase. Cell 50: 277-87. 
Toh, E.A. and M. Nishizawa. 2001. Structure and function of cyclin-dependent Pho85 kinase of Saccharomyces cerevisiae. J Gen Appl Microbiol 47: 107-117.

Vidan, S. and A.P. Mitchell. 1997. Stimulation of yeast meiotic gene expression by the glucose-repressible protein kinase Rim15p. Mol Cell Biol 17: 2688-97.

Visintin, R., K. Craig, E.S. Hwang, S. Prinz, M. Tyers, and A. Amon. 1998. The phosphatase Cdc14 triggers mitotic exit by reversal of Cdk-dependent phosphorylation. Mol Cell 2: 709-18.

Wan, Y. and M.W. Kirschner. 2001. Identification of multiple $C D H 1$ homologues in vertebrates conferring different substrate specificities. Proc Natl Acad Sci U S A 98: 13066-71.

Wang, H., D. Liu, Y. Wang, J. Qin, and S.J. Elledge. 2001. Pds1 phosphorylation in response to DNA damage is essential for its DNA damage checkpoint function. Genes Dev 15: 1361-72.

Washburn, B.K. and R.E. Esposito. 2001. Identification of the Sin3-binding site in Ume6 defines a two-step process for conversion of Ume6 from a transcriptional repressor to an activator in yeast. Mol Cell Biol 21: 2057-69.

Weinstein, J. 1997. Cell cycle-regulated expression, phosphorylation, and degradation of p55Cdc. A mammalian homolog of CDC20/Fizzy/slp1. J Biol Chem 272: 2850111.

Xu, L., M. Ajimura, R. Padmore, C. Klein, and N. Kleckner. 1995. NDT80, a meiosisspecific gene required for exit from pachytene in Saccharomyces cerevisiae. Mol Cell Biol 15: 6572-81.

Yamada, H., K. Kumada, and M. Yanagida. 1997. Distinct subunit functions and cell cycle regulated phosphorylation of $20 \mathrm{~S} \mathrm{APC} / \mathrm{cyclosome}$ required for anaphase in fission yeast. J Cell Sci 110: 1793-804.

Yamashita, Y.M., Y. Nakaseko, I. Samejima, K. Kumada, H. Yamada, D. Michaelson, and M. Yanagida. 1996. 20S cyclosome complex formation and proteolytic activity inhibited by the cAMP/PKA pathway. Nature 384: 276-9.

Yoshida, S. and A. Toh-e. 2002. Budding yeast Cdc5 phosphorylates Net1 and assists Cdc14 release from the nucleolus. Biochem Biophys Res Commun 294: 687-91.

Yu, H. 2002. Regulation of APC-Cdc20 by the spindle checkpoint. Curr Opin Cell Biol 14: 706-14.

Yu, H., J.M. Peters, R.W. King, A.M. Page, P. Hieter, and M.W. Kirschner. 1998. Identification of a cullin homology region in a subunit of the anaphase-promoting complex. Science 279: 1219-22.

Zachariae, W. and K. Nasmyth. 1999. Whose end is destruction: cell division and the anaphase-promoting complex. Genes Dev 13: 2039-58.

Zachariae, W., M. Schwab, K. Nasmyth, and W. Seufert. 1998a. Control of cyclin ubiquitination by CDK-regulated binding of Hctl to the anaphase promoting complex. Science 282: 1721-4.

Zachariae, W., A. Shevchenko, P.D. Andrews, R. Ciosk, M. Galova, M.J. Stark, M. Mann, and K. Nasmyth. 1998b. Mass spectrometric analysis of the anaphase-promoting complex from yeast: identification of a subunit related to cullins. Science 279: 1216-9. 


\title{
Chapter 2
}

\section{Synergistic inhibition of APC/C by glucose and activated Ras}

\author{
proteins can be mediated by each of the Tpk1-3 proteins in
}

\author{
Saccharomyces cerevisiae
}

\begin{abstract}
Proteolysis triggered by the anaphase-promoting complex/cyclosome (APC/C) is essential for the progression through mitosis. APC/C is a highly conserved ubiquitin ligase whose activity is regulated during the cell cycle by various factors, including spindle checkpoint components and protein kinases. The cAMP-dependent protein kinase (PKA) was identified as negative regulator of $\mathrm{APC} / \mathrm{C}$ in yeast and mammalian cells. In the yeast Saccharomyces cerevisiae, PKA activity is induced upon glucose addition or by activated Ras proteins. Here, we show that glucose and the activated Ras $2{ }^{\text {Val19 }}$ protein synergistically inhibit APC/C function via the cAMP/PKA pathway in yeast. Remarkably, Ras2 proteins defective in the interaction with adenylate cyclase fail to influence APC/C, implying that its function is regulated exclusively by PKA, but not by alternative Ras pathways. Furthermore, we show that the three PKAs in yeast, Tpk1, Tpk2 and Tpk3, have redundant functions in regulating $\mathrm{APC} / \mathrm{C}$ in response to glucose medium. Single or double deletions of $T P K$ genes did not prevent inhibition of APC/C, suggesting that each of the Tpk proteins can take over this function. However, Tpk2 seems to inhibit APC/C function more efficiently than Tpk1 and Tpk3. Finally, we provide evidence that Cdc20 is involved in $\mathrm{APC} / \mathrm{C}$ regulation by the $\mathrm{AMP} / \mathrm{PKA}$ pathway.
\end{abstract}




\section{Introduction}

The anaphase-promoting complex/cyclosome (APC/C) is a highly conserved multisubunit complex which contains ubiquitin ligase activity (Zachariae and Nasmyth 1999; Peters 2002). APC/C is essential for two major events during mitosis: the separation of sister chromatids at the metaphase/anaphase transition and the exit from mitosis. The crucial role of APC/C in metaphase is ubiquitination of securins. In the budding yeast Saccharomyces cerevisiae, proteolytic destruction of securin Pds1 allows the separase Esp1 to become active (Amon 2001; Nasmyth 2002). Esp1 then cleaves the cohesin subunit Scc1 and thereby triggers sister chromatid separation. Important targets for the exit from mitosis are B-type cyclins whose degradation leads to the inactivation of cyclin-dependent kinases (Morgan 1999). Many other substrates of APC/C ubiquitin ligase have been identified, including the polo kinase $\mathrm{Cdc5}$, kinesins, spindle associated proteins and regulators of DNA replication (Zachariae and Nasmyth 1999; Harper et al. 2002; Peters 2002).

APC/C activity is cell cycle regulated. It is kept inactive during S-, G2- and early M-phase, turned on during metaphase and then remains active throughout late M-phase and during the subsequent G1-phase. A variety of regulatory proteins of APC/C have been identified in the last few years. Most is known about the two proteins Cdc20 and Cdh1 (Peters 2002). Recent data demonstrated that they function as substrate recognition proteins, which target substrates to the APC/C core complex (Hilioti et al. 2001; Pfleger et al. 2001; Schwab et al. 2001; Vodermaier 2001). An important feature is the temporal control of APC/C activation by Cdc20 and Cdh1 (Harper et al. 2002; Peters 2002). Cdc20 always precedes Cdh1 in binding and activation during mitosis. Both WD40 proteins have fundamental functions in controlling APC/C during mitosis. They are the targets of the spindle checkpoint, either directly or indirectly (Gardner and Burke 2000). Factors of the spindle assembly checkpoint directly bind and inhibit Cdc20 in response to defects in the integrity of the mitotic spindle or in the bipolar attachment of kinetochors. A checkpoint monitoring the orientation of the mitotic spindle indirectly inhibits the association of Cdh1 with $\mathrm{APC} / \mathrm{C}$ and thereby delays cell division.

Further important regulatory proteins of APC/C are protein kinases, such as the cyclindependent kinase Cdk1 and polo kinase (Nigg 2001). Both kinases were shown to trigger phosphorylation of specific APC/C subunits, known as Apc1, Cdc16, Cdc23 and Cdc27 (Rudner and Murray 2000; Golan et al. 2002). It was recently shown that either of theses 
kinases is capable to activate $\mathrm{APC} / \mathrm{C}$, but both of them are required for efficient $\mathrm{APC} / \mathrm{C}$ activation (Golan et al. 2002).

A further protein kinase regulating APC/C activity is cAMP-dependent protein kinase (also termed protein kinase A or PKA). By using purified mammalian APC/C, it was shown that PKA directly phosphorylates the subunits Apc1 and Cdc27 in vitro (Kotani et al. 1998). In contrast to Cdk1 and polo kinase, PKA-mediated phosphorylation inhibits APC/C activity. In vitro ubiquitination assays revealed that the addition of purified PKA blocked the ability of APC/C to catalyse the formation of polyubiquitin chains on cyclin B (Kotani et al. 1999). These studies also showed that PKA may affect the binding of Cdc20 because Cdc20 failed to bind APC/C pre-incubated with PKA.

In budding and fission yeast, a direct phosphorylation of APC/C subunits by PKA has not yet been shown. Nevertheless, genetic data strongly implicated yeast PKA as negative regulator of $\mathrm{APC} / \mathrm{C}$ similar to mammalian cells. A variety of fission and budding yeast mutants defective in APC/C subunits genes were suppressed by reducing cAMP levels or PKA activity (Yamashita et al. 1996; Yamada et al. 1997; Anghileri et al. 1999; Irniger et al. 2000). It was shown that the addition of cAMP caused cell cycle arrests in mitosis, both at the metaphase/anaphase transition and in telophase (Anghileri et al. 1999). Many yeast APC/C subunits contain multiple PKA consensus phosphorylation sequences (Kennelly and Krebs 1991). The Apc1 subunit for example contains 28 of these motifs.

In budding yeast, the cAMP/PKA pathway can be activated either by the addition of glucose to cells grown on poor carbon sources and by the activation of Ras proteins (Broach 1991; Thevelein and de Winde 1999). Recent data showed that the glucose signal is not transmitted by Ras proteins to adenylate cyclase Cyr1, as previously thought. Instead, a G-protein- receptor system, consisting of the receptor Gpr1 and the G $\alpha$ protein Gpa2, stimulates adenylate cyclase in response to glucose addition (Colombo et al. 1998).

Activation of the small GTP-binding proteins Ras1 and Ras2 is catalysed by Cdc25, a protein that promotes the exchange of GDP with GTP on Ras (Broek et al. 1987; Robinson et al. 1987). Ras-GTP stimulates adenylate cyclase and thereby induces an increase in cAMP levels and activation of PKA (Toda et al. 1985). In budding yeast, this kinase is encoded by three separate genes, TPK1, TPK2 and TPK3 (Toda et al. 1987). In the presence of cAMP the inhibitory protein Bcy1 releases the catalytic subunits which are then able to phosphorylate their target proteins (Broach 1991; Thevelein and de Winde 1999). 
Consistent with the findings that PKA negatively regulates $\mathrm{APC} / \mathrm{C}$, we have previously shown that glucose medium and activation of Ras signalling is lethal for mutants defective in APC/C function (Irniger et al. 2000). Mutants in APC/C subunit genes, such as apc1022 or $c d c 27-1$, were suppressed either by decreasing Ras activity or by growth on the poor carbon source raffinose. In contrast, a constitutively activated $R A S 2^{\text {Vall9 }}$ allele or shifts to glucose medium were deleterious to these mutants. In this study, we show that glucose and activated Ras $2^{\text {Val19 }}$ synergistically cause APC/C inhibition and that Tpk1, Tpk2 and Tpk3 apparently have overlapping functions in this process. 


\section{Materials and Methods}

Yeast strains and plasmids. Yeast strains used in this study are derivatives of the Saccharomyces cerevisiae W303 strain (MATa ade2-1 trp1-1 can1-100 leu2-3,12 his311,15 ura3 GAL psi+) and are listed in Table 1. All strains obtained from a different background were backcrossed at least four times to W303 strains to make them congenic. Plasmids containing the $R A S 2^{\text {Vall9 }}, R A S 2^{\text {Vall9Gly41 }}$ and $R A S 2^{\text {Vall9Asn45 }}$ alleles on the centromeric plasmid YCplac33 (Mösch et al. 1999), the TPK1, TPK2 and TPK3 genes on the high-copy plasmid pRS426 (Mösch et al. 1999) and the STE11-4 allele (Stevenson et al. 1992) cloned into the centromeric plasmid YCp50 were previously described. TPK genes expressed from the inducible GAL1 promoter were constructed by PCR amplification of the corresponding genes and subsequent fusions to the GAL1 promoter on the $2 \mu$ plasmid YEplac195. The $G A L-C D C 20$ gene fusion was isolated from a $G A L-c D N A$ library (unpublished results).

For deletion of a single $T P K$ gene (TPK1, TPK2 or TPK3), a deletion cassette containing the kanamycin resitance gene, kan-R, from the Escherichia coli transposon TN903 flanked by the $5^{\prime}$-region and the $3^{\prime}$-region of the $T P K$ gene, was transformed into yeast strains. Transformants were selected twice on YEPD+Geneticin ${ }^{\circledR}$-plates. Deletions in wild-type, apc10-22 and $c d c 27-1$ strains were verified by Southern hybridisation.

Double deletions of $T P K$ genes were constructed starting from the single deletion strains. The tpk-deletion cassette contains on both sides of the kan-R marker gene a lox $P$ recombination sequence from the bacteriophage $\mathrm{P} 1$ (Guldener et al. 1996). By recombination of both loxP sequences, the kan-R sequence was removed from the genome and the strain regained sensitivity to Geneticin ${ }^{\circledR}$. Afterwards another tpk deletion cassette was transformed into the single deletion strain and the kan-R gene served as selection marker for the second tpk-deletion. Plasmid pSH47 (Guldener et al. 1996) containing the Cre-recombinase under control of the inducible GAL1 promoter and an URA3 selection marker was transformed in a first step into tpk single deletion strains. Induction of the $G A L 1$ promoter resulted in the expression of the Cre-recombinase which performed recombination of the loxP sequences. Loss of the kan-R marker gene was verified by selection for Geneticin ${ }^{\circledR}$ sensitive transformants. 
Table 1. Yeast strains used in this study

\begin{tabular}{|c|c|}
\hline strain & relevant genotype \\
\hline S001 & wildtype strain W303 \\
\hline & MATa, ade2-1, trp1-1, can1-100, leu2-3, 112, his3-11, 15, ura3, GAL, psi+ \\
\hline S095 & MATa, apc10-22 \\
\hline S201 & MATalpha, $c d h 1: \because H I S 5$ \\
\hline S211 & MATa, apc10-22, cdh1::HIS5 \\
\hline S221 & MATa, $c d c 27-1$ \\
\hline S320 & MATa, apc10-22, tpk1::Kan-R \\
\hline S321 & MATa, apc10-22, tpk2::Kan-R \\
\hline S322 & MATa, tpkl::Kan-R \\
\hline S323 & MATa, tpk2::Kan-R \\
\hline S324 & MATa, $c d c 27-1, t p k 2:: \mathrm{Kan}-\mathrm{R}$ \\
\hline S325 & MATa, apc10-22, tpk3::Kan-R \\
\hline S326 & MATa, $c d c 27-1, t p k 3::$ Kan-R \\
\hline S327 & MATa, tpk3::Kan-R \\
\hline S328 & MATa, $c d c 27-1, t p k 1::$ Kan-R \\
\hline S330 & MATa, tpk2::tpk1::Kan-R \\
\hline S331 & MATa, tpk2::tpk3::Kan-R \\
\hline S332 & MATa, tpk3::tpk1::Kan-R \\
\hline S333 & MATa, cdc27-1, tpk2::tpk1::Kan-R \\
\hline S334 & MATa, cdc27-1, tpk2::tpk3::Kan-R \\
\hline S335 & MATa, cdc27-1, tpk3::tpk1::Kan-R \\
\hline S336 & MATa, apc10-22, tpk2::tpk1::Kan-R \\
\hline S337 & MATa, apc10-22, tpk2::tpk3::Kan-R \\
\hline S444 & MATa, apc10-22, tpk1::tpk3::KanR \\
\hline S469 & MATa, GAL-HA3-CDH1::TRP1 \\
\hline S481 & MATa, MYC18-CDC20::TRP1 \\
\hline
\end{tabular}

Genetic techniques and media. Standard genetic techniques were used for manipulating yeast strains. To test synthetic phenotypes, the corresponding haploid strains were crossed resulting in diploids, which were sporulated, and then tetrads were analysed by dissection. Only tetrads producing four germinating spores were used for the analysis of genetic interaction.

When yeast cells were grown in complete medium, YEP medium (2\% bactopeptone, $1 \%$ yeast extract, $0.005 \%$ adeninsulfate) supplemented either with $2 \%$ glucose (YEPD), $2 \%$ galactose $(\mathrm{YEP}+\mathrm{Gal})$ or $2 \%$ raffinose $(\mathrm{YEP}+\mathrm{Raf})$ was used. For the selection of plasmid 
containing strains, cells were grown in minimal medium, a synthetic medium containing $0.8 \%$ yeast nitrogen base, $50 \mu \mathrm{g} \mathrm{ml}^{-1}$ uracil and adenine, supplemented with amino acids and $2 \%$ glucose or $2 \%$ raffinose (Rose 1990).

Growth conditions and cell cycle arrests. Prior to the incubation of mutant strains at elevated temperature on agar plates, the cells were always pre-incubated at $25{ }^{\circ} \mathrm{C}$ for $12-18$ hours. Prior to cell cycle arrests in liquid medium, cultures were pre-grown to an A600 0.3 to 0.6 at $25^{\circ} \mathrm{C}$. When a gene was expressed from the inducible GAL1 promoter, cells were pre-grown in medium containing raffinose as the sole carbon source. The GAL1-10 promoter was induced by the addition of $2 \%$ galactose. To arrest cells in G1 phase with alpha-factor pheromone, $5 \mu \mathrm{g}$ alpha-factor $\mathrm{ml}^{-1}$ was added. For prolonged alpha-factor treatments, additional alpha -factor was added after every 120 min to prevent a drop in the alpha-factor concentration.

Immunoblotting. Whole cell extracts for immunoblotting were prepared as previously described (Surana et al. 1993). Immunoblotting was performed using the enhanced chemiluminescence detection system (ECL, Amersham). Clb2- and Cdc28- antibodies were used in 1:1000 and 1:2000 dilutions, respectively. 


\section{Results}

\section{Glucose and activated Ras2 proteins synergistically inhibit APC/C function}

In previous experiments we showed that glucose or activated Ras2 proteins are deleterious for temperature-sensitive mutants in APC/C subunit genes (Irniger et al. 2000). Since it was earlier reported that glucose activates adenylate cyclase independently of Ras proteins (Colombo et al. 1998; Thevelein and de Winde 1999), we tested whether this model may also apply to the regulation of APC/C. We argued that if the glucose signal and Ras proteins acted on separate pathways on adenylate cyclase, then the simultaneous activation of both pathways may have a synergistic effect on adenylate cyclase, PKA activity and inhibition of APC/C.

To test this model, apc10-22 mutants were transformed with a centromeric plasmid containing either the constitutively activated $R A S 2^{\text {Vall }}$ allele or, as control, the empty vector YCplac22 (TRP1 marker). Transformants were pregrown at $25{ }^{\circ} \mathrm{C}$ in minimal medium lacking tryptophan (-Trp) and containing raffinose as sole carbon source. Then cells were streaked to fresh -Trp plates containing either glucose or raffinose. apc10-22 mutants containing $R A S 2^{\text {Vall9 }}$ were viable at $28{ }^{\circ} \mathrm{C}$ on raffinose plates, but inviable on glucose plates, displaying severe growth defects even at $25{ }^{\circ} \mathrm{C}$ (Fig. 1). apc10-22 cells carrying the control plasmid were viable under these conditions. apc10-22 RAS2 ${ }^{\text {Vall9 }}$ cells were inviable on raffinose plates at $34{ }^{\circ} \mathrm{C}$, a temperature tolerated by apc10-22 mutant carrying the control plasmid. Both strains were inviable on glucose medium at this temperature. These findings show that both glucose and activated Ras proteins interfere with viability of apc10-22 mutants. The lethality of apc10-22 $R A S 2^{\text {Vall9 }}$ cells at $28{ }^{\circ} \mathrm{C}$ demonstrates that glucose and the activated Ras 2 protein synergistically reduce the viability of apc10-22 mutants. Similar findings were observed for $c d c 27-1$ mutants (data not shown). Thus, glucose and activated Ras2 have a combined effect on APC/C function. 

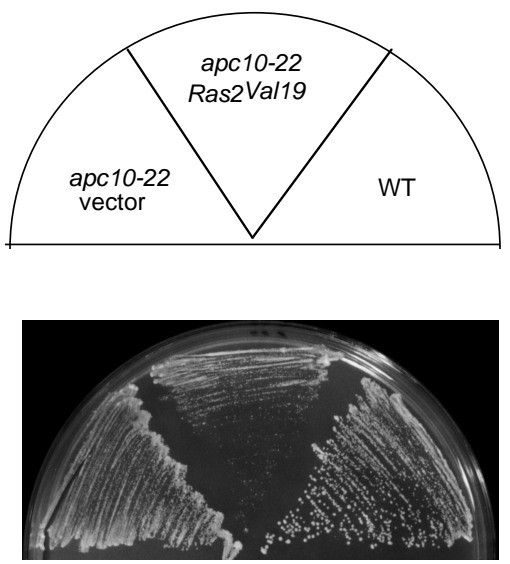

Gluc $25^{\circ} \mathrm{C}$

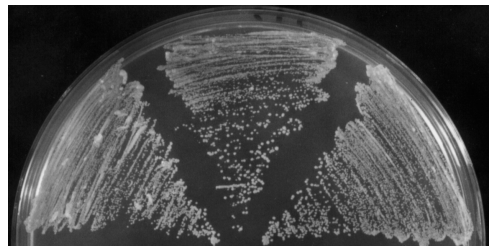

Raf $28^{\circ} \mathrm{C}$

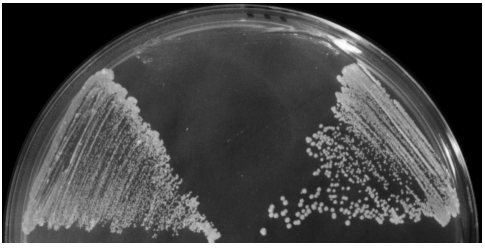

Gluc $28^{\circ} \mathrm{C}$

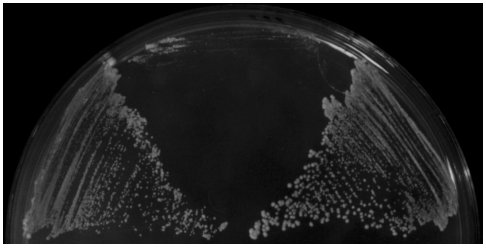

Raf $34^{\circ} \mathrm{C}$

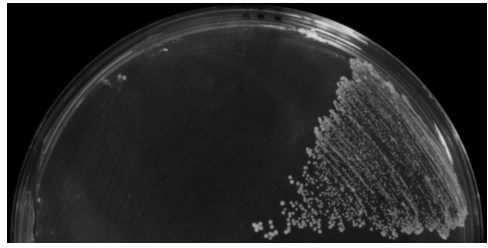

Gluc $34^{\circ} \mathrm{C}$

Fig. 1

Glucose and the activated $R A S 2^{\text {Vall }}$ allele have a combined lethal effect on apc10-22 mutants. apc10-22 mutants carrying either a centromeric plasmid with the RAS2 ${ }^{\text {Vall9 }}$ gene or an empty vector plasmid (YIplac22, containing the TRP1 marker) were pregrown on minimal medium lacking tryptophan and containing raffinose as carbon source (MM-Trp+Raf). Cells were then streaked on MM-Trp plates containing either raffinose or glucose and incubated for 2.5 days at the indicated temperatures. A wild-type strain was used as control.

\section{Inhibition of APC/C by activated Ras2 requires the PKA pathway}

We next asked whether activated Ras proteins mediate their effect on APC/C by cAMP/PKA or whether other pathways may be involved. Ras1 and Ras2 activate two different signalling pathways, the cAMP/PKA pathway and the mitogen-activated protein kinase (MAPK) pathway consisting of Cdc42/Ste20/Ste11/Ste7/Kss1/Ste12 proteins (Mösch 2000). For invasive growth of yeast, activation of either of these pathways by Ras was sufficient indicating that cAMP/PKA and MAPK signalling had redundant functions in transmitting the signal from Ras to the effectors (Mösch et al. 1999).

To test whether APC/C inhibition by activated Ras may also be transmitted by both of these pathways, we used RAS2 alleles, which contained, in addition to the activating mutation in the Val19 codon, second-site mutations at codons 41 and 45. Exchanges of Pro41 to Gly and Asp45 to Asn were shown to cause defects in the binding and activation of adenylate cyclase, but these proteins were still able to activate the MAPK pathway (Mösch et al. 1999). Thus, Ras $2^{\text {Val19 }}$ is able to activate both pathways, but Ras $2^{\text {Val19Gly41 }}$ and Ras $2^{\text {Val19Asn45 }}$ functions are restricted to the MAPK pathway. Centromeric plasmids containing either $R A S 2^{\text {Vall9 }}, R A S 2^{\text {Vall9Gly41 }}, R A S 2^{\text {Vall9Asn45 }}$ genes or no insert were transformed into a wild-type strain and into the apc mutant strains apc10-22 and $c d c 27-1$. The plasmid 
carrying strains were shifted to $34{ }^{\circ} \mathrm{C}$ or $30{ }^{\circ} \mathrm{C}$, respectively, on -Trp minimal medium with raffinose as the sole carbon source. In contrast to mutant cells carrying $R A S 2^{\text {Vall } 9}$, apc10-22 and $c d c 27-1$ transformants with the double mutations in the $R A S 2$ genes were viable under these conditions (Fig. 2A,B). apc10-22 mutants containing RAS2 $2^{\text {Val19Gly41 }}$ or RAS2 $2^{\text {Val19Asn45 }}$ were also viable on glucose medium at $28{ }^{\circ} \mathrm{C}$ and therefore do not display the synergistic phenotype observed when glucose and activated Ras $2^{\text {Val19 }}$ protein were combined (Fig. 2C). We conclude that Ras 2 proteins, which are defective in binding adenylate cyclase do not affect APC/C function. Thus, the signal from Ras appears to be transmitted through cAMP and PKA. Unlike in signalling for the induction of invasive growth, the MAPK pathway is apparently unable to replace the cAMP/PKA pathway. 

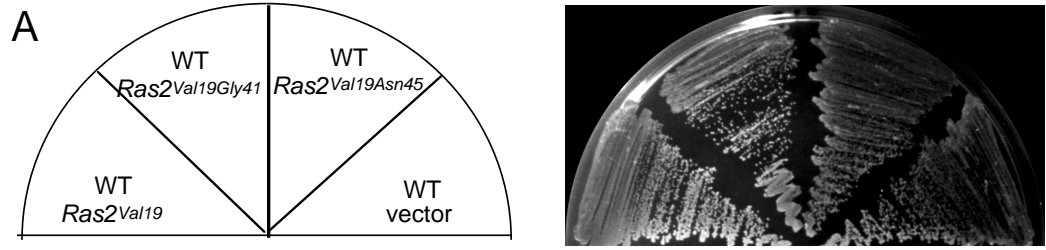

Raf $34^{\circ} \mathrm{C}$
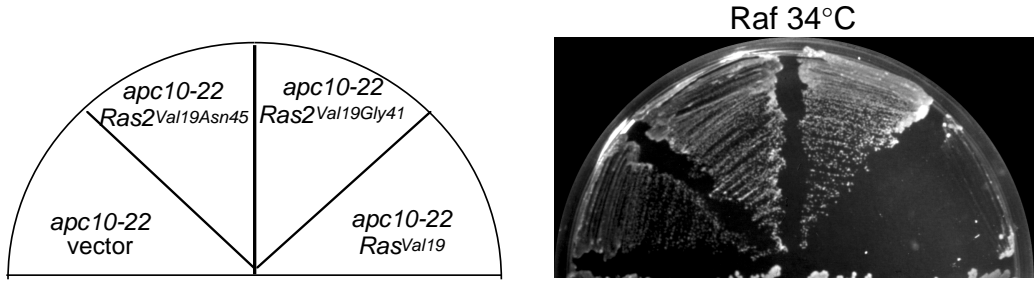

Raf $34^{\circ} \mathrm{C}$

B
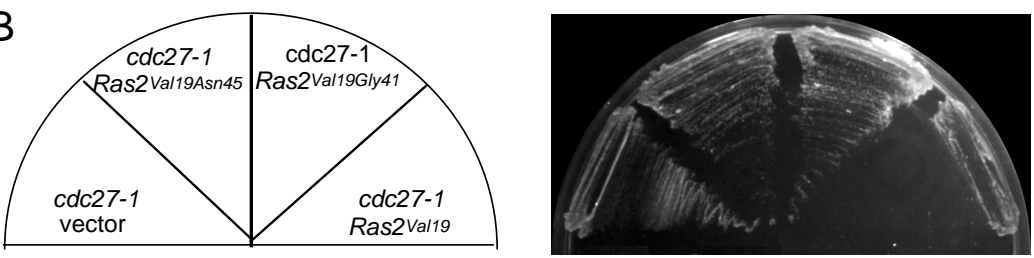

Raf $30^{\circ} \mathrm{C}$
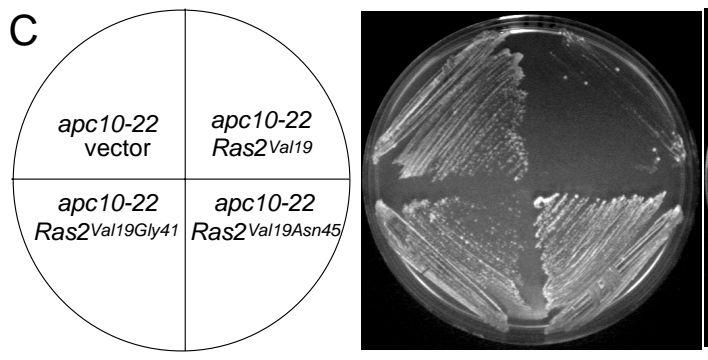

Gluc $28^{\circ} \mathrm{C}$

$\mathrm{D}$

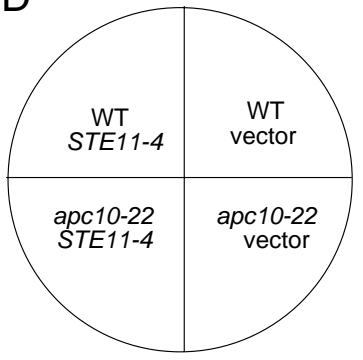

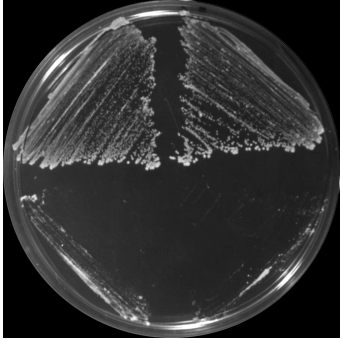

Gluc $34^{\circ} \mathrm{C}$

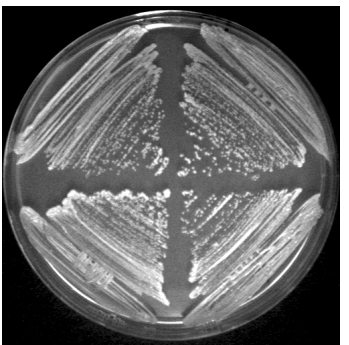

Raf $28^{\circ} \mathrm{C}$

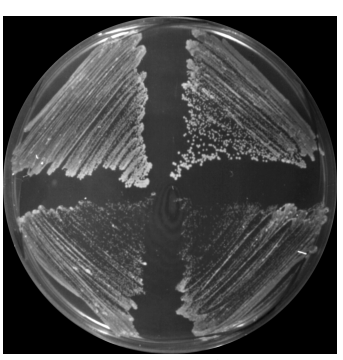

Raf $34^{\circ} \mathrm{C}$
Fig. 2

Activated RAS2 alleles defective in stimulating adenylate cyclase are not lethal for apc10-22 and $c d c 27-1$ mutants.

A, B) Centromeric plasmids carrying either the RAS $2^{\text {Val19, }}$

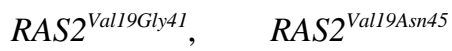
genes or the empty plasmid Ycplac22 (containing TRP1 as selectable marker) were transformed into a wild-type strain and the apc10-22 and $c d c 27-1$ mutant strains. Transfomants were pregrown on MM-Trp+Raf medium at 25 ${ }^{\circ} \mathrm{C}$, then streaked onto fresh plates and shifted to semipermissive temperatures, $34{ }^{\circ} \mathrm{C}$ for apc10-22 mutants (A) and $30{ }^{\circ} \mathrm{C}$ for $c d c 27-1$ mutants (B). Plates were incubated for 2.5 days.

C) Transformants of apc10-22 mutants were streaked onto MM-Trp plates containing either glucose or raffinose and incubated at $28{ }^{\circ} \mathrm{C}$ for 2.5 days.

D) Wild-type and apc10-22 mutants were transformed with centromeric plasmids containing the STE11-4 allele or the empty plasmid Ycplac50 (with URA3 as selectable marker). Transformants were pregrown on MM-Ura+Raf at $25^{\circ} \mathrm{C}$, streaked to fresh plates containing either glucose or raffinose and incubated at $34^{\circ} \mathrm{C}$ for 2.5 days.

\section{Activation of the MAPK pathway does not influence apc mutants}

To further elucidate whether the MAPK pathway may cause APC/C inhibition, we transformed apc10-22 mutants with plasmids carrying a hyperactive STE11 allele, STE11- 
4 (Stevenson et al. 1992), on the centromeric plasmid YCp50. The Ste11 protein kinase is one component of the MAPK signalling cascade. We argued that APC/C inhibition caused by highly active MAPK signalling would interfere with viability of apc mutants, as seen for Ras $2^{\text {Val19 }}$. Transformants carrying plasmids with either the STE11-4 allele or no insert were tested on minimal medium containing raffinose as the sole carbon source. We found that apc10-22 containing STE11-4 produced colonies on raffinose plates, similar to mutant strains with the empty vector (Fig. 2D). Mutant cells containing either of the plasmids were inviable on glucose plates. Thus, APC/C is apparently not affected, neither positively nor negatively, by activation of the MAPK cascade.

These results underline the model that APC/C inhibition caused by activated Ras signalling is mediated exclusively by the PKA pathway and not by the MAPK pathway.

\section{Each of the Tpk1-3 proteins is sufficient for $\mathrm{APC} / \mathrm{C}$ inhibition in response to glucose}

Previous findings have shown that for some of the functions of yeast PKA, the Tpk1, Tpk2 and Tpk3 proteins are redundant, whereas other processes, such as the regulation of pseudohyphal growth, require one specific Tpk protein (Robertson and Fink 1998; Robertson et al. 2000). To test the role of the three Tpk proteins in APC/C inhibition, we constructed apc10-22 and $c d c 27-1$ mutants containing either single deletions or double deletions of $T P K$ genes. We argued that if APC/C inhibition were mediated by a specific Tpk protein then a deletion of the corresponding gene would abolish lethality of apc mutants upon shift to glucose medium.

A $c d c 27-1$ strain, $c d c 27-1$ strains containing single tpk deletions $(c d c 27-1$ tpk1 $\Delta, c d c 27-1$

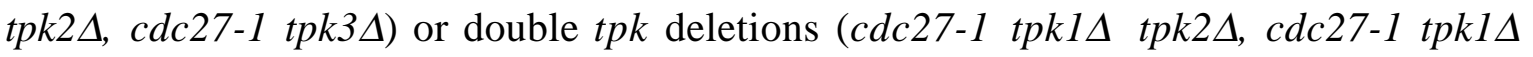

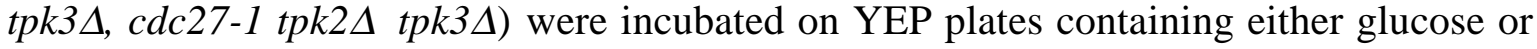
raffinose at $30{ }^{\circ} \mathrm{C}$, a semi-permissive temperature for $c d c 27-1$ mutants. All $c d c 27-1$ strains were viable at $30{ }^{\circ} \mathrm{C}$ on raffinose medium, but failed to form colonies in the presence of glucose (Fig. 3A). Similarly, apc10-22 mutant and each of the tpk double deletions grew on raffinose medium, but were inviable on YEPD at the semi-permissive temperature, 34 ${ }^{\circ} \mathrm{C}$ (Fig. 3B). These results show that single or double deletions of TPK genes do not affect the viabilty of $a p c$ mutants. Thus, it appears that each of the TPK genes is sufficient for signal transmission from glucose to APC/C suggesting that the three TPK genes fulfill a redundant function in this process. 


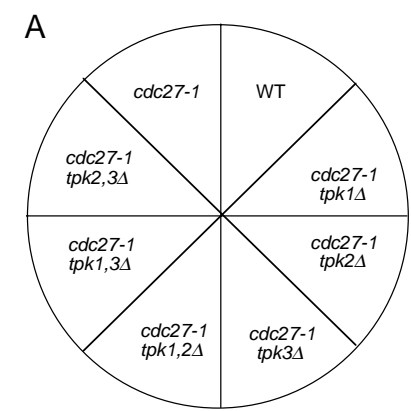

B

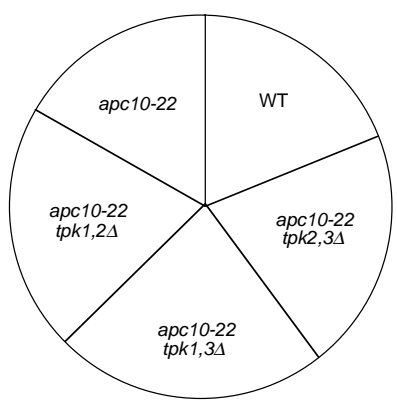

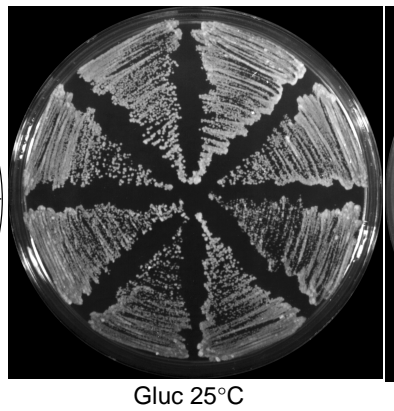

Gluc $25^{\circ} \mathrm{C}$

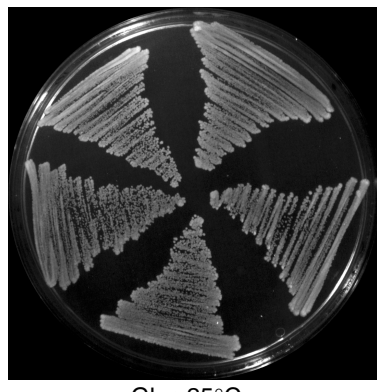

Gluc $25^{\circ} \mathrm{C}$
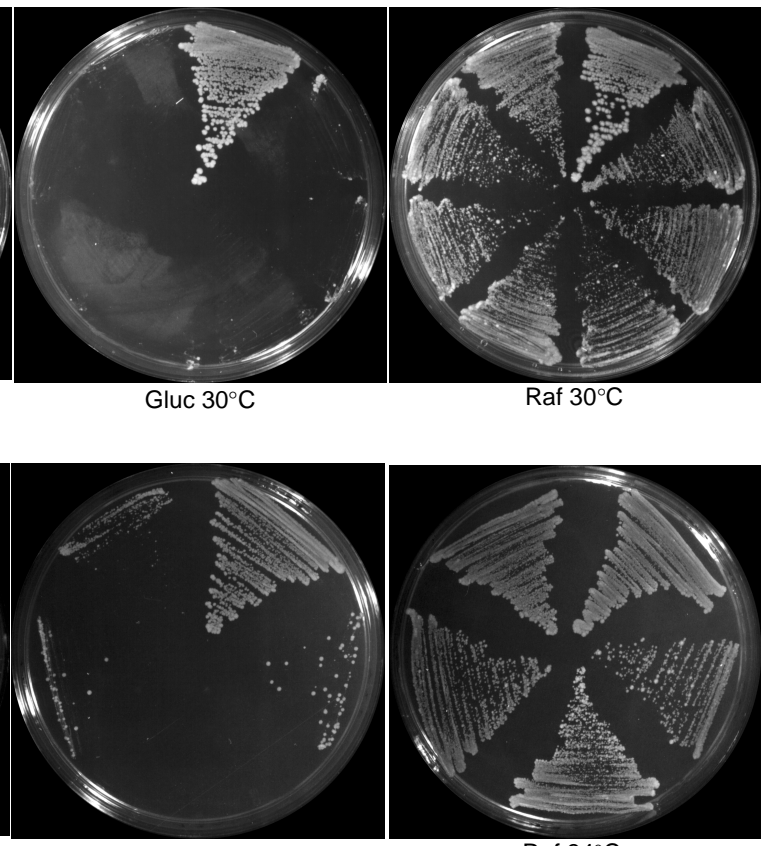

Gluc $34^{\circ} \mathrm{C}$

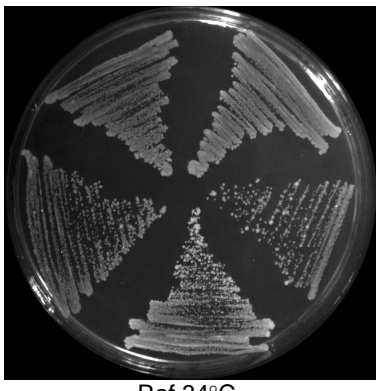

Raf $34^{\circ} \mathrm{C}$

Fig. 3

One Tpk protein is sufficient for APC/C inhibition in response to glucose.

A) $c d c 27-1$ mutants strains deleted for a single $T P K$ gene $(c d c 27-1$ tpk1 $\Delta, c d c 27-1$ tpk2 $4, c d c 27-1$ tpk3 $)$

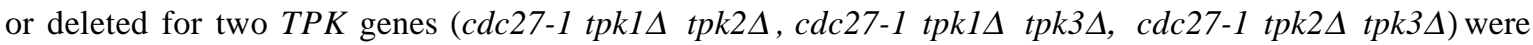
pregrown on $\mathrm{YEP}+\mathrm{Raf}$ plates at $25{ }^{\circ} \mathrm{C}$, then streaked to fresh $\mathrm{YEP}+\mathrm{Glu}$ or $\mathrm{YEP}+\mathrm{Raf}$ plates and incubated at either $25^{\circ} \mathrm{C}$ or $30^{\circ} \mathrm{C}$ for 2.5 days.

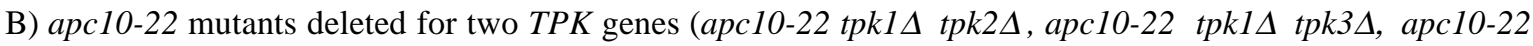

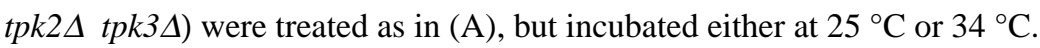

To further test the effect of glucose on $a p c$ mutants containing only a single $T P K$ gene, $c d c 27-1$ and $c d c 27-1$ tpk double deletion strains were first pregrown in raffinose medium at $28{ }^{\circ} \mathrm{C}$. Under these conditions, $c d c 27-1$ mutants undergo cell cycle progression without obvious defects when using raffinose as carbon source. Cultures were split in two halfes and either glucose or, as control, the poor carbon source galactose were added. We argued that glucose induced inhibition of APC/C function would block $c d c 27-1$ cells in mitosis. To monitor whether glucose causes $c d c 27-1$ mutants to arrest in mitosis, alpha-factor was added and the cultures were further incubated at $28{ }^{\circ} \mathrm{C}$. Alpha-factor induces cells to arrest as unbudded cells in G1-phase. We found that $c d c 27-1$ as well as $c d c 27-1$ strains containing only one TPK gene were blocked in mitosis upon glucose addition (Fig. 4A,B). After 3 hours of incubation in the presence of pheromone, 40- 70\% of cells were still largebudded. In contrast, most cells arrested in G1-phase as unbudded cells in the cultures 
treated with galactose, similar to wild-type cells. In these cultures, the amount of budded cells rapidly decreased after alpha-factor addition. Importantly, each of the $c d c 27-1$ tpk double deletion strains shows a similar phenotype as the $c d c 27-1$ strain upon glucose or galactose addition.

To test whether indeed APC/C- mediated proteolysis is impaired in the $c d c 27-1$ tpk double deletion strains upon treatment with glucose, we determined protein levels of the mitotic cyclin $\mathrm{Clb} 2$, a substrate of APC/C. Clb2 levels were analysed by immunoblotting before and three hours after pheromone treatment. Before alpha-factor addition, $\mathrm{Clb} 2$ is present in all cultures, but $\mathrm{Clb} 2$ protein levels are marginally higher in $c d c 27-1$ mutant strains treated with glucose (Fig. 4C). After alpha-factor addition Clb2 levels dropped to low levels in wild-type cells and in $c d c 27-1$ cells incubated in galactose medium. In contrast, cyclin levels remained on higher levels in $c d c 27-1$ cells grown in glucose medium (Fig. 4D). In cdc27-1 tpk1 $\Delta$ tpk3 $\Delta$ cells, Clb2 levels were similarly as in $c d c 27-1$ cells, but partially decreased in the other double tpk deletion strains. These results indicate that Tpk2 has a more potent function than Tpk1 and Tpk3 in APC/C regulation. However, Clb2 degradation was at least partially affected in each $c d c 27-1$ strain with double tpk deletions in the presence of glucose. Thus, the inhibitory signal from glucose to APC/C is transmitted in each of these strains.

Taken together, these results show that one single Tpk protein is sufficient for APC/C inhibition in response to glucose and that Tpk2 may be particularly efficient in this process. 
A Galactose + alpha factor
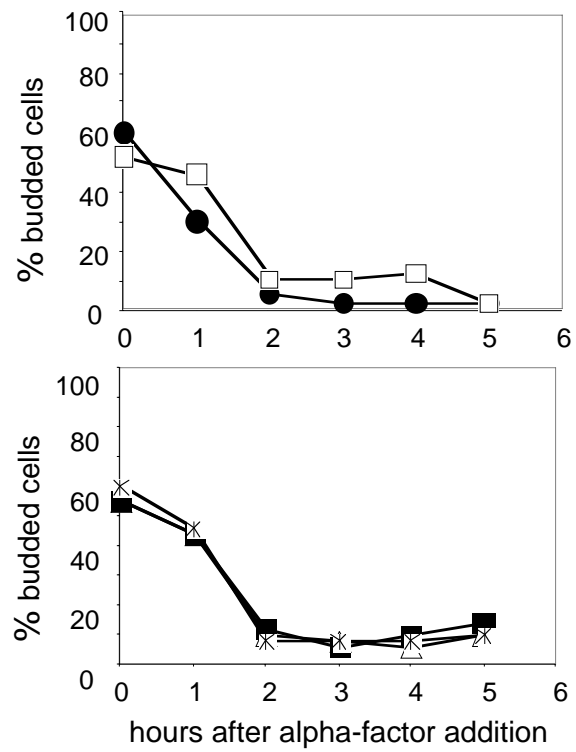

Glucose + alpha factor
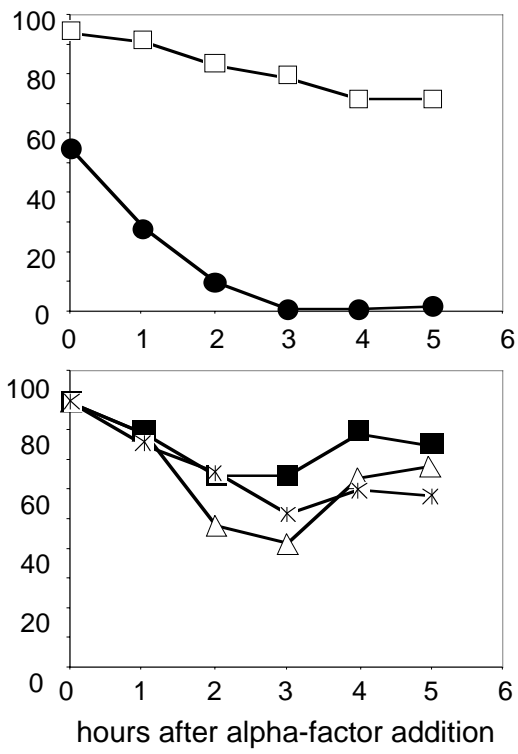

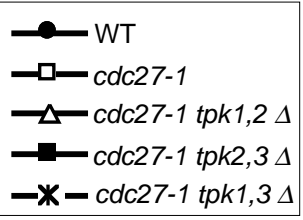

- $\mathbf{X}-c d c 27-1$ tpk1,3 $\Delta$

B

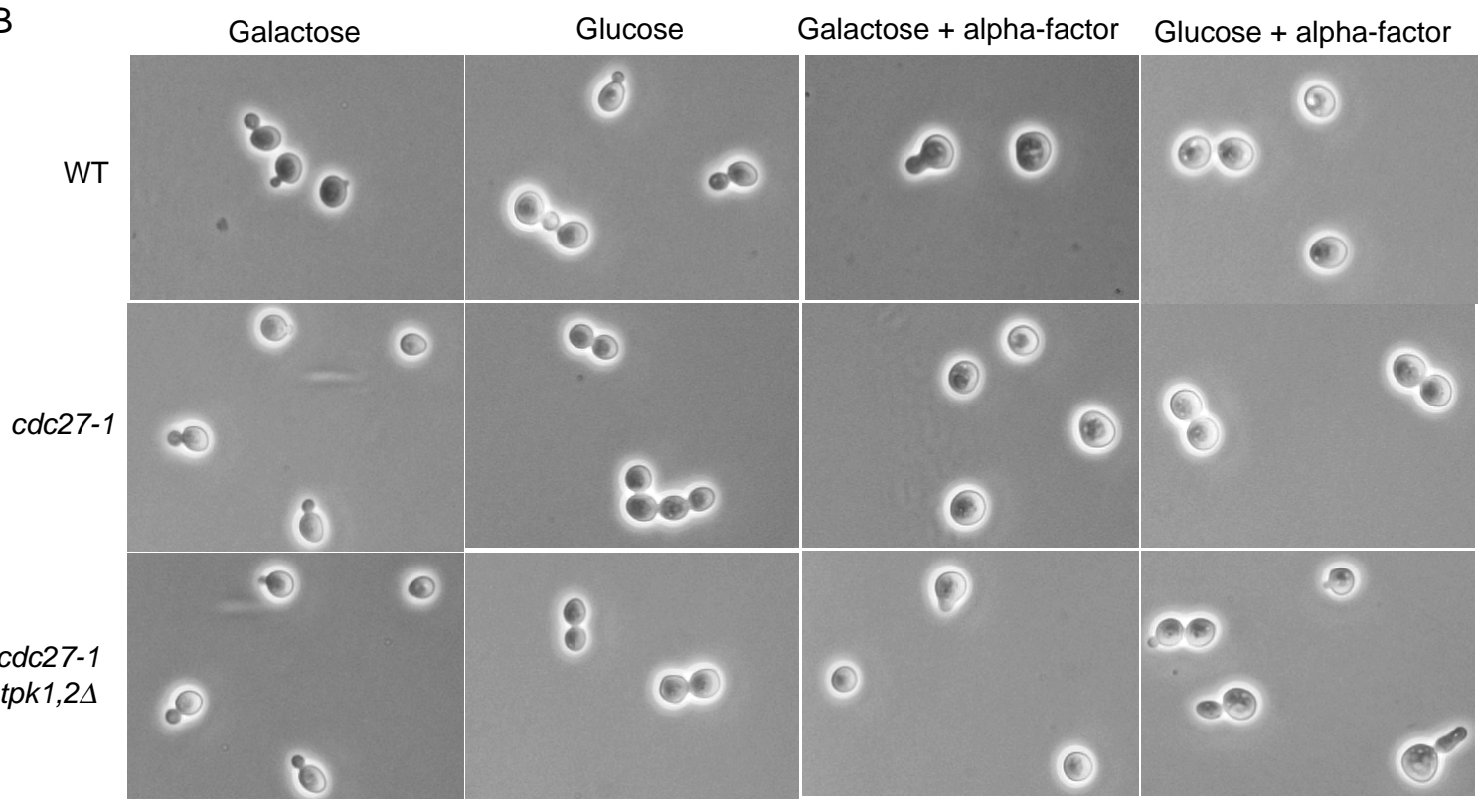

C

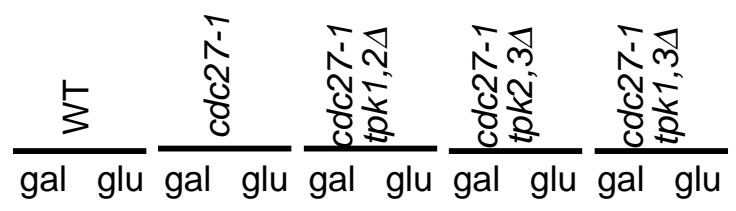

no alpha-factor

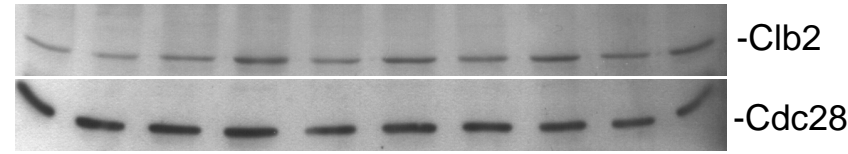

D

+ alpha factor

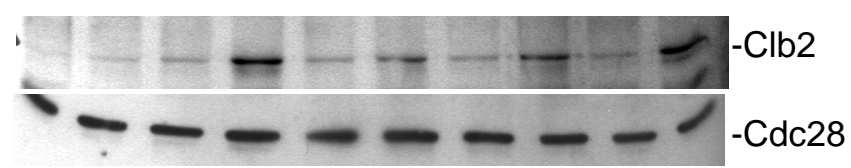


Fig. 4

One Tpk protein is sufficient for the mitotic arrest of $c d c 27-1$ mutants.

A wild-type strain, a $c d c 27-1$ mutant strain and $c d c 27-1$ mutants deleted for two TPK genes ( $c d c 27-1$ tpkl $\Delta$

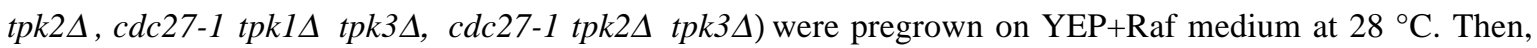
either $2 \%$ glucose or $2 \%$ galactose was added and cells were further incubated for 5 hours at the same temperature. Subsequently, alpha-factor was added to arrest cells, which are able to complete mitosis, in G1 phase.

A) Percentage of budded cells at the indicated time points after alpha-factor addition. Values are an average of three independent experiments. B) Photographs of cells of the indicated strains grown on galactose or glucose medium before alpha-factor addition (left) and 5 hours after alpha-factor addition (right).

$\mathrm{C}$, D) Immunoblotting of $\mathrm{Clb} 2$ protein levels before (C) or after (D) alpha-factor addition using $\mathrm{Clb} 2$ antibodies. Cdc28 was used as loading control.

\section{Overexpression of $T P K$ genes is deleterious to apc mutants}

To further test whether Tpk proteins may mediate APC/C inhibition with different efficiencies, we determined the effects of high levels of Tpk proteins on the viability of apc mutants. $c d c 27-1$ and apc10-22 mutants were transformed with high-copy plasmids containing either the $T P K 1, T P K 2$ or $T P K 3$ genes. The viability of these mutants at elevated temperatures was determined on -Ura minimal medium containing raffinose (Fig 5). Consistent with our data suggesting that Tpk2 efficiently inhibits APC/C (Fig. 4D), we found that overexpression of TPK2 caused a distinct reduction of the viability of apc mutants. In contrast, the TPK1 containing plasmid only marginally affected apc mutants. Remarkably, overexpressed TPK3 also efficiently interferes with the viability of these mutants. Previously, Tpk3 was shown to have a low catalytic activity, but this was apparently due to the poor expression of the TPK3 gene (Mazon et al. 1993). When present in high levels, Tpk3 also appears to have high catalytic activity and thereby efficiently inhibits APC/C function. Since TPK3 is only expressed to low levels in cells containing single copies of $T P K$ genes, Tpk2 is apparently the most efficient Tpk protein in mediating APC/C inhibition in response to activation of the cAMP/PKA signalling pathway. 

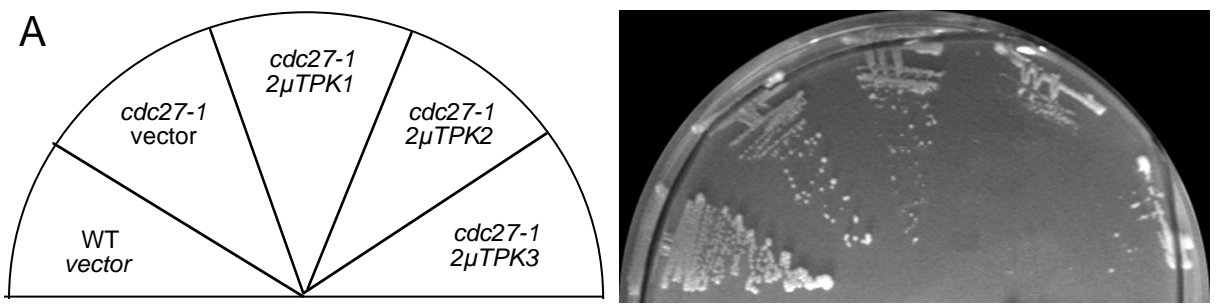

$30^{\circ} \mathrm{C}$
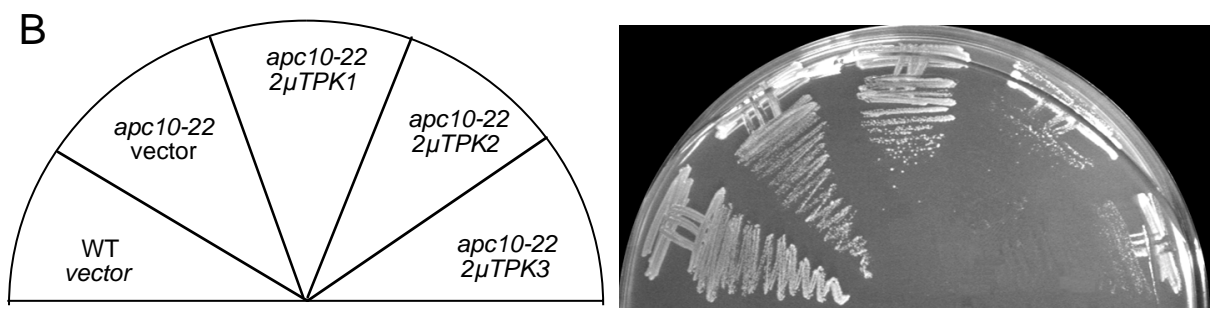

$35^{\circ} \mathrm{C}$

Fig. 5

Different effects of overexpressing different TPK genes on $c d c 27-1$ and apc10-22 mutants.

cdc27-1 and apc10-22 mutants carrying either TPK1, TPK2, TPK3 or no insert in a high-copy plasmid (with $U R A 3$ as selectable marker) were streaked to minimal medium lacking uracile and containing raffinose as carbon source. Plates were incubated at (A) $30^{\circ} \mathrm{C}$ or (B) $35^{\circ} \mathrm{C}$ for 2.5 days. A wild-type strain was used as control.

\section{Glucose affects $\mathrm{APC} / \mathrm{C}$ independently of the regulatory protein $\mathrm{Cdh} 1$}

Cdh1 and Cdc20 are regulatory proteins of APC/C and we addressed the question whether the cAMP/PKA pathway affects APC/C function by regulating these proteins. To find out whether PKA may regulate APC/C activity via Cdh1, we first tested the ability of PKA to phosphorylate Cdh1. Cdh1 was previously shown to be phosphorylated by Cdk1 and this modification can be monitored by mobility shifts in immunoblots (Zachariae et al. 1998). In G1 cells, Cdk1 is inactive and Cdh1 is not phosphorylated. This allowed us to test whether Tpk proteins are able to trigger Cdh1 phosphorylation. We induced the expression of either TPK1, TPK2 or TPK3 genes in alpha-factor arrested G1 cells and analysed the mobility of Cdh1 by immunoblotting. In contrast to cycling cells, no slower migrating forms of Cdh1 were detectable upon the expression of $T P K$ genes to high levels, indicating that $\mathrm{Cdh} 1$ is not a target of Tpk proteins (Fig. 6A).

We tested the possible role of Cdh1 in PKA-mediated APC/C regulation by an alternative experiment, by constructing apc10-22 mutants lacking the non-essential $C D H 1$ gene. We argued that if PKA regulates APC/C activity predominantly by Cdh1 phosphorylation, then a deletion of $C D H 1$ would abolish the lethal effect of glucose on apc10-22 mutants. apc10$22 c d h 1 \Delta$ mutants were tested with regard to their viability on glucose and raffinose 
medium. On glucose medium, apc10-22 and the double mutant apc10-22 cdh1 $\Delta$ were unable to grow at $34{ }^{\circ} \mathrm{C}$ (Fig. 6B). Both strains were viable on YEP+Raf medium at this temperature. Thus, the absence of the regulatory protein Cdh1 has no influence on the viability of apc10-22 mutants on glucose or raffinose medium. These results indicate that inhibition of APC/C activity in response to glucose occurs independently of Cdh1.

\section{Evidence for Cdc20 as potential target of the cAMP/PKA pathway}

We next aimed to determine whether cAMP/PKA-mediated inhibition of APC/C function may involve the Cdc20 protein. Cdc20 protein levels are cell cycle regulated by transcriptional and post-transcriptional mechanism (Harper et al. 2002). We first tested whether high PKA activity affects Cdc20 protein levels. A yeast strain containing an $\mathrm{N}$ terminally Myc-tagged Cdc20 (Myc18-Cdc20; (Shirayama et al. 1998) was transformed with high-copy plasmids containing either $G A L-T P K 1$ or $G A L-T P K 2$ fusions. Cells were then grown in raffinose medium and arrested in metaphase with the microtubuledepolymerising drug nocodazole. In this period of the cell cycle, $\mathrm{Cdc} 20$ protein levels are normally high (Shirayama et al. 1998). To determine whether the overexpression of TPK1 or TPK2 genes affects Cdc20 protein levels, galactose was added and Cdc20 was analysed by immunoblotting (Fig. 6C). We found that $\mathrm{Cdc} 20$ protein remained on equal levels under conditions of low or high PKA activity.

We then addressed the question whether Cdc20 function may be affected by PKA activity. We argued that if this were the case, then the inhibitory effect of activated Ras $2^{\text {Val19 }}$ on apc mutants may be reduced by the overexpression of $C D C 20$. To test this, a $c d c 27-1$ mutant containing both $R A S 2^{\text {Vall }}$ and GAL-CDC2O on centromeric plasmids was pregrown in raffinose medium at $25^{\circ} \mathrm{C}$, streaked to either raffinose or galactose plates and incubated at $30^{\circ} \mathrm{C}$. Microscopic examination of cells showed that high levels of Cdc20 allowed many cells to form colonies (Fig. 6D), albeit distinctly more slow than wild-type cells. Thus, high levels of Cdc20 partially suppress the inhibitory influence of activated Ras signalling on the viability of $c d c 27-1$ mutants. These results provide evidence that the activation of the cAMP/PKA pathway affects APC/C, at least in part, via the Cdc20 regulatory protein. 
A

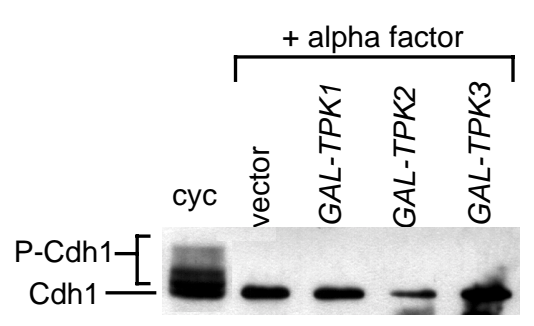

C

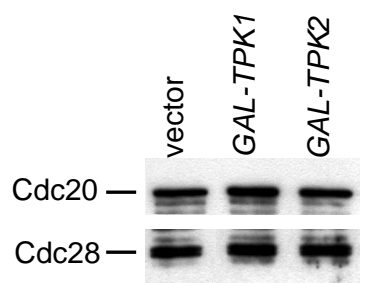

B
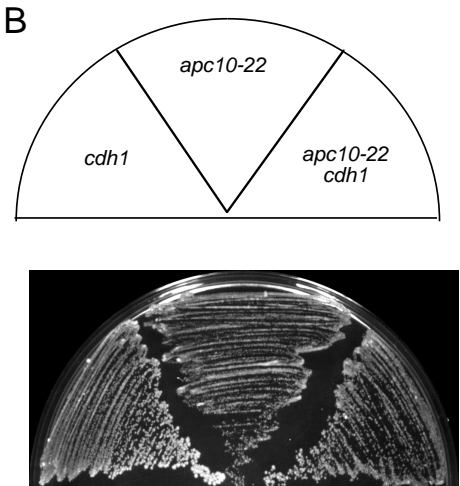

$\mathrm{YEP}+\mathrm{Raf} 34^{\circ} \mathrm{C}$

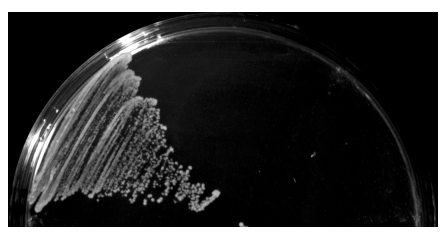

YEPD $34^{\circ} \mathrm{C}$

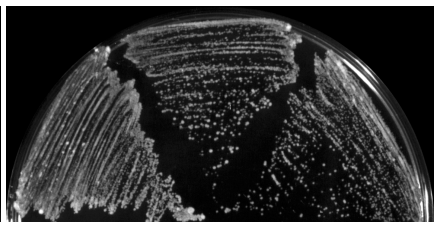

YEPD $25^{\circ} \mathrm{C}$

D

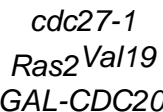

GAL-CDC20

Fig. 6

APC/C inhibition in response to glucose occurs independently of Cdh1, but may involve Cdc20.

A) Strains containing a GALL-HA3-CDH1 construct and carrying either a GAL-TPK1, GAL-TPK2 or GALTPK3 fusion or no insert on a $2 \mu$ plasmid (with $U R A 3$ as selectable marker) were pregrown in MM-Ura+Raf medium. Alpha-factor was added to arrest cells in G1 phase. Then galactose was added to express the corresponding fusion genes and cells were incubated for 2 hours. Cdh1 protein was analysed by immunoblotting using the HA antibody. A cycling culture was used as control for the detection of phosphorylated Cdh1.

B) $c d h 1 \Delta$, apc10-22 and apc10-22 cdh1 $\Delta$ strains were pregrown on YEP+Raf plates at $25{ }^{\circ} \mathrm{C}$, streaked to fresh YEP+Raf or YEP+Glu plates and then incubated at either $25^{\circ} \mathrm{C}$ or $34^{\circ} \mathrm{C}$ for 2.5 days.

C) A strain containing an N-terminally Myc18-tagged CDC20 gene and either GAL-TPK1 or GAL-TPK2 fusion or no insert on a $2 \mu$ plasmid (with $U R A 3$ as selectable marker) were pregrown in MM-Ura+Raf medium. Nocodazole was added to arrest cells in mitosis. Then galactose was added to express the corresponding fusion genes and cells were incubated for 2 hours. Cdc20 protein was analysed by immunoblotting using the MYC antibody.

D) A $c d c 27-1$ mutant carrying a centromeric plasmid containing a GAL-CDC2O (with URA3 as selectable marker) and a centromeric plasmid containing $R A S 2^{\text {Vall9 }}$ (with TRP1 as selectable marker) were pregrown on minimal medium lacking uracile and tryptophan and containing raffinose at $30^{\circ} \mathrm{C}$. Cells were then streaked to minimal medium lacking uracile and tryptophan and containing raffinose and galactose to induce $C D C 20$ expression. Cells were incubated at $30^{\circ} \mathrm{C}$ and photographed after 40 hours incubation. 


\section{Discussion}

The activity of the anaphase-promoting complex/cyclosome (APC/C) is controlled during the cell cycle by a variety of positive and negative regulators (Zachariae and Nasmyth 1999; Harper et al. 2002; Peters 2002). One of these regulatory factors is cAMP-dependent protein kinase, also known as protein kinase A (PKA), which inhibits APC/C activity in yeast and mammalian cells.

In Saccharomyces cerevisiae, PKA can be stimulated by a shift to glucose medium or by the activation of Ras proteins (Thevelein and de Winde 1999). We have presented genetic data showing that glucose and dominantly active Ras $2^{\text {Val19 }}$ proteins, the equivalent to the oncogenic mammalian Ras ${ }^{\mathrm{Val12}}$, severely reduce the viability of apc mutants in a synergistic manner. We suggest that the expression of the $R A S 2^{\text {Vall9 }}$ allele in combination with growth on glucose medium causes an efficient activation of adenylate cyclase, resulting in enhanced PKA activity and potent inhibition of APC/C. Our findings are consistent with the model proposing that glucose stimulates adenylate cyclase independently of Ras1 and Ras2 (Colombo et al. 1998).

We also showed that $\mathrm{APC} / \mathrm{C}$ inhibition in response to activated Ras2 proteins seems to occur exclusively via cAMP and PKA, but not by the MAPK pathway. Furthermore, we found that Tpk1, Tpk2 and Tpk3 have overlapping roles in APC/C inhibition suggesting that each of the Tpk proteins is capable to take over this function in response to a shift to glucose medium. However, our data provide evidence that Tpk2 performs this function more efficiently than Tpk1 or Tpk3 (Fig. 4D). This effect might be explained by the findings that these kinases have distinctly different catalytic activities (Toda et al. 1987; Mazon et al. 1993; Zahringer et al. 1998). Indeed, Tpk2 was shown to have higher catalytic activity than Tpk1 and Tpk3. For Tpk3, this is apparently due to its poor expression (Mazon et al. 1993). This is consistent with our data, showing that TPK3, similar to TPK2, mediates efficient APC/C inhibition when overexpressed (Fig. 5). In conclusion, Tpk proteins have overlapping functions in APC/C inhibition but obviously have different efficiences under normal expression levels.

Genetic and biochemical data suggest that PKA-mediated inhibition of APC/C is conserved in eukaryotes from yeast to mammals (Yamashita et al. 1996; Yamada et al. 1997; Kotani et al. 1998; Anghileri et al. 1999; Kotani et al. 1999). In budding and fission yeast, it remains to be shown whether PKA directly phosphorylates APC/C subunits, as shown in vitro with the reconstituted mammalian APC/C (Kotani et al. 1998). Most yeast 
APC/C subunits contain consensus phosphorylation sites for PKA (Kennelly and Krebs 1991). Remarkably, 28 potential sites were found for the Apc1 subunit, and 7-8 sites for three other subunits. An important task in the future will be to find out how PKA inhibits APC/C activity. In mammalian cells, it was shown that the activator protein Cdc20 was unable to bind APC/C when the complex was preincubated with PKA. Thus, PKA may inhibit APC/C function by modifying critical subunits required for the binding of Cdc20, thereby preventing its association with the core complex. Our results showing that high levels of Cdc20 partially suppress the inhibitory effect of $R A S 2^{\text {Vall9 }}$ (Fig. 6D) are consistent with such a model.

It will be an interesting task to elucidate which intra- or extracellular signals regulate PKA during mitosis. The growth medium appears to be one of these signals (Anghileri et al. 1999; Irniger et al. 2000). The availability of rich carbon sources such as glucose may cause a delay in the progression through mitosis, by activation of PKA and inhibition of APC/C. Such a model is consistent with the findings that daughter cells are born at larger cell size on rich medium (Alberghina et al. 1998). PKA-mediated inhibition of APC/C may also be a mechanism for the delay in mitosis during pseudohyphal growth (Kron et al. 1994; Rua et al. 2001). Other intra- or extracellular signals may be transmitted by Ras proteins. Taken together, the cAMP/PKA pathway represents a suitable system for the integration of multiple signals which are then communicated to the cell cycle machinery.

\section{Acknowlegments}

We thank Hans-Ulrich Mösch and Maria Meyer for support and for providing plasmids and yeast strains. We acknowledge Ingrid Bahr for help with the figures. This work was supported by the Deutsche Forschungsgemeinschaft (grant IR 36/1-3), the Fonds der Chemischen Industrie and the Volkswagen-Stiftung. 


\section{References}

Alberghina, L., C. Smeraldi, B.M. Ranzi, and D. Porro. 1998. Control by nutrients of growth and cell cycle progression in budding yeast, analyzed by double-tag flow cytometry. J Bacteriol 180: 3864-72.

Amon, A. 2001. Together until separin do us part. Nat Cell Biol 3: E12-4.

Anghileri, P., P. Branduardi, F. Sternieri, P. Monti, R. Visintin, A. Bevilacqua, L. Alberghina, E. Martegani, and M.D. Baroni. 1999. Chromosome separation and exit from mitosis in budding yeast: dependence on growth revealed by cAMPmediated inhibition. Exp Cell Res 250: 510-23.

Broach, J.R. 1991. RAS genes in Saccharomyces cerevisiae: signal transduction in search of a pathway. Trends Genet 7: 28-33.

Broek, D., T. Toda, T. Michaeli, L. Levin, C. Birchmeier, M. Zoller, S. Powers, and M. Wigler. 1987. The $S$. cerevisiae CDC25 gene product regulates the RAS/adenylate cyclase pathway. Cell 48: 789-99.

Colombo, S., P. Ma, L. Cauwenberg, J. Winderickx, M. Crauwels, A. Teunissen, D. Nauwelaers, J.H. de Winde, M.F. Gorwa, D. Colavizza, and J.M. Thevelein. 1998. Involvement of distinct G-proteins, Gpa2 and Ras, in glucose- and intracellular acidification-induced cAMP signalling in the yeast Saccharomyces cerevisiae. Embo J 17: 3326-41.

Gardner, R.D. and D.J. Burke. 2000. The spindle checkpoint: two transitions, two pathways. Trends Cell Biol 10: 154-8.

Golan, A., Y. Yudkovsky, and A. Hershko. 2002. The cyclin-ubiquitin ligase activity of cyclosome/APC is jointly activated by protein kinases Cdk1-cyclin B and Plk. $J$ Biol Chem 277: 15552-7.

Guldener, U., S. Heck, T. Fielder, J. Beinhauer, and J.H. Hegemann. 1996. A new efficient gene disruption cassette for repeated use in budding yeast. Nucleic Acids Res 24: 2519-24.

Harper, J.W., J.L. Burton, and M.J. Solomon. 2002. The anaphase-promoting complex: it's not just for mitosis any more. Genes Dev 16: 2179-206.

Hilioti, Z., Y.S. Chung, Y. Mochizuki, C.F. Hardy, and O. Cohen-Fix. 2001. The anaphase inhibitor Pds1 binds to the APC/C-associated protein $\mathrm{Cdc} 20$ in a destruction boxdependent manner. Curr Biol 11: 1347-52.

Irniger, S., M. Bäumer, and G.H. Braus. 2000. Glucose and ras activity influence the ubiquitin ligases APC/C and SCF in Saccharomyces cerevisiae. Genetics 154: 1509-21.

Kennelly, P.J. and E.G. Krebs. 1991. Consensus sequences as substrate specificity determinants for protein kinases and protein phosphatases. J Biol Chem 266: 15555-8.

Kotani, S., H. Tanaka, H. Yasuda, and K. Todokoro. 1999. Regulation of APC activity by phosphorylation and regulatory factors. J Cell Biol 146: 791-800.

Kotani, S., S. Tugendreich, M. Fujii, P.M. Jorgensen, N. Watanabe, C. Hoog, P. Hieter, and K. Todokoro. 1998. PKA and MPF-activated polo-like kinase regulate anaphase-promoting complex activity and mitosis progression. Mol Cell 1: 371-80.

Kron, S.J., C.A. Styles, and G.R. Fink. 1994. Symmetric cell division in pseudohyphae of the yeast Saccharomyces cerevisiae. Mol Biol Cell 5: 1003-22.

Mazon, M.J., M.M. Behrens, E. Morgado, and F. Portillo. 1993. Low activity of the yeast cAMP-dependent protein kinase catalytic subunit Tpk3 is due to the poor expression of the TPK3 gene. Eur J Biochem 213: 501-6. 
Morgan, D.O. 1999. Regulation of the APC and the exit from mitosis. Nat Cell Biol 1: E47-53.

Mösch, H.U. 2000. Pseudohyphal development of Saccharomyces cerevisiae. Contrib Microbiol 5: 185-200.

Mösch, H.U., E. Kübler, S. Krappmann, G.R. Fink, and G.H. Braus. 1999. Crosstalk between the Ras2p-controlled mitogen-activated protein kinase and cAMP pathways during invasive growth of Saccharomyces cerevisiae. Mol Biol Cell 10: 1325-35.

Nasmyth, K. 2002. Segregating sister genomes: the molecular biology of chromosome separation. Science 297: 559-65.

Nigg, E.A. 2001. Mitotic kinases as regulators of cell division and its checkpoints. Nat Rev Mol Cell Biol 2: 21-32.

Peters, J.M. 2002. The anaphase-promoting complex: proteolysis in mitosis and beyond. Mol Cell 9: 931-43.

Pfleger, C.M., E. Lee, and M.W. Kirschner. 2001. Substrate recognition by the Cdc20 and Cdh1 components of the anaphase- promoting complex. Genes Dev 15: 2396-407.

Robertson, L.S., H.C. Causton, R.A. Young, and G.R. Fink. 2000. The yeast A kinases differentially regulate iron uptake and respiratory function. Proc Natl Acad Sci U S A 97: 5984-8.

Robertson, L.S. and G.R. Fink. 1998. The three yeast A kinases have specific signaling functions in pseudohyphal growth. Proc Natl Acad Sci U S A 95: 13783-7.

Robinson, L.C., J.B. Gibbs, M.S. Marshall, I.S. Sigal, and K. Tatchell. 1987. CDC25: a component of the RAS-adenylate cyclase pathway in Saccharomyces cerevisiae. Science 235: 1218-21.

Rose, M.D., Winston, F., Hieter, P. 1990. Laboratory course manual for methods in yeast genetics. Cold Spring Harbor Laboratory press, Cold Spring Harbor.

Rua, D., B.T. Tobe, and S.J. Kron. 2001. Cell cycle control of yeast filamentous growth. Curr Opin Microbiol 4: 720-7.

Rudner, A.D. and A.W. Murray. 2000. Phosphorylation by Cdc28 activates the Cdc20dependent activity of the anaphase-promoting complex. J Cell Biol 149: 1377-90.

Schwab, M., M. Neutzner, D. Mocker, and W. Seufert. 2001. Yeast Hct1 recognizes the mitotic cyclin $\mathrm{Clb} 2$ and other substrates of the ubiquitin ligase APC. Embo $J \mathbf{2 0}$ : 5165-75.

Shirayama, M., W. Zachariae, R. Ciosk, and K. Nasmyth. 1998. The Polo-like kinase Cdc5p and the WD-repeat protein Cdc20p/fizzy are regulators and substrates of the anaphase promoting complex in Saccharomyces cerevisiae. Embo J 17: 1336-49.

Stevenson, B.J., N. Rhodes, B. Errede, and G.F. Sprague, Jr. 1992. Constitutive mutants of the protein kinase STE11 activate the yeast pheromone response pathway in the absence of the G protein. Genes Dev 6: 1293-304.

Surana, U., A. Amon, C. Dowzer, J. McGrew, B. Byers, and K. Nasmyth. 1993. Destruction of the $C D C 28 / C L B$ mitotic kinase is not required for the metaphase to anaphase transition in budding yeast. Embo J 12: 1969-78.

Thevelein, J.M. and J.H. de Winde. 1999. Novel sensing mechanisms and targets for the cAMP-protein kinase A pathway in the yeast Saccharomyces cerevisiae. Mol Microbiol 33: 904-18.

Toda, T., S. Cameron, P. Sass, M. Zoller, and M. Wigler. 1987. Three different genes in $S$. cerevisiae encode the catalytic subunits of the cAMP-dependent protein kinase. Cell 50: 277-87. 
Toda, T., I. Uno, T. Ishikawa, S. Powers, T. Kataoka, D. Broek, S. Cameron, J. Broach, K. Matsumoto, and M. Wigler. 1985. In yeast, RAS proteins are controlling elements of adenylate cyclase. Cell 40: 27-36.

Vodermaier, H.C. 2001. Cell cycle: Waiters serving the Destruction machinery. Curr Biol 11: R834-7.

Yamada, H., K. Kumada, and M. Yanagida. 1997. Distinct subunit functions and cell cycle regulated phosphorylation of 20S APC/cyclosome required for anaphase in fission yeast. J Cell Sci 110: 1793-804.

Yamashita, Y.M., Y. Nakaseko, I. Samejima, K. Kumada, H. Yamada, D. Michaelson, and M. Yanagida. 1996. 20S cyclosome complex formation and proteolytic activity inhibited by the cAMP/PKA pathway. Nature 384: 276-9.

Zachariae, W. and K. Nasmyth. 1999. Whose end is destruction: cell division and the anaphase-promoting complex. Genes Dev 13: 2039-58.

Zachariae, W., M. Schwab, K. Nasmyth, and W. Seufert. 1998. Control of cyclin ubiquitination by CDK-regulated binding of Hct1 to the anaphase promoting complex. Science 282: 1721-4.

Zahringer, H., H. Holzer, and S. Nwaka. 1998. Stability of neutral trehalase during heat stress in Saccharomyces cerevisiae is dependent on the activity of the catalytic subunits of cAMP-dependent protein kinase, Tpk1 and Tpk2. Eur J Biochem 255: 544-51. 


\title{
Chapter 3
}

\section{Inhibition of APC-mediated proteolysis by the meiosis-specific protein kinase Ime 2}

\begin{abstract}
Proteolysis triggered by the anaphase-promoting complex (APC) is needed for sister chromatid separation and the exit from mitosis. APC is an ubiquitin-ligase whose activity is tightly controlled during the cell cycle. To identify factors involved in the regulation of APC-mediated proteolysis, a Saccharomyces cerevisiae GAL-cDNA library was screened for genes whose overexpression prevented degradation of an APC target protein, the mitotic cyclin Clb2. Genes encoding G1-, S- and mitotic cyclins were identified, consistent with previous data showing that the cyclin-dependent kinase Cdk1 associated with different cyclins is a key factor for inhibiting $\mathrm{APC}^{\mathrm{Cdh} 1}$ activity from late G1-phase until mitosis. In addition, the meiosis-specific protein kinase Ime2 was identified as a negative regulator of APC-mediated proteolysis. Ectopic expression of IME2 in G1 arrested cells inhibited the degradation of mitotic cyclins and of other APC substrates. IME2 expression resulted in the phosphorylation of Cdh1 in G1 cells indicating that Ime2 and Cdk1 regulate $\mathrm{APC}^{\mathrm{Cdh} 1}$ in a similar manner. The expression of Ime2 in cycling cells inhibited bud formation and caused cells to arrest in mitosis. We further show that Ime 2 is itself an unstable protein, whose proteolysis occurs independently of the APC and SCF ubiquitinligases. Our findings suggest that Ime2 represents an unstable, meiosis-specific regulator of $\mathrm{APC}^{\mathrm{Cdh} 1}$.
\end{abstract}




\section{Introduction}

Crucial processes in the cell cycle, such as initiation of DNA replication, separation of sister chromatids and exit from mitosis, depend on proteolytic degradation of critical regulatory proteins (Peters 1998; Jorgensen and Tyers 1999; Zachariae 1999). Ubiquitinligases play essential roles in these degradation processes. These enzymes catalyse the formation of chains of ubiquitin on their substrates, targeting them thereby for degradation by the $26 \mathrm{~S}$ proteasome (Hochstrasser 1996). The anaphase-promoting complex (APC), also known as cyclosome, is a multi-subunit complex acting as ubiquitin-ligase (Morgan 1999; Zachariae and Nasmyth 1999). APC is essential for mitosis and its activity is tightly cell cycle regulated. Its activation at the metaphase/anaphase transition requires its association with the activator protein $\mathrm{Cdc} 20$. APC ${ }^{\mathrm{Cdc} 20}$ triggers proteolytic degradation of the securin Pds1. Upon Pds1 proteolysis, the separase Esp1 is liberated, cleaves the cohesin subunit Scc1 and thereby triggers sister chromatid separation (Nasmyth et al. 2000). APC ${ }^{\mathrm{Cdc} 20}$ also initiates proteolysis of the S-phase cyclin Clb5 and a fraction of mitotic cyclins (Shirayama et al. 1999; Bäumer et al. 2000; Yeong et al. 2000). APC ${ }^{\mathrm{Cdc20}}$ activation is inhibited by the spindle assembly checkpoint which prevents sister chromatid separation upon defects in the mitotic spindle or in the attachment of kinetochores (Amon 1999).

Cdh1 (also termed Hct1) is related to Cdc20 and is needed for complete degradation of mitotic cyclins (Schwab et al. 1997; Visintin et al. 1997). Cdh1's potential to associate with the APC is controlled by phosphorylation (Visintin et al. 1998; Jaspersen et al. 1999). The cyclin-dependent kinase Cdk1 phosphorylates Cdh1, thereby preventing its interaction with APC. A Cdk1-antagonising phosphatase, Cdc14, is kept inactive in the nucleolus for most of the cell cycle (Shou et al. 1999; Visintin et al. 1999). Its release during anaphase promotes $\mathrm{APC}^{\mathrm{Cdh} 1}$ complex formation, and also induces transcription and stabilisation of the Cdk1 inhibitor Sic1 (Visintin et al. 1998). Thus, Cdc14 activates two mechanisms, cyclin proteolysis and Cdk1 inhibition, both resulting in Cdk1 inactivation and exit from mitosis. APC ${ }^{\mathrm{Cdh} 1}$ remains active in the subsequent G1-phase and is turned off at the G1/S transition by Cdk1 phosphorylating the Cdh1 protein (Amon et al. 1994; Zachariae et al. 1998).

Recent data showed that APC is also important for meiotic cell divisions. During meiosis, two rounds of chromosome segregation follow one round of DNA duplication. Little is known about APC regulation during meiosis. Pds1 is degraded during meiosis I in an $\mathrm{APC}^{\mathrm{Cdc20}}$ dependent manner, reaccumulates and disappears again in meiosis II (Salah and 
Nasmyth 2000). Furthermore, destruction of the cyclin Clb1 seems to be mediated by a meiosis-specific activator related to Cdc20/Cdh1, Ama1 (Cooper et al. 2000).

We performed a genetic screening to identify factors involved in the APC regulation. We screened for cDNAs whose expression in G1-phase inhibit proteolysis of a fusion protein of the mitotic cyclin $\mathrm{Clb} 2$ with lacZ. Various cyclins and the meiosis-specific protein kinase Ime2 were identified as proteins which stabilised Clb2-lacZ. Ectopic expression of IME2 in G1 cells stabilised mitotic cyclins and other APC substrates. Since Ime2 accumulation caused phosphorylation of $\mathrm{Cdh} 1$, Ime 2 may be involved in APC ${ }^{\mathrm{Cdh} 1}$ regulation during meiosis. 


\section{Materials and Methods}

Yeast strains and plasmids. All strains are derivatives of the S. cerevisiae W303 strain. Strains carrying HA-tagged versions of Clb2 (Zachariae et al. 1998), Clb3 (Irniger and Nasmyth 1997), Pds1 (Cohen-Fix et al. 1996) and Cdh1 (Zachariae et al. 1998) were described. A $2.8 \mathrm{~kb}$ fragment containing the GAL-IME2 fusion was cloned from the $C E N$ plasmid, isolated from the GAL-cDNA library, into integrative plasmids YIplac204 and Yiplac211 (Gietz and Sugino 1988). For integrations, plasmids were linearised by Bsu36I and transformed into yeast cells. To tag the IME2 gene, a XbaI restriction site was introduced upstream of the stop codon of IME2 in the plasmid YIplac204-GAL-IME2. Six copies of the HA-fragment were cloned as a XbaI-fragment into this site.

Growth conditions and cell cycle arrests. Prior to gene expression from the GAL1 promoter, cells were grown in raffinose medium. The GAL1 promoter was induced by the addition of galactose ( $2 \%$ final concentration). To turn off the GAL1 promoter, cells were filtered and resuspended in medium containing $2 \%$ glucose.

Strains lacking the G1 cyclins $C L N 1, C L N 2$ and $C L N 3$, but containing CLN2 expressed from the methionine-repressible MET3 promoter were cultivated in minimal medium lacking methionine. To arrest these cells in G1, methionine was added to a final concentration of $2 \mathrm{mM}$. To arrest cells in G1 with $\alpha$-factor pheromone, cultures were incubated for 2.5 hours in the presence of $5 \mu \mathrm{g} / \mathrm{ml} \alpha$-factor. To arrest cells in metaphase, cultures were incubated for 2 hours in the presence of $15 \mu \mathrm{g} / \mathrm{ml}$ nocodazole.

Screening for cDNAs stabilising Clb2-lacZ. A strain lacking all G1 cyclins $(c \ln 1, c \ln 2$, cln3) containing MET-CLN2 and GAL-CLB2-lacZ gene fusions (S65) was transformed with a GAL-cDNA library (Liu et al. 1992) on a centromeric plasmid (URA3 marker). Transformants were plated on minimal medium plates lacking methionine and uracil. Colonies were transferred to nylon filters and arrested in G1-phase by placing filters on plates containing $2 \mathrm{mM}$ methionine. After 3 hours, filters were transferred to plates containing $2 \%$ galactose and $2 \mathrm{mM}$ methionine. After 2.5 hours, filters were frozen in liquid nitrogen and colonies were analysed for beta-galactosidase activity. Blue colonies were collected. Plasmids of these colonies were retested and analysed by restriction and sequencing. Since the expression of cDNAs encoding APC inhibitors likely results in cell 
cycle defects, plasmids were transformed into wild-type cells and only plasmids producing cell cycle phenotypes on galactose plates were further analysed.

Immunoblot, immunofluorescence and FACS analysis. Preparation of yeast cell extracts and protein immunoblot analysis were performed as described (Surana et al. 1993). The enhanced chemiluminescence detection system was used. For indirect immunofluorescence, cells were fixed in $3.7 \%$ formaldehyde. Spheroplasts were prepared as described (Pringle et al. 1991). DAPI (4',6-diamidino-2-phenylindole) staining and antitubulin antibodies were used for visualisation of nuclei and spindles respectively. FACS analysis was performed as described (Epstein and Cross 1992). 


\section{Results}

A screen for cDNAs inhibiting cyclin degradation in S. cerevisiae. To identify putative regulators of the APC, we screened for genes whose ectopic expression inhibited the degradation of a Clb2-lacZ fusion protein in G1 arrested cells. To arrest cells in G1-phase, we used a strain deleted of the G1 cyclins CLN1, CLN2, CLN3, and containing a methionine repressible MET3-CLN2 gene fusion, which caused cells to arrest in G1 upon methionine addition. This strain, also containing a $G A L-C L B 2-l a c Z$ gene fusion (Irniger et al. 1995), was transformed with a yeast cDNA library expressed from the GAL1 promoter (Liu et al. 1992). About $10^{5}$ plasmid carrying colonies were screened. Colonies were arrested on plates containing methionine and then transferred to galacatose plates to express simultaneously the GAL-CLB2-lacZ and GAL-cDNA constructs. Cells impaired in cyclin proteolysis were expected to produce blue colonies on galactose medium, in contrast to white colonies produced by cells with normal APC activity.

Plasmids from blue colonies were retransformed into a wild-type strain and those plasmids causing cell cycle defects on galactose plates were further analysed. They contained the complete open reading frames from the $\mathrm{G} 1$ cyclin gene $C L N 2$, the B-type cyclin genes $C L B 1, C L B 3$ and $C L B 5$, and a truncated CLB1 cDNA lacking the N-terminal 120 amino acids, $C L B 1-d N$. In addition, we identified plasmids containing the entire open reading frame of $I M E 2$, encoding a meiosis-specific protein kinase with sequence similarities to cyclin-dependent kinases (Mitchell et al. 1990; Yoshida et al. 1990). Immunoblotting showed that the expression of these $c D N A s$ caused the accumulation of Clb2-lacZ protein in G1 arrested cells (Fig. 1A). Except the strain expressing CLN2, cells remained mostly arrested as unbudded cells (not shown).

The identification of $C L B 1$ and $C L B 1-d N$ cDNAs prompted us to compare the potential of full-length and truncated $\mathrm{Clb} 1$ protein to stabilise $\mathrm{Clb} 2$. In contrast to $\mathrm{Clb} 1, \mathrm{Clb} 1-\mathrm{dN}$ is thought to be stable in G1 cells, because it lacks the region encompassing the cyclin destruction box. It can therefore efficiently accumulate and activate Cdk1. We coexpressed $C L B 2$ and either $C L B 1$ or $C L B 1-d N$ in $\alpha$-factor arrested G1 cells. Cells expressing full-length $C L B 1$ accumulated only low amounts of $\mathrm{Clb2}$, but $C L B 1-d N$ caused Clb2 accumulation to high levels (Fig. 1B). Promoter shutoff experiments demonstrated that Clb2 was stabilised by Clb1-dN (Fig. 1C). These results show that Clb1-dN, but not 
Clb1 efficiently inhibits Clb2 degradation. Thus, high Cdk1 activity apparently correlates with a high capacity to inhibit Clb2 degradation.

Our identification of G1-, S- and mitotic cyclins as negative regulators of Clb2 proteolysis is consistent with earlier data demonstrating that Cdk1 inhibits APC ${ }^{\mathrm{Cdh} 1}$ from late G1 until anaphase (Amon 1997).

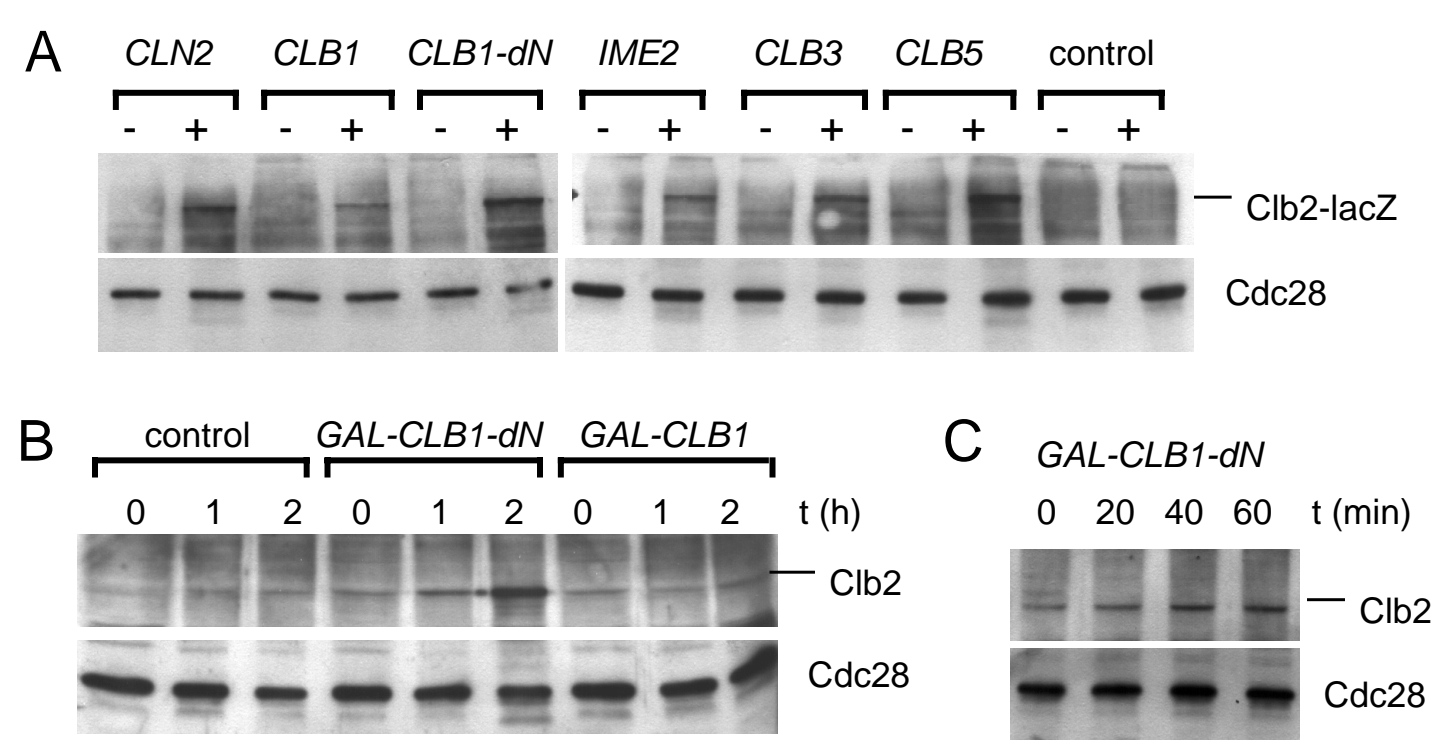

Fig. 1

Ectopic expression of various cyclin genes and of IME2 inhibits Clb2 proteolysis in G1 cells.

A) A S. cerevisiae strain deleted for all G1 cyclins $(c \ln 1, \operatorname{cln} 2, c \ln 3)$, containing MET-CLN2 and GAL-CLB2lacZ gene fusions (S65) was retransformed with centromeric plasmids isolated from the screening of the $G A L-c D N A$ library. Plasmids contained cDNAs of either the CLN2, CLB1, CLB1-dN (N-terminal 120 amino acids deleted), CLB3, CLB5 5 or IME2 genes. Cells were arrested in G1-phase by methionine addition and genes were expressed by galactose addition. Clb2-lacZ protein was detected by immunoblotting with $\mathrm{Clb} 2$ antibodies before (-) and 2,5 hours after galactose addition (+). Cdc28 (Cdk1) was used as loading control.

B) A barl deletion strain containing $G A L-C L B 2$ (S61) was transformed with centromeric plasmids containing either $G A L-C L B 1, G A L-C L B 1-d N$ or a control plasmid. Cells were arrested in G1 with $\alpha$-factor. Galactose was added and cells were incubated for 2 hours. C) Cells containing the GAL-CLB1-dN plasmid were transferred to glucose medium 60 min after galactose addition to turn off the $G A L 1$ promoter (0 time point).

Ectopic expression of IME2 stabilises cyclins Clb2 and Clb3. Our screening revealed that IME2 expression displayed a phenotype similar to the expression of cyclins. Thus, Ime 2 may like Cdk1 inhibit APC-mediated proteolysis. To analyse the effect of Ime 2 in more detail, a GAL-IME2 gene fusion was integrated into yeast cells. Cells containing a single integration of $G A L-I M E 2$ were only modestly affected when grown on galactose medium, but cells carrying five copies of this construct displayed significant cell cycle 
defects (see below). Therefore, this strain was used for further experiments.

To test whether ectopic expression of IME2 affects $\mathrm{Clb} 2$ proteolysis in G1-phase, cells containing both GAL-CLB2 and GAL-IME2 constructs were arrested in G1 by $\alpha$-factor pheromone. Then CLB2 and IME2 expression was induced by galactose. The simultaneous expression of both genes caused the accumulation and stabilisation of $\mathrm{Clb} 2$, in contrast to cells containing only the $G A L-C L B 2$ construct (Fig. 2A, B). IME2 overexpression resembles thereby the phenotype of cells expressing CLB1-dN in G1-phase (Fig. 1). It is known that the expression of stable cyclins induces G1 cells to enter into S-phase (Amon et al. 1994). The co-expression of IME2 and CLB2 caused many of the G1 arrested cells to initiate DNA replication (Fig. 2C), but cells did not start budding (not shown). Thus, the activity of the meiosis-specific kinase IME2 inhibits $\mathrm{Clb} 2$ proteolysis and causes entry into S-phase.

We next tested whether Ime2 stabilises other mitotic cyclins. Unlike CLB2, CLB3 is a cyclin gene expressed also during meiosis (Grandin and Reed 1993; Dahmann and Futcher 1995). CLB3 and IME2 were expressed in G1 arrested cells. Clb3 accumulated to only low levels in the absence of Ime2, but the co-expression of both genes resulted in the accumulation and stabilisation of $\mathrm{Clb} 3$ (Fig. 2D). The appearance of $\mathrm{Clb} 3$ caused cells to initiate DNA replication (Fig. 2E).

These results show that Ime 2 inhibits proteolysis of at least two mitotic cyclins. 


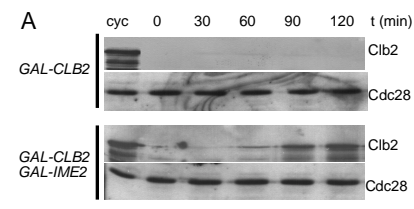

D

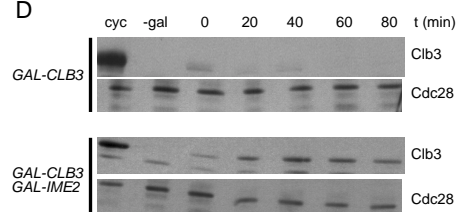

F

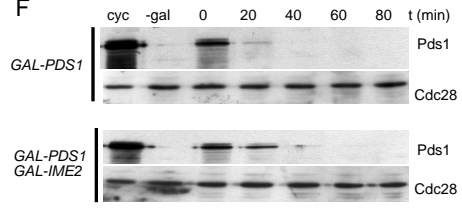

B

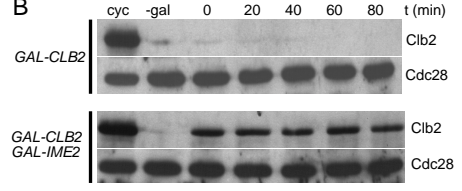

C

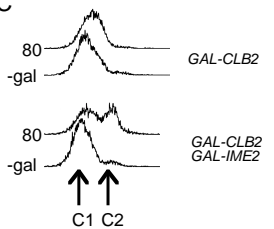

E

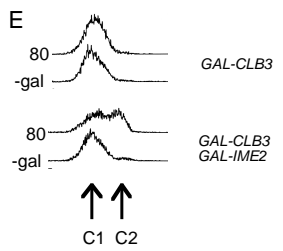

G

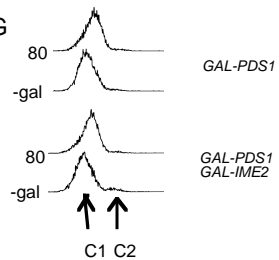

$\mathrm{H}$

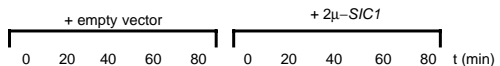

GAL-PDS
GAL-IME2
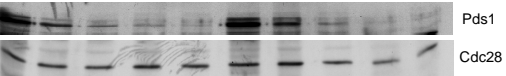

I

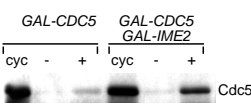

Fig. 2

Ectopic expression of IME2 inhibits degradation of mitotic cyclins and of securin Pds1.

A) Strains containing bar1 deletions and either GAL-CLB2 (S57) or GAL-CLB2 GAL-IME2 (S381) constructs (CLB2 C-terminally tagged with the HA-epitope) were arrested in G1-phase with $\alpha$-factor for 2,5 hours. Galactose was added (0 time point) and cells were incubated for $120 \mathrm{~min}$. HA-tagged Clb2 was detected by immunoblotting using the anti-HA antibody (12CA5). Cdc28 was used as loading control. B) Strains S57 and S381 were arrested with $\alpha$-factor for 2,5 hours. Galactose was added and after 1.5 hours, cells were filtered and transferred to glucose medium containing $\alpha$-factor ( 0 time point $)$. cyc, cycling cells treated with galactose for 1,5 hours C) DNA content of samples collected either before galactose addition (gal) or 80 min after glucose addition. D) Strains containing barl deletions and either GAL-CLB3 (S56) or GAL-CLB3 GAL-IME2 (S416) constructs (CLB3 C-terminally HA-tagged) were treated as in (B). E) DNA content. F) Strains containing barl deletions and either GAL-PDS1 (S206) or GAL-PDS1 GAL-IME2 (S415) constructs (PDS1 C-terminally HA-tagged) were treated as in (B). G) DNA content. H) Strain S415 was transformed with either a high-copy plasmid carrying the SIC1 gene or an empty plasmid. Transformed strains were treated as in (B) except that synthetic medium lacking leucine was used for plasmid selection. I) Strains containing bar1 deletions and either GAL-CDC5 (S88) or GAL-CDC5 GAL-IME2 (S417) constructs (CDC5 C-terminally HA-tagged) were arrested with $\alpha$-factor and galactose was added. Samples before (-) or 2 hours after $(+)$ galactose addition were collected.

Ime2 inhibits proteolysis of APC substrates Pds1 and Cdc5. We next tested whether IME2 overexpression causes the stabilisation of a non-cyclin APC substrate, the anaphase inhibitor protein Pds1. GAL-PDS1 and GAL-IME2 gene fusions were transiently coexpressed in G1 arrested cells. Whereas Pds1 rapidly disappeared in cells expressing only 
$P D S 1$, the simultaneous expression of $P D S 1$ and IME2 resulted in a partial, but reproducible stabilisation of Pds1 within 20 min after the promoter shutoff (Fig. 2F). This experiment shows that ectopic expression of IME2 delays Pds1 degradation in G1 cells.

The expression of GAL-IME2 and GAL-PDS1 did not induce cells to initiate DNA replication (Fig. 2G) indicating that $\mathrm{Cdk} 1 / \mathrm{Clb}$ kinases are not activated under these conditions. However, it was previously shown that Ime 2 induces activation of $\mathrm{Cdk} 1 / \mathrm{Clb}$ kinases in meiosis (Dirick et al. 1998). To distinguish whether the partial Pds1 stabilisation is due to Ime 2 activity or rather caused by residual $\mathrm{Cdk} 1 / \mathrm{Clb}$ activity in these $\mathrm{G} 1$ cells, we determined the effect of Ime 2 on the half-life of Pds 1 in cells containing the $\mathrm{Cdk} 1 / \mathrm{Clb}$ kinase inhibitor SICl on a high copy plasmid. Pds1 was partially stabilised in the presence of high Sic1 levels similar to control strain (Fig. 2H).

To test whether Ime2 affected proteolysis of the polo-like kinase Cdc5, another APC substrate (Shirayama et al. 1998), we determined the accumulation of Cdc5 in G1 cells. In wild-type cells Cdc5 accumulates only to low levels when expressed from the GALpromoter, due to its instability (Shirayama et al. 1998) (Fig. 2I). Upon expression of IME2, increased levels of Cdc5 accumulated suggesting that Ime2 inhibits efficient Cdc5 degradation.

We conclude that high levels of IME2 affect proteolysis of various APC substrates during G1 phase.

\section{High levels of IME2 in G1 arrested cells are not sufficient to trigger DNA replication.}

It was earlier proposed that Ime 2 replaces the G1-specific Cdk1, the Cdk1/Cln kinase, during the meiotic cell cycle (Dirick et al. 1998; Lee and Amon 2001). If Ime2 were functionally equivalent to $\mathrm{Cdk} 1 / \mathrm{Cln}$, then ectopitc expression of $I M E 2$ should suppress the $\mathrm{G} 1$ arrest of cells having functional $\mathrm{Cdk} 1 / \mathrm{Cln}$ kinases. To determine whether high levels of $I M E 2$ trigger DNA replication in the absence of $\mathrm{Cdk} 1 / \mathrm{Cln}, G A L-I M E 2$ was expressed for a prolonged period in $\alpha$-factor arrested cells. FACS analysis revealed that IME2 expression alone did not trigger DNA replication within 5 hours (Fig. 3A). In contrast, cells coexpressing IME2 and CLB2 or CLB3 mostly replicated their DNA. Therefore, high levels of Ime 2 are not sufficient to initiate DNA replication in $\alpha$-factor arrested cells. The expression of a cyclin gene is also required.

Similarly, Ime2 did not trigger DNA replication in cells deleted for all G1 cyclins (Fig. 3B), whereas cells expressing additionally a CLB2-lacZ gene frequently entered S-phase. 
Thus, high levels of Ime 2 cannot replace $\mathrm{Cdk} 1 / \mathrm{Cln}$ kinases in triggering DNA replication implying that Ime2 is not capable to take over all the functions of the G1-specific Cdk1 at the G1/ S transition.

A

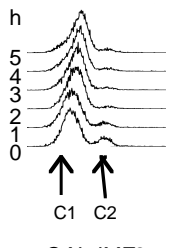

GAL-IME2
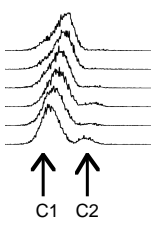

GAL-CLB2
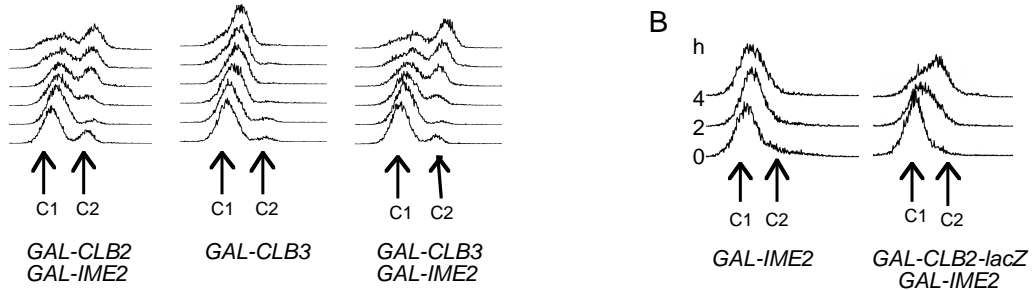

Fig. 3

High levels of Ime2 are not sufficient to trigger DNA replication in G1 arrested cells. A) A barl deletion strain carrying GAL-IME2 (S418) was arrested in G1 with $\alpha$-factor. Galactose was added (0 time point) and cells were incubated in the presence of $\alpha$-factor. The DNA content was determined by FACS analysis. Similarly, strains expressing the indicated $G A L$-constructs were analysed. B) A $c \ln 1, c \ln 2, c \ln 3$ deletion strain carrying a MET-CLN2 construct (S66) and a similar strain containing in addition a GAL-CLB2-lacZ construct (S65) were transformed with a centromeric plasmid containing GAL-IME2. Transformed strains were arrested in G1 with methionine and galactose was added.

Ectopic expression of IME2 triggers phosphorylation of Cdh1. APC ${ }^{\mathrm{Cdh} 1}$ inactivation in the mitotic cell cycle is meditated by phosphorylation of $\mathrm{Cdh} 1$, causing the dissociation of Cdh1 from APC. Both Cln and $\mathrm{Clb}$ associated Cdk1 kinases seem to contribute to APC ${ }^{\text {Cdh1 }}$ inactivation (Huang et al. 2001; Yeong et al. 2001).

To test whether the inhibitory effect of Ime 2 on APC-mediated proteolysis is also be due to Cdh1 phosphorylation, we used strains containing an HA-tagged version of Cdh1 expressed from a weak GAL-promoter, earlier described as GALL-HA3-HCT1 (Zachariae et al. 1998). In G1 arrested wild-type cells, Cdh1 is not phosphorylated (Fig. 4, lane 3), but G1 arrested cells expressing the GAL-IME2 construct produced slower migrating bands (lane 4) which most likely correspond to phosphorylated forms of Cdh1 (Zachariae et al. 1998). Similar mobility shifts were observed in cycling cultures, which contain active Cdk1 kinases (lane2).

These results suggest that ectopic expression of IME2 promotes phosphorylation of Cdh1 during G1 phase. 


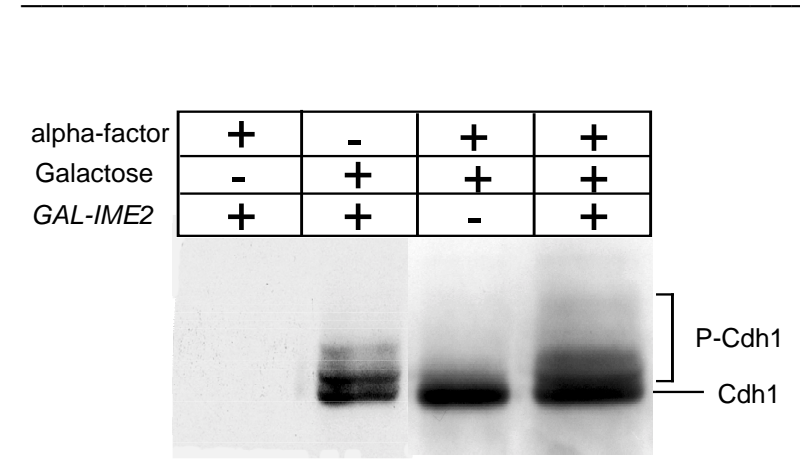

Fig. 4

Ectopic expression of IME2 promotes phosphorylation of Cdh1 in G1 arrested cells.

A wild-type strain (S437) and a GAL-IME2 strain (S457), both containing barl deletions and Nterminally HA-tagged versions of $C D H 1$ expressed from the $G A L L$-promoter (Zachariae et al. 1998) were arrested in G1 with $\alpha$-factor. Galactose was added to express the $G A L$-constructs. HA-tagged Cdh1 was analysed by immunoblotting (lane 3: S437, lane 4: S457). As controls, strain S457 was either not treated with galactose (lane 1) or not arrested with $\alpha$-factor (lane 2).

High levels of Ime2 inhibit bud formation and arrest cells in mitosis. To analyse the phenotype of high levels of IME2 expressed in dividing cells, strains containing five copies of GAL-IME2 were shifted to galactose medium. The expression of IME2 caused the accumulation of unbudded cells in both haploid and diploid cells (Fig. 5A). Initially, cells were delayed in G1-phase (Fig. 5B, 2 hour sample), but then they replicated their DNA. Nuclei and spindle staining revealed that these cells failed to segregate their DNA and arrest in G2/M-phase, containing sometimes short spindles (Fig. 5C).

It was previously shown that cells defective in budding activate a control mechanism termed the morphogenesis checkpoint, resulting in a cell cycle delay in G2/M phase (Lew 2000). To test whether the arrest of GAL-IME2 cells is caused by this control mechanism, we expressed IME2 in swe1 mutant cells defective in the morphogenesis checkpoint. Only few swe 1 cells had undivided nuclei, whereas most cells contained segregated chromosomes and elongated mitotic spindles.

Thus, the expression of Ime2 to high levels inhibits budding and blocks progression through mitosis. The cell cycle block in late anaphase/telophase is consistent with the model that Ime 2 affects specifically APC ${ }^{\mathrm{Cdh} 1}$ rather than general APC function. 
A

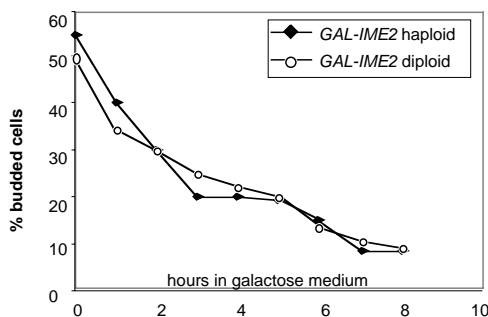

B
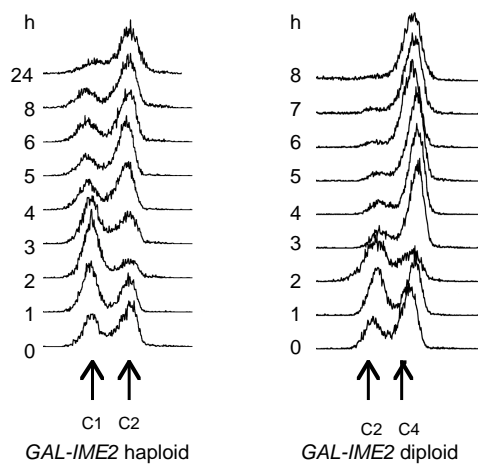

C

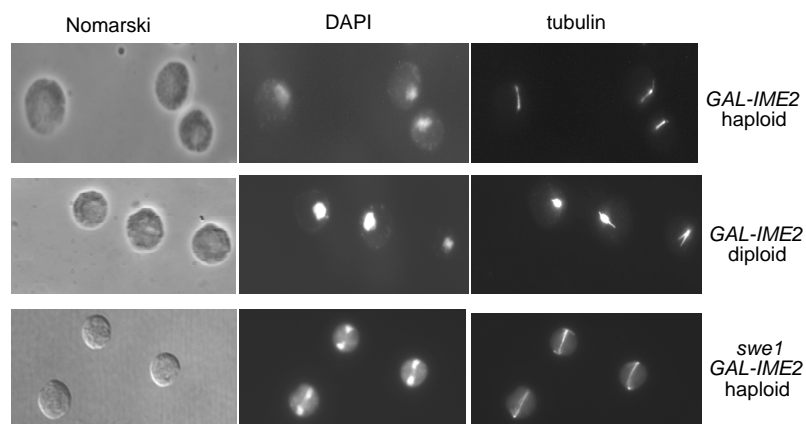

D

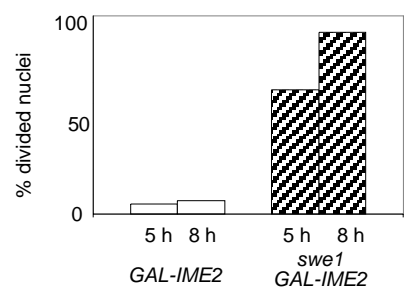

Fig. 5

High levels of Ime 2 causes the accumulation of unbudded cells delayed in mitosis.

Haploid (S379) and diploid (S424) strains containing the GAL-IME2 construct were grown in raffinose medium. Galactose was added (0 time point) and samples were collected at the indicated time points for monitoring the precentage of budded cells (A) and for determining the DNA content (B). C) Immunfluorescence microscopy of haploid and diploid cells, and of a swe1 deletion strain (swe1::LEU2, S454) containing GAL-IME2, 5 hours after galactose addition. (D) Percentage of divided nuclei in haploid SWE1 and swel strains, 5 and 8 hours after galactose addition.

Ime2 is an unstable protein whose degradation is dependent neither on APC nor on SCF ubiquitin-ligases. Since high levels of Ime2 have deleterious effects on cell cycle progression, it is tempting to speculate that Ime 2 inactivation during meiosis may be similarly important as CDK inactivation during mitosis. Ime 2 contains two motifs (KxxL,

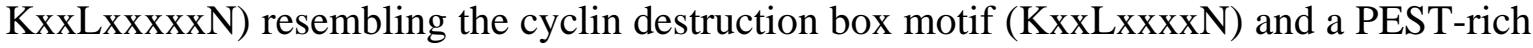
region implicated in protein instability. This prompted us to analyse the stability of Ime2 by promoter shutoff experiments. HA-tagged Ime 2 was rapidly degraded in normally dividing cells (Fig. 6A). Ime2's instabililty was not cell cycle regulated, because Ime2 was similarly degraded in cells arrested in G1 by $\alpha$-factor (Fig. 6B) or in M-phase by the microtubule depolymerising drug nocodazole (Fig. 6C). Ime2 proteolysis was neither delayed in $c d c 23-1$ mutants defective in APC function (Fig. 6B) nor in $c d c 4-1$ and $c d c 34-2$ mutants impaired in the SCF complex (Fig. 6C). 
These findings indicate that Ime2 is an unstable protein kinase whose proteolysis occurs independently of the conventional APC and SCF ubiquitin-ligases.

A
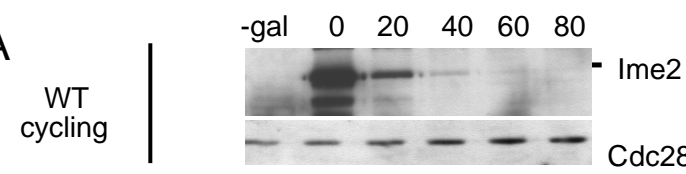

B
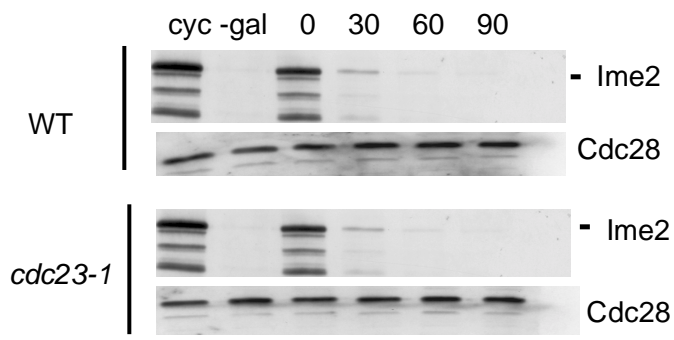

C
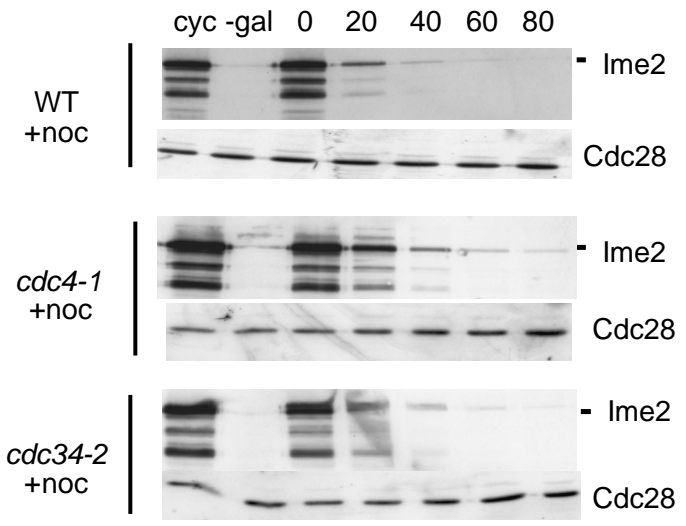

$\underset{\substack{c d c 34-2 \\-\text { noc }}}{\mid}$

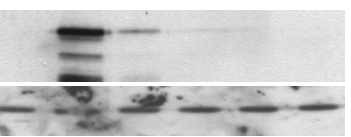

- Ime2

Cdc28

\section{Fig. 6}

Ime 2 is an unstable protein whose degradation is independent of APC and SCF.

A) A strain (S396) containing a GAL-IME2 construct (IME2 C-terminally HA-tagged) was shifted for 2 hours to galactose medium and then transferred to glucose medium (0 time point). Ime 2 was analysed by immunoblotting with HA-antibodies. cyc, cycling cells. B) S396 and isogenic cdc23-1 mutants (S397), both containing barl deletions, were arrested in G1 with $\alpha$-factor at $25^{\circ} \mathrm{C}$. Galactose was added and cells were incubated for $45 \mathrm{~min}$. Cells were shifted to $36^{\circ} \mathrm{C}$, incubated for $45 \mathrm{~min}$, then transferred to glucose medium containing $\alpha$-factor and incubated at $36^{\circ} \mathrm{C}$. C) S396 and isogenic $c d c 4-1$ (S407) and cdc34-2 (S408) mutants were arrested in M-phase with nocodazole at $25^{\circ} \mathrm{C}(+$ noc $)$. Expression of IME2 was induced by galactose for $45 \mathrm{~min}$. Then cells were shifted to $36^{\circ} \mathrm{C}$, incubated for $45 \mathrm{~min}$., transferred to glucose medium containing nocodazole and incubated at $36^{\circ} \mathrm{C}$. A $c d c 34-2$ culture was treated similarly, but nocodazole was omitted (-noc). 


\section{Discussion}

Identification of negative regulators of APC-mediated proteolysis. We aimed to identify regulators of the APC by screening a yeast cDNA library for genes whose expression to high levels prevents degradation of a Clb2-lacZ reporter protein in $\mathrm{G} 1$ arrested cells. We identified various cyclins and the meiosis-specific protein kinase Ime2 as inhibitors of APC-mediated proteolysis.

The identification of G1-, S- and mitotic cyclins implies that Cdk1 associated with any of these cyclins is capable of inhibiting APC-mediated proteolysis. These findings are consistent with previous data showing that Cdk1 is a key factor for turning off $\mathrm{APC}^{\mathrm{Cdh} 1}$ in late G1 and for keeping it inactive during S-, G2- and most of M-phase (Amon 1997; Zachariae and Nasmyth 1999). Cdk1 associated with different cyclin proteins were shown to directly phosphorylate the activator protein Cdh1 and trigger its dissociation from APC (Zachariae et al. 1998; Jaspersen et al. 1999). Our findings underline the crucial role of $\mathrm{Cdk} 1$ as an inhibitor of $\mathrm{APC}^{\mathrm{Cdh} 1}$. The continuous presence of Cdk1 activated by different type of cyclins helps to ensure that $\mathrm{APC}^{\mathrm{Cdh} 1}$ cannot be activated during the cell cycle before Cdc14 phosphatase is released from the nucleolus, a process which is dependent on proper spindle orientation and the mitotic exit network (Hoyt 2000). 
Ime2, a putative meiosis-specific regulator of $\mathbf{A P C}^{\mathbf{C d h 1}}$. We have shown that ectopic expression of $I M E 2$ results in the accumulation and stabilisation of the mitotic cyclins $\mathrm{Clb} 2$ and Clb3 in G1 arrested cells. We further showed that Ime 2 triggers phosphorylation of Cdh1 suggesting that Ime 2 inhibits APC activity via the Cdh1 activator protein. IME2 expression also delayed proteolysis of Pds1 and Cdc5, two additional APC substrates. Pds1 was only little affected, possibly because it is degraded primarily by $\mathrm{APC}^{\mathrm{Cdc} 20}$ during G1 phase, but other data suggested that $\mathrm{APC}^{\mathrm{Cdh} 1}$ is involved in Pds1 removal (Visintin et al. 1997; Rudner et al. 2000). The rather weak influence of Ime2 on Pds1 could also be explained by Ime2's own instability. After turning off the $G A L$-promoter in our test system, Ime2 gets degraded at about the same time as Pds1 (compare Figs. 2F and 5).

In summary, our results demonstrate that ectopic expression of IME2 in G1 cells inhibits APC-meditated proteolysis. Since IME2 is normally expressed only in meiotic cells, we suggest that this protein kinase acts as a regulator of $\mathrm{APC}^{\mathrm{Cdh} 1}$ during meiosis.

Similarities and differences of Ime2 with Cdk1/CIn kinases. There are several indications that Ime2 fulfils in meiosis the functions of the G1-specific CDKs, the Cdk1/Cln kinases. First, Ime2 shares sequence similarities with CDKs (Mitchell 1994). Second, deletion of all CLN genes does not affect sporulation implying that $\mathrm{Cdk} 1 / \mathrm{Cln}$ kinases are dispensable for meiosis (Dirick et al. 1998). Third, degradation of the Cdk1 inhibitor Sic1 is triggered in the mitotic cell cycle by $\mathrm{Cdk} 1 / \mathrm{Cln}$ and in meiosis by Ime 2 (Dirick et al. 1998).

The capacity of Ime2 to promote Cdh1 phosphorylation suggests that this kinase may replace $\mathrm{Cdk} 1 / \mathrm{Cln}$ in triggering inactivation of $\mathrm{APC}^{\mathrm{Cdh} 1}$ in late $\mathrm{G} 1$ phase of the meiotic cell cycle. It was recently shown that G1-specific kinases are not sufficient for completely inactivating $\mathrm{APC}^{\mathrm{Cdh} 1}$ in the mitotic cell cycle. This process also requires $\mathrm{Cdk} 1 / \mathrm{Clb}$ kinases (Huang et al. 2001; Yeong et al. 2001). Similarly, the combined function of both Ime 2 and accumulating $\mathrm{Cdk} 1 / \mathrm{Clb}$ kinases may be needed for completely turning off $\mathrm{APC}^{\mathrm{Cdh} 1}$ in meiosis.

Ime 2 clearly displays some functional similarities with $\mathrm{Cdk} 1 / \mathrm{Cln}$, but there are significant differences between these kinases. High levels of Ime2 expressed in $\alpha$-factor arrested cells or in cells lacking G1 cyclins failed to promote DNA replication implying that Ime 2 is not sufficient to replace $\mathrm{Cdk} 1 / \mathrm{Cln}$ in this process. Ime 2 may be not sufficient to induce 
transcription of $C L B$ genes. Indeed, upon co-expression of $I M E 2$ with $C L B$ genes, most cells replicated their DNA. We conclude that Ime2 has only partially functional similarities to $\mathrm{Cdk} 1 / \mathrm{Cln}$ kinases and fulfils some, but not all of their functions in promoting entry into S-phase.

Another difference between Cdk1/Cln and Ime2 is striking. The G1-specific kinase triggers budding, but Ime 2 clearly inhibits this process. The expression of IME2 in cycling cultures induced the accumulation of unbudded cells which replicated their DNA. The inhibition of budding in mitotic cells suggest also a role of Ime 2 in preventing budding in meiosis.

Is Ime2 activity regulated via its stability? We have shown that Ime2 is unstable when expressed in normally dividing cells. Proteolysis of Ime2 appears to be independent of the APC or the SCF ubiquitin-ligases and the machinery responsible for Ime 2 instability remains to be identified. The permanent instability of Ime 2 in dividing cells may help to ensure that Ime2 never accumulates in the mitotic cell cycle, where it could interfere with processes such as budding or APC activity. It is unknown whether Ime2 is also permanently unstable during meiosis or whether it then gets periodically stabilised. Stabilisation could be a mechanism to allow efficient accumulation of Ime2 in early meiosis, in addition to the transcriptional induction of the IME2 gene (Mitchell et al. 1990; Mitchell 1994).

Not only accumulation, but also removal of Ime 2 may be important during meiosis. We have shown that high levels of Ime2 blocked progression through mitosis. The continued presence of active Ime2 may also interfere with cell cycle progression in meiosis. Since Ime2 is itself an unstable protein, its inactivation during meiosis may be triggered by turning on its rapid proteolysis.

Up to now, little is known about APC regulation during meiosis. Pds1 was found to be degraded at anaphase onset in both meiosis I and II (Salah and Nasmyth 2000). Pds1 reaccumulation after its destruction in meiosis I implies that APC needs to be inactivated between meiosis I and II. Recently, Ama1, a meiosis-specific protein related to Cdc20/Cdh1, was identified (Cooper et al. 2000). Ama1 seems to be required for Clb1 degradation in meiosis I, but it is not essential for meiosis II. $\mathrm{CDHI}$ expression was also found to be induced in meiosis (Chu et al. 1998) indicating that Cdh1 and Ama1 may have redundant roles in triggering cyclin proteolysis. 
It seems that at least three different APC complexes need to be regulated during meiosis. The identification of Ime2 as an inhibitor of APC-mediated proteolysis suggests that this protein kinase represents an important player in APC regulation during meiosis.

\section{Acknowledgements}

We thank Anthony Bretscher for providing a GAL-cDNA library, Marta Galova and Kim Nasmyth for strains and plasmids, and Wilfried Kramer and Anke Schürer for help with FACS analysis. We acknowledge Patrick Dieckhoff and Yasemin Sancak for support and comments on the manuscript. This work was supported by the Deutsche Forschungsgemeinschaft, the Fonds der Chemischen Industrie and the VolkswagenStiftung. 


\section{References}

Amon, A. 1997. Regulation of B-type cyclin proteolysis by Cdc28-associated kinases in budding yeast. Embo J 16: 2693-702.

Amon, A. 1999. The spindle checkpoint. Curr Opin Genet Dev 9: 69-75.

Amon, A., S. Irniger, and K. Nasmyth. 1994. Closing the cell cycle circle in yeast: G2 cyclin proteolysis initiated at mitosis persists until the activation of G1 cyclins in the next cycle. Cell 77: 1037-50.

Bäumer, M., G.H. Braus, and S. Irniger. 2000. Two different modes of cyclin Clb2 proteolysis during mitosis in Saccharomyces cerevisiae. FEBS Lett 468: 142-8.

Chu, S., J. DeRisi, M. Eisen, J. Mulholland, D. Botstein, P.O. Brown, and I. Herskowitz. 1998. The transcriptional program of sporulation in budding yeast. Science $\mathbf{2 8 2}$ : 699-705.

Cohen-Fix, O., J.M. Peters, M.W. Kirschner, and D. Koshland. 1996. Anaphase initiation in Saccharomyces cerevisiae is controlled by the APC-dependent degradation of the anaphase inhibitor Pds1p. Genes Dev 10: 3081-93.

Cooper, K.F., M.J. Mallory, D.B. Egeland, M. Jarnik, and R. Strich. 2000. Ama1p is a meiosis-specific regulator of the anaphase promoting complex/cyclosome in yeast. Proc Natl Acad Sci U S A 97: 14548-53.

Dahmann, C. and B. Futcher. 1995. Specialization of B-type cyclins for mitosis or meiosis in S. cerevisiae. Genetics 140: 957-63.

Dirick, L., L. Goetsch, G. Ammerer, and B. Byers. 1998. Regulation of meiotic S phase by Ime2 and a Clb5,6-associated kinase in Saccharomyces cerevisiae. Science 281: 1854-7.

Epstein, C.B. and F.R. Cross. 1992. CLB5: a novel B cyclin from budding yeast with a role in S phase. Genes Dev 6: 1695-706.

Gietz, R.D. and A. Sugino. 1988. New yeast-Escherichia coli shuttle vectors constructed with in vitro mutagenized yeast genes lacking six-base pair restriction sites. Gene 74: 527-34.

Grandin, N. and S.I. Reed. 1993. Differential function and expression of Saccharomyces cerevisiae B-type cyclins in mitosis and meiosis. Mol Cell Biol 13: 2113-25.

Hochstrasser, M. 1996. Ubiquitin-dependent protein degradation. Annu Rev Genet 30: 40539.

Hoyt, M.A. 2000. Exit from mitosis: spindle pole power. Cell 102: 267-70.

Huang, J.N., I. Park, E. Ellingson, L.E. Littlepage, and D. Pellman. 2001. Activity of the $\mathrm{APC}(\mathrm{Cdh} 1)$ form of the anaphase-promoting complex persists until $\mathrm{S}$ phase and prevents the premature expression of Cdc20p. J Cell Biol 154: 85-94.

Irniger, S. and K. Nasmyth. 1997. The anaphase-promoting complex is required in G1 arrested yeast cells to inhibit B-type cyclin accumulation and to prevent uncontrolled entry into S-phase. J Cell Sci 110: 1523-31.

Irniger, S., S. Piatti, C. Michaelis, and K. Nasmyth. 1995. Genes involved in sister chromatid separation are needed for B-type cyclin proteolysis in budding yeast [published erratum appears in Cell 1998 May 1;93(3):487]. Cell 81: 269-78.

Jaspersen, S.L., J.F. Charles, and D.O. Morgan. 1999. Inhibitory phosphorylation of the APC regulator Hct1 is controlled by the kinase Cdc28 and the phosphatase Cdc14. Curr Biol 9: 227-36.

Jorgensen, P. and M. Tyers. 1999. Altered states: programmed proteolysis and the budding yeast cell cycle. Curr Opin Microbiol 2: 610-7.

Lee, B. and A. Amon. 2001. Meiosis: how to create a specialized cell cycle. Curr Opin Cell Biol 13: 770-7. 
Lew, D.J. 2000. Cell-cycle checkpoints that ensure coordination between nuclear and cytoplasmic events in Saccharomyces cerevisiae. Curr Opin Genet Dev 10: 47-53.

Liu, H., J. Krizek, and A. Bretscher. 1992. Construction of a GAL1-regulated yeast cDNA expression library and its application to the identification of genes whose overexpression causes lethality in yeast. Genetics 132: 665-73.

Mitchell, A.P. 1994. Control of meiotic gene expression in Saccharomyces cerevisiae. Microbiol Rev 58: 56-70.

Mitchell, A.P., S.E. Driscoll, and H.E. Smith. 1990. Positive control of sporulation-specific genes by the IME1 and IME2 products in Saccharomyces cerevisiae. Mol Cell Biol 10: $2104-10$.

Morgan, D.O. 1999. Regulation of the APC and the exit from mitosis. Nat Cell Biol 1: E47-53.

Nasmyth, K., J.M. Peters, and F. Uhlmann. 2000. Splitting the chromosome: cutting the ties that bind sister chromatids. Science 288: 1379-85.

Peters, J.M. 1998. SCF and APC: the Yin and Yang of cell cycle regulated proteolysis. Curr Opin Cell Biol 10: 759-68.

Pringle, J.R., A.E. Adams, D.G. Drubin, and B.K. Haarer. 1991. Immunofluorescence methods for yeast. Methods Enzymol 194: 565-602.

Rudner, A.D., K.G. Hardwick, and A.W. Murray. 2000. Cdc28 activates exit from mitosis in budding yeast. J Cell Biol 149: 1361-76.

Salah, S.M. and K. Nasmyth. 2000. Destruction of the securin Pds1p occurs at the onset of anaphase during both meiotic divisions in yeast. Chromosoma 109: 27-34.

Schwab, M., A.S. Lutum, and W. Seufert. 1997. Yeast Hct1 is a regulator of Clb2 cyclin proteolysis. Cell 90: 683-93.

Shirayama, M., A. Toth, M. Galova, and K. Nasmyth. 1999. APC(Cdc20) promotes exit from mitosis by destroying the anaphase inhibitor Pds1 and cyclin Clb5 [see comments]. Nature 402: 203-7.

Shirayama, M., W. Zachariae, R. Ciosk, and K. Nasmyth. 1998. The Polo-like kinase Cdc5p and the WD-repeat protein Cdc20p/fizzy are regulators and substrates of the anaphase promoting complex in Saccharomyces cerevisiae. Embo J 17: 1336-49.

Shou, W., J.H. Seol, A. Shevchenko, C. Baskerville, D. Moazed, Z.W. Chen, J. Jang, H. Charbonneau, and R.J. Deshaies. 1999. Exit from mitosis is triggered by Tem1dependent release of the protein phosphatase Cdc14 from nucleolar RENT complex. Cell 97: 233-44.

Surana, U., A. Amon, C. Dowzer, J. McGrew, B. Byers, and K. Nasmyth. 1993. Destruction of the $C D C 28 / C L B$ mitotic kinase is not required for the metaphase to anaphase transition in budding yeast. Embo J 12: 1969-78.

Visintin, R., K. Craig, E.S. Hwang, S. Prinz, M. Tyers, and A. Amon. 1998. The phosphatase Cdc14 triggers mitotic exit by reversal of Cdk-dependent phosphorylation. Mol Cell 2: 709-18.

Visintin, R., E.S. Hwang, and A. Amon. 1999. Cfil prevents premature exit from mitosis by anchoring Cdc14 phosphatase in the nucleolus [see comments]. Nature 398: 818-23.

Visintin, R., S. Prinz, and A. Amon. 1997. $C D C 20$ and $C D H 1$ : a family of substratespecific activators of APC- dependent proteolysis. Science 278: 460-3.

Yeong, F.M., H.H. Lim, C.G. Padmashree, and U. Surana. 2000. Exit from mitosis in budding yeast: biphasic inactivation of the $\mathrm{Cdc} 28-\mathrm{Clb} 2$ mitotic kinase and the role of Cdc20. Mol Cell 5: 501-11. 
Yeong, F.M., H.H. Lim, Y. Wang, and U. Surana. 2001. Early expressed Clb proteins allow accumulation of mitotic cyclin by inactivating proteolytic machinery during S phase. Mol Cell Biol 21: 5071-81.

Yoshida, M., H. Kawaguchi, Y. Sakata, K. Kominami, M. Hirano, H. Shima, R. Akada, and I. Yamashita. 1990. Initiation of meiosis and sporulation in Saccharomyces cerevisiae requires a novel protein kinase homologue. Mol Gen Genet 221: 176-86.

Zachariae, W. 1999. Progression into and out of mitosis [see comments]. Curr Opin Cell Biol 11: 708-16.

Zachariae, W. and K. Nasmyth. 1999. Whose end is destruction: cell division and the anaphase-promoting complex. Genes Dev 13: 2039-58.

Zachariae, W., M. Schwab, K. Nasmyth, and W. Seufert. 1998. Control of cyclin ubiquitination by CDK-regulated binding of Hct1 to the anaphase promoting complex. Science 282: 1721-4. 


\title{
Chapter 4
}

\section{Ime2 protein stability depends on an intact C-terminal domain and is required for yeast sporulation}

\begin{abstract}
Meiosis represents a specialised cell cycle triggering diploid yeast cells to the formation of four haploid spores in response to nutrient starvation conditions. The protein kinase Ime2 represents one key regulator of the sporulation program in budding yeast Saccharomyces cerevisiae. Ime 2 is involved in initiation of pre-meiotic DNA replication, degradation of cyclin dependent kinase inhibitor Sic1, expression of early and middle meiotic genes, expression and regulation of meiotic transcription activator Ndt80. Ime2 was shown to be a highly unstable protein with a yet unknown degradation mechanism. Ime2 protein levels during sporulation fluctuate, reaching highest levels in early and late meiosis. We aimed to identify Ime 2 regions responsible for its rapid degradation by the construction of a systematic deletion set of the corresponding gene. None of the small deletions of approximately 60 - 70 amino acids caused stabilisation of Ime2, suggesting that this protein contains redundant degradation signals. In contrast, a deletion of the last 241 codons drastically stabilised the resulting truncated Ime2 which is highly active. When expressed in dividing cells, Ime $2 \Delta 405-645$ efficiently induced a cell cycle arrest in mitosis and the stabilisation of cyclin $\mathrm{Clb} 2$. Expression in meiosis under the control of its own promoter resulted in formation of asci containing three or two instead of four spores. These results suggest that Ime2 instability is an important prerequisite for the meiotic cell cycle.
\end{abstract}




\section{Introduction}

Meiosis is a specialised cell division allowing diploid cells to exchange genetic material and to generate haploid spores. In the meiotic cell cycle one round of DNA replication is followed by two rounds of chromosome segregation (Lee and Amon 2001). In the first division, meiosis I, homologous chromosomes segregate to opposite poles, but sister chromatids remain connected. In meiosis II sister chromatids are separated (Amon 2001). Initiation of meiosis in $S$. cerevisiae is regulated by nutritional conditions. When diploid cells are starved for nitrogen in the presence of a non-fermentable carbon source and in the absence of glucose, the sporulation program gets started. Nutritional signalling pathways converge on transcriptional regulation of two key factors of meiosis: IME1, which encodes a transcription factor; and $I M E 2$, which encodes a Ser/Thr protein kinase. Ime1 activates expression of several genes expressed early in meiosis, including IME2 (Kassir et al. 2003).

Previous data have shown that Ime 2 is required for efficient pre-meiotic DNA replication and that this kinase triggers degradation of the Cdc28-inhibitor Sic1 prior to the initiation of DNA replication (Dirick et al. 1998). Ime2 is also required for late events in meiosis. One of these functions is the activation of the transcription factor Ndt80, which is needed for the expression of middle and late meiotic genes (Xu et al. 1995). Ime2 protein levels and kinase activity peak late in meiosis, when cells undergo nuclear division (Benjamin et al. 2003). It was shown by using an analog-sensitive version of Ime2, that Ime2 inhibition in late meiosis leads to a cell cycle arrest prior to meiosis II. This suggests that Ime2 possesses in addition Ndt80-independent roles in triggering meiotic cell division. Previous findings suggest that a late role of Ime 2 may be the regulation of the anaphase promoting complex/cyclosome (APC/C), because Ime2 was identified in a genetic screen for negative regulators of the APC/C. Expression of IME2 leads to phosphorylation of Cdh1 and to stabilisation of APC/C substrates (Bolte et al. 2002). These data indicate that Ime2 may take over the role of $\mathrm{Cdc} 28$ in $\mathrm{APC} / \mathrm{C}^{\mathrm{Cdh} 1}$ phosphorylation in the meiotic cell cycle.

Like in the mitotic cell cycle, ubiquitin-dependent proteolysis triggered by the APC/C, is essential for cell cycle progression during meiosis, but little is known about its regulation. In the mitotic cell cycle the activity of the $\mathrm{APC} / \mathrm{C}$ is tightly cell cycle regulated, and depends on its association with one of its regulator proteins, Cdc20 and Cdh1 (Peters 2002). At the metaphase/anaphase transition the $\mathrm{APC} / \mathrm{C}^{\mathrm{Cdc} 20}$ mediates proteolysis of the securin Pds1, and thereby enables sister chromatid separation. S-phase cyclins and a part of 
the mitotic cyclins are also ubiquitinated by the $\mathrm{APC} / \mathrm{C}^{\mathrm{Cdc} 20}$ (Shirayama et al. 1999; Bäumer et al. 2000; Yeong et al. 2000). The second mitotic regulatory protein of the APC/C, Cdh1 (Hct1), is needed for complete destruction of mitotic cyclins in late anaphase and exit from mitosis (Schwab et al. 1997; Visintin et al. 1997).

In meiosis $C D C 2 O$ and $C D H 1$ are also expressed. In addition Ama1 displaying similarities to $\mathrm{Cdc} 20$ and $\mathrm{Cdh} 1$ seems to be involved in $\mathrm{APC} / \mathrm{C}$ regulation, suggesting that three different APC/C complexes mediate proteolysis during meiosis (Cooper et al. 2000). Up to know only the destruction of the securin Pds1 has been analysed. Like in mitosis $\mathrm{APC} / \mathrm{C}^{\mathrm{Cdc} 20}$ is responsible for destruction of the securin Pds1, in metaphase I as well as in metaphase II (Salah and Nasmyth 2000).

The ability of Ime 2 to phosphorylate Cdh1 suggests that Ime 2 could be responsible for turning off the $\mathrm{APC} / \mathrm{C}^{\mathrm{Cdh} 1}$ at the $\mathrm{G} 1 / \mathrm{S}$ transition by phosphorylating $\mathrm{Cdh} 1$, and in addition, control the regulator proteins Ama1 and Cdh1 later on during meiosis.

In contrast to $\mathrm{Cdc} 28$ whose activity is regulated by cyclin binding, no cyclins are known for Ime2. Ime2 is known to be a very unstable protein (Bolte et al. 2002), so kinase activity is perhaps regulated by its own instability. The present study therefore deals with the identification of degradation signals leading to the high instability of Ime2. We found that deletion of a large $\mathrm{C}$-terminal region results in a hyperactive and stabilised version of the Ime2 protein. 


\section{Materials and Methods}

Yeast strains and plasmids. Yeast strains used for experiments in this study were derivatives of the $S$. cerevisiae W303 strain, with exception of the sporulation experiments, in which the high efficiently sporulating strain background SK1 was used. Strains carrying HA-tagged versions of Clb2 (Zachariae et al. 1998) and Ime2 (Bolte et al. 2002) were described. All strains used in this work are listed in table1.

A chromosomal C-terminal MYC9-tag was introduced in the SK1 strain using a direct tagging approach described by Knop et al. (1999). Integration was verified by PCR. The Ime2 deletion set was constructed basing on the plasmid YIplac204-GAL-IME2-HA (Bolte et al. 2002). Ten different N- and C-terminal fragments of this construct were amplified and fused by using a newly introduced PstI restriction site. Ten deletions of approximately $200 \mathrm{bp}$ and two large deletions in the C-terminal part of the IME2 gene resulting in proteins lacking 45 up to 241 out of 645 aa were received. The deletion constructs were cloned into the CEN-plasmid YCplac22 (Gietz and Sugino 1988). The obtained plasmids pME2584 - pME2595, listed in table 2, were named in accordance to the lacking amino acids. All plasmids were transformed into different yeast strains. Transformants were selected on minimal medium lacking tryptophan.

Table 1: strains used in this study

\begin{tabular}{|c|c|c|}
\hline strain & & relevant genotype \\
\hline S001 & $\overline{\text { (RH2524) }}$ & $\begin{array}{l}\text { W303 wild-type strain } \\
\text { MATa, ade2-1, trp1-1, can1-100, leu2-3,1122, his3-11,15, ura3, GAL, psi+ }\end{array}$ \\
\hline S006 & (RH3152) & MATa, bar- \\
\hline S023 & (RH2664) & MATa, bar-, GAL-CLB2::URA3 \\
\hline S396 & (RH2559) & MATa, bar-, GAL-IME2-HA6::TRP1 (5 copies) \\
\hline S456 & (RH2833) & MATa, bar-, GAL-CLB2::URA3, GAL-IME2::TRP1 \\
\hline S497 & (RH2834) & $\begin{array}{l}\text { SK1 background } \\
M A T a / \alpha, \text { ho:his } G \text {, lys2, ura3, his3, trp1DFA }\end{array}$ \\
\hline S504 & (RH2835) & $\begin{array}{l}\text { SK1 background } \\
\text { MATa/ } \alpha, \text { ho::LYS2, ura3, leu2::hisG, trp } 1: \because \text { his } G, \text { his } 3:: \text { his } G \\
\text { IME2-MYC9/IME2-MYC9 TRP1+ }\end{array}$ \\
\hline S511 & (RH3153) & MATa, bar-, GAL-IME2::URA3, GALL-HA-CDH1::TRP1, CDC23-MYC::LEU2 \\
\hline S512 & (RH3154) & MATa, bar-, GALL-HA-CDH1::TRP1, CDC23-MYC::LEU2 \\
\hline S577 & (RH3155) & MATa, bar-, GAL-IME2 $\triangle P E S T-H A:: T R P 1$ \\
\hline S579 & (RH3156) & MATa/ $\alpha$, IME2/IME2 $\triangle$ C-term(405-645)-HA-KanMX6 \\
\hline S580 & (RH3157) & 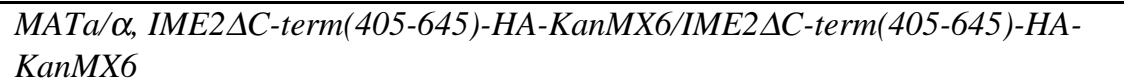 \\
\hline
\end{tabular}


Table 2: plasmids used in this study

\begin{tabular}{|c|c|c|}
\hline plasmid & relevant genotype & reference \\
\hline YCplac22 & CEN4/ARSH1, TRP1, Amp ${ }^{R}$ (bla), lacZ, ori & Gietz and Sugino, 1988 \\
\hline pME2116 & TRP1, GAL-IME2-HA3(2x), Amp ${ }^{R}($ bla $)$, lacZ, ori & Bolte et al., 2002 \\
\hline pME2584 & TRP1, GAL-IME2 $\triangle 2-67-H A 3(2 x), A_{m p}^{R}($ bla $)$, lacZ, ori & This work \\
\hline pME2585 & TRP1, GAL-IME2 $\Delta 68-135-H A 3(2 x), A m p^{R}$ (bla), lacZ, ori & This work \\
\hline pME2586 & TRP1, GAL-IME2 $\Delta 136-201-H A 3(2 x), A m p^{R}($ bla $)$, lacZ, ori & This work \\
\hline pME2587 & TRP1, GAL-IME2 $\triangle 202-264-H A 3(2 x), A m p^{R}($ bla $)$, lacZ, ori & This work \\
\hline pME2588 & TRP1, GAL-IME2 $\triangle 265-337-H A 3(2 x), A m p^{R}($ bla $)$, lacZ, ori & This work \\
\hline pME2589 & TRP1, GAL-IME2 $4338-404-H A 3(2 x), A m p^{R}($ bla $)$, lacZ, ori & This work \\
\hline pME2590 & TRP1, GAL-IME2 $\triangle 405-466-H A 3(2 x), A m p^{R}($ bla $)$, lacZ, ori & This work \\
\hline pME2591 & TRP1, GAL-IME2 $4467-533-H A 3(2 x), A_{m p}^{R}($ bla $)$, lacZ, ori & This work \\
\hline pME2592 & TRP1, GAL-IME2 $\triangle 534-600-H A 3(2 x), A m p^{R}($ bla $)$, lacZ, ori & This work \\
\hline pME2593 & TRP1, GAL-IME2 $\Delta 601-645-H A 3(2 x), A m p^{R}($ bla $)$, lacZ, ori & This work \\
\hline pME2594 & TRP1, GAL-IME2 $\triangle 405-533-H A 3(2 x), A m p^{R}($ bla $)$, lacZ, ori & This work \\
\hline pME2595 & TRP1, GAL-IME2 $4405-645-H A 3(2 x), A m p^{R}($ bla $)$, lacZ, ori & This work \\
\hline
\end{tabular}

Growth conditions and cell cycle arrests. Prior to expression of genes from the GAL1promoter, cells were pregrown in raffinose medium. By addition of galactose to a $2 \%$ final concentration, the GAL1-promoter was induced. To shut off the promoter, cells were harvested, washed and resuspended in glucose medium. To arrest cells in G1 with alphafactor pheromone (Nova Biochem), cells were incubated 2 hours in the presence of $5 \mu \mathrm{g}$ alpha-factor per ml medium. Temperature sensitive mutants were always pregrown at a permissive temperature of $25^{\circ} \mathrm{C}$ to $\mathrm{OD}_{600} 0,3-0,6$ before they were shifted to their restrictive temperature.

Meiotic time-course experiments. In order to detect Ime 2 protein levels during sporulation a SK1 strain containing a chromosomal MYC9-tagged version of the IME2 gene was used. To obtain a synchronously sporulating culture, the SK1 strain was grown to saturation in YEPD (1\% yeast extract, $2 \%$ peptone, $2 \%$ glucose, $0,005 \%$ adenine), transferred into YEPAcetate (1\% potassium acetate) for 13,5 hours and then transferred to sporulation medium ( $3 \%$ potassium acetate, $0,02 \%$ raffinose). Progression through meiosis was monitored by fluorescence microscopy after spheroblast preparation and DAPI (4', 6diamidino-2-phenylindole) staining of the DNA (Pringle 1991). 
Sporulation of the W303 strain background was analysed after transfer of an overnight culture in YEPD to VB-sporulation medium $(0,82 \%$ sodium acetate, $0,19 \%$ potassium chloride, $0,035 \% \mathrm{Mg}_{2} \mathrm{SO}_{4}, 0,12 \% \mathrm{NaCl}$ ).

Immunoblotting. Whole-cell extracts and immunoblotting were performed as described previously by Surana et al. (1993). For immunoblot detection the enhanced chemiluminescence detection system (ECL, Amersham) was used. Clb2 and Cdc28 antibodies were used in 1:1000 and 1:2000 dilutions respectively, MYC and HA antibodies were both used in 1:100 dilutions.

Immunoprecipitation. For immunoprecipitation whole-cell extracts were prepared as described by Tyers et al. (1992). Inhibition of proteinases in buffer3 was obtained by the addition of the proteinase inhibitor mixture Complete (Amersham Biosciences). For immunoprecipitation of HA- or MYC-tagged proteins antibodies were used in a tenfold higher concentration than for immunoblot detection. Incubation time of the crude extracts with the antibody and the proteinA-sepharose (Amersham Biosciences) was varied between 1 and 3 hours. 


\section{Results}

Ime2 protein level fluctuates during meiosis. In previous experiments we showed that Ime2 is an unstable protein, when expressed ectopically in mitotic cells (Bolte et al. 2002). Since IME2 expression is restricted to the meiotic cell cycle, we investigated protein levels in sporulating cultures. Therefore, a genomic C-terminal MYC9-tag was introduced in the efficiently sporulating strain SK1. The resulting strain homozygous for IME2-MYC9 (S504) showed normal sporulation pattern, indicating that the tagged version of Ime 2 is functional.

To monitor Ime2-MYC9 protein levels during the course of meiosis, we used cultures, which synchronously progress through meiosis. For this purpose the diploid strain was grown to stationary phase in YEPD for 36 hours. This pre-culture was diluted 1:50 in YEPAcetate (2\% potassium acetate) to starve the cells for a fermentable carbon source. After 13,5 hours cells were harvested and washed with sterile water to remove all nutrients, than the pellet was resuspended in sporulation medium. Immunoblot analysis of samples taken from the pre-cultures and every 30 or 60 minutes during sporulation revealed that Ime 2 protein started to accumulate in acetate medium. During the first two hours in sporulation medium the amount of Ime 2 protein increased continuously, but subsequently decreased. In the time period from 4 to 5,5 hours only low protein levels could be detected. Afterwards protein levels began to rise again and remained on a high level up to the end of sporulation (Fig. 1A). Thus, Ime2 protein levels fluctuate during meiosis. The time point of reduced Ime2 levels corresponded with the first appearance of cells with two nuclei (Fig. 1B). With regard to the fact, that the expression of IME2 is more or less constant all over the time-course of sporulation (SGD database), these findings indicate that Ime2 protein levels are regulated by altering Ime 2 stability during meiosis. 


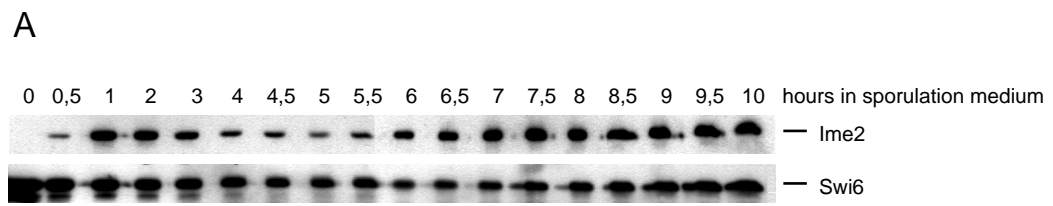

B

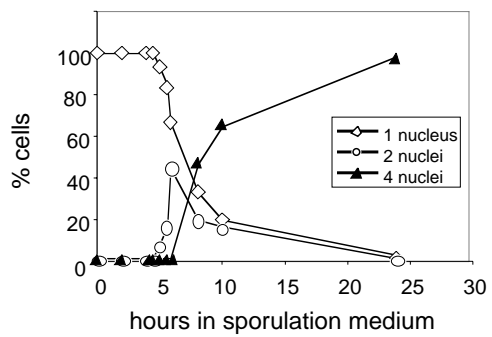

Fig. 1

Ime2 protein levels fluctuate during yeast meiosis. A synchronously sporulating culture of the diploid SK1 strain containing a chromosomal C-terminal MYC9-tagged Ime2 (S504) was used for monitoring Ime2 protein level and kinase activity during sporulation. A) Ime2-MYC protein was deteced by Western blot analysis, samples were taken at the indicated timepoints. Swi6 was used as loading control. B) Percentage of cells containing 1, 2 or 4 nuclei during $24 \mathrm{~h}$ in sporulation medium were determined by DAPI staining.

Deletion of the PEST-rich region does not stabilise Ime2. Ime2 is a very unstable protein, whose degradation occurs independently of the APC/C and SCF complex (Bolte et al. 2002). In silico analysis showed that Ime 2 contains a PEST-rich region including the amino acids 479 to 499 (Fig. 3). PEST denotes the amino acids proline, glutamate, serine and threonine. PEST-rich regions are known to be a signal for rapid protein degradation in many proteins (Rogers et al. 1986; Rechsteiner and Rogers 1996). Kassir and co-workers showed that overexpression of Ime 2 lacking the PEST-sequence leads to reduced viability compared to full-length Ime2. They suggested that this is due to stabilisation of Ime2 (Guttmann-Raviv et al. 2002).

To test the role of the PEST-sequence for Ime 2 instability, we deleted amino acids 479 to 499 to create a GAL-IME2 $\triangle P E S T-H A$ construct. Then we tested Ime2 and Ime2 $\triangle P E S T$ protein stability by promoter shutoff experiments using a W303 wild-type strain containing a GAL-IME2 $\triangle P E S T$-HA construct (S577). Cells were pre-grown in medium with raffinose as carbon source and the GAL-promoter was induced by addition of galactose. After 1,5 hours galactose was washed away and cells were transferred to glucose medium. Protein levels of Ime2-HA were determined at different time points before and after promoter shutoff. Western blot analysis showed that Ime2 $\triangle$ PEST was not stabilised in comparison to 
the full-length HA-tagged Ime2 protein (Fig. 2). Obviously the PEST-rich region of Ime2 is not essential for its rapid degradation.

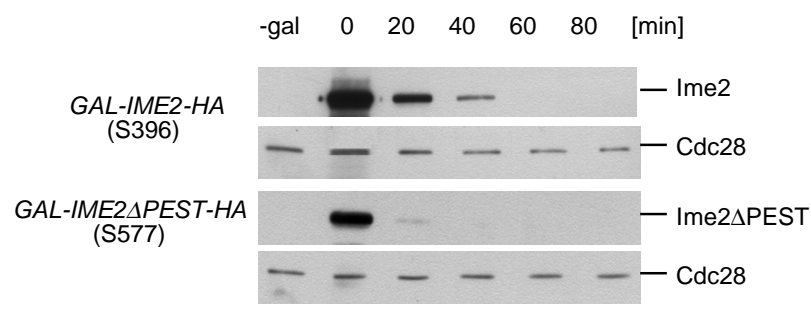

Fig. 2

Deletion of the PEST-rich region does not lead to stabilisation of Ime2. Stability of Ime2 and Ime2 $\triangle$ PEST was determined in $G A L$-promoter shutoff experiments. Cultures were pregrown with raffinose as carbon source, the $G A L$-promoter was induced by addition of galactose to the culture. After $1,5 \mathrm{~h}$ cells were washed and transferred to glucose medium. Samples were taken before induction of the $G A L$-promoter (-gal) and at the indicated timepoints after $G A L$-promoter shutoff. Cdc28 was used as loading control.

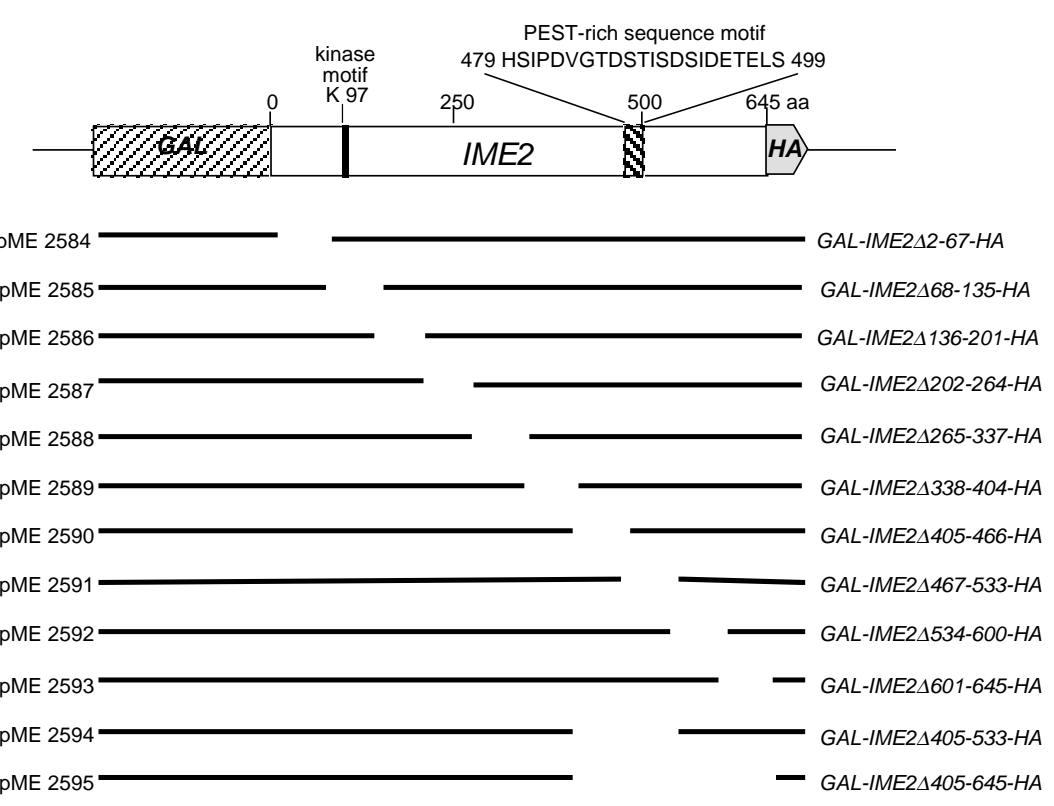

Fig. 3

Illustration of the GAL-IME2-HA construct including the amino acid sequence of the PEST-rich region motif of Ime2 and summary of the IME2-deletion constructs used in this study. The lacking amino acids were indicated. 
The C-terminal region of the IME2 gene is responsible for its rapid degradation. In order to find out which sequence targets the Ime 2 protein for its rapid degradation, a systematic deletion set was constructed. Ten systematic deletion constructs were created; each of them lacking approximately $200 \mathrm{bp}$. Taken together, every part of the protein was deleted once in the deletion set (for an overview see Fig.3). All truncated proteins were cloned in the $C E N$-plasmid YCplac22 (Gietz and Sugino 1988), carrying the TRP1 marker, and expressed ectopically from the GAL-promoter (table 2). Western analysis of $G A L$ promoter shutoff experiments revealed that with exception of IME24202-264 (pME2587) all IME2-deletion constructs could be expressed. Most of the truncated Ime2 proteins were as unstable or even less stable than the full-length protein (Fig. 4A, IME2 $22-67$,

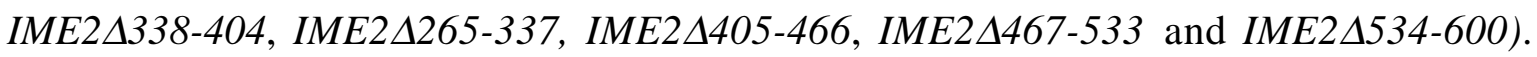
Three other constructs were slightly more stable than Ime2. Gene products of IME2 $\triangle 68$ 135 and IME2A136-201 were detectable up to $40 \mathrm{~min}$ after promoter shutoff. Only deletion of the last 45 aa led to a higher stabilisation, protein levels decreased after promoter shutoff, but after 80 min there was still some protein left (Fig. 4A). Since none of the $+/-65$ aa deletions led to complete stabilisation of Ime2, two larger Ime2-deletion constructs were created, one lacking 129 aa around the PEST-rich sequence (GAL-IME2 $4405-533-H A)$ and the other one lacking the last 241 aa at the C-terminus (GAL-IME2 $4405-645-H A)$. The 129 aa deletion resulted in a moderate stabilisation of the kinase, whereas the large deletion turned out to be the distinctly stabilised Ime2 protein (Fig. 4B).

In summary, neither small deletions of approximately 65 aa nor deletion of the PEST-rich sequence caused Ime 2 stabilisation, but deletion of a large C-terminal region prevented Ime 2 proteolysis. These results suggest that two or more redundant degradation signals are present in the $\mathrm{C}$-terminal region. 
A

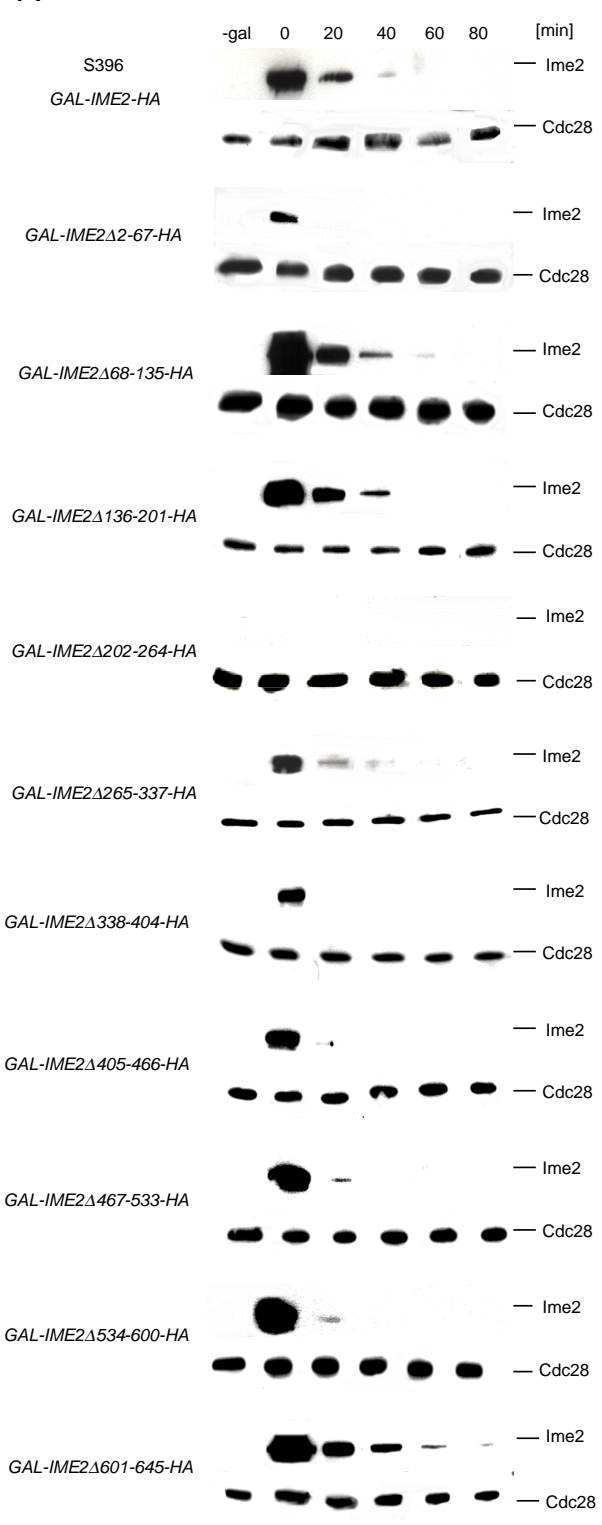

B

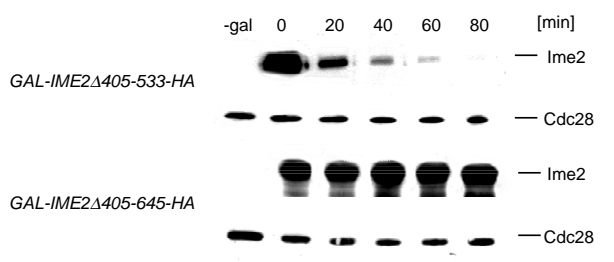

Fig. 4

A) Small deletions have little effects on yeast Ime2 stability. Wild-type strain S001 was transformed with centromeric plasmids containing one out of ten GAL-IME2-deletion constructs. Transformants were selected on minimal medium lacking tryptophan. Ime 2 protein stability was determined by $G A L$-promoter shutoff experiments. Cultures were pregrown with raffinose as carbon source, the $G A L$-promoter was induced by addition of galactose. After $1,5 \mathrm{~h}$ cells were washed and transferred to glucose medium. Samples were taken before induction of the $G A L$-promoter (-gal) and at the indicated timepoints after $G A L$-promoter shutoff. B) Deletion of a large C-terminal region prevents Ime2 proteolysis, suggesting that the $\mathrm{C}$-terminal region contains degradation signals for the rapid degradation of Ime2. A wild-type strain was transformed with centromeric plasmids containing either GAL-IME2 $\triangle 504-533-H A$ or GAL-IME2 $\triangle 504-645-H A$ deletion constructs. Transformants were selected on minimal medium lacking tryptophan. Cultures were treated as in (A).

Ectopic co-expression of $C L B 2$ and the stabilised, truncated $I M E 2 \triangle 504-645-H A$ is lethal. Cells expressing GAL-IME2 are viable, but co-expression of the mitotic cyclin gene CLB2 and IME2 shows a synthetic lethal effect (Fig. 5). This allows us to test wether the truncated Ime 2 proteins are still functional. The effect of the co-expression of CLB2 and the truncated IME2 $\triangle-H A$ constructs was tested in a strain containing a genomically integrated $G A L-C L B 2$ and the $G A L-I M E 2 \triangle-H A$ construct on a $C E N$-plasmid. Cells were pregrown on minimal medium lacking tryptophan with raffinose as carbon source. Viability was monitored after transferring dilution series on medium containing either glucose or galactose as carbon source. The full-length Ime2 protein was able to reduce viability significantly when co-expressed with CLB2 on galactose medium (Fig. 5). The 
deletion constructs showed different effects on viability. Deletions in the $\mathrm{N}$-terminal region (including amino acids 1 to 404, pME2584 - pME2589) only showed slightly reduced viability on galactose medium (Fig. 5). Thus, N-terminal and central parts of Ime2 are obviously essential for Ime2 activity. With the exeption of GAL-IME2 $4534-600-H A$ (pME2592), expression of most deletion constructs lacking parts of the C-terminal region reduced viability to the same extent as the full-length protein (pME2590-2591 and pME2593-2595). Even Ime2 containing the large deletions in the C-terminal region caused lethality on galactose plates. Therefore, the C-terminal part of the protein does not seem to be necessary for the function of Ime2. These results indicate that proteins lacking parts of the C-terminus, including the stabilised version of the Ime2 protein, are still highly active.

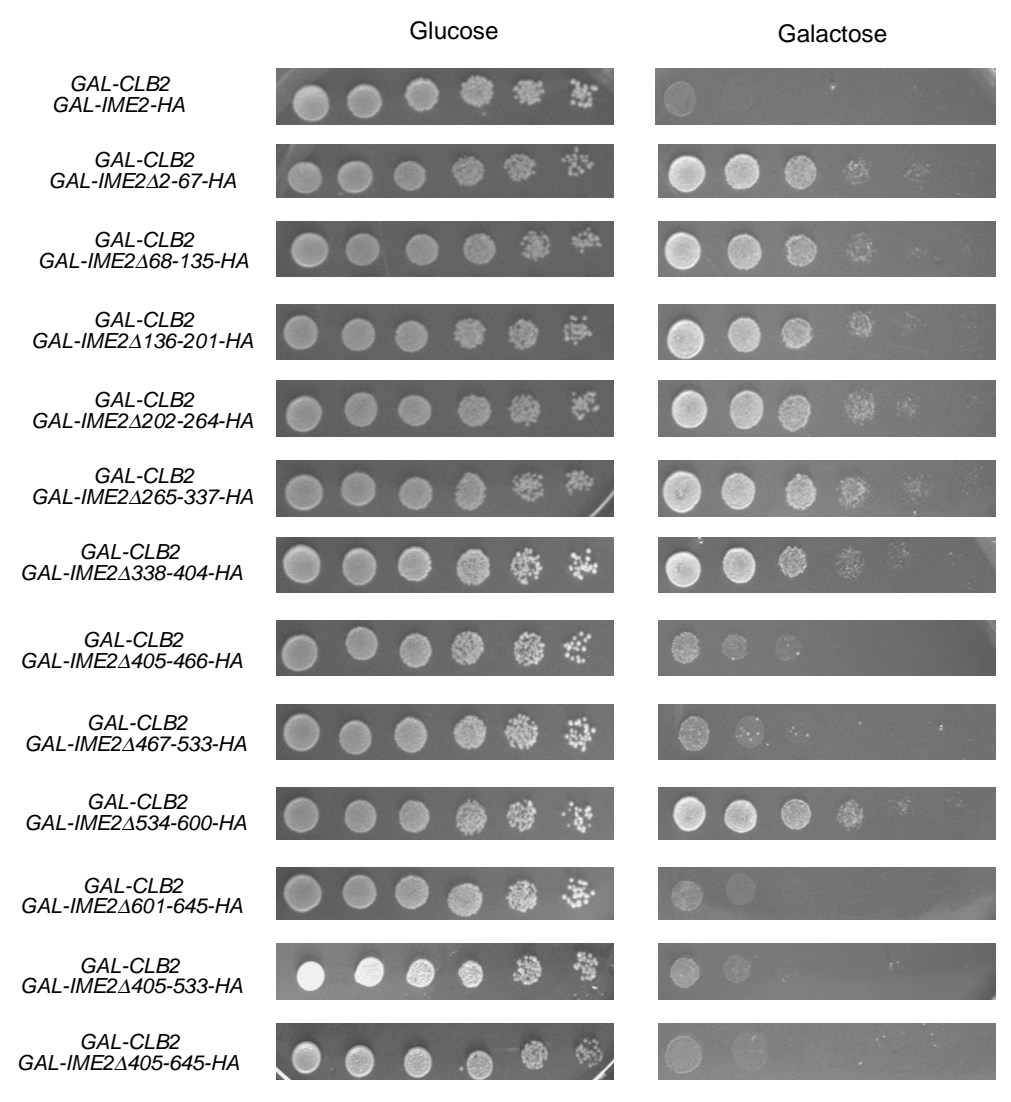

Fig. 5

Ectopic co-expression of $C L B 2$ and the truncated IME2 $4405-645-H A$ is lethal. To test the activity of the truncated Ime2 protein kinases a yeast strain containing a GAL-CLB2 construct was transformed with a $C E N-$ plasmids carrying one of the GAL-IME2 $\triangle-H A$ constructs, transformants were selected on minimal medium lacking tryptophan. Viabilitiy of the strains was determined on galactose and as control on glucose. A strain containing the complete GAL-IME2 construct was used as a control. 
Ectopic expression of the stabilised, truncated IME2 $\triangle 405-645-H A$ leads to a cell cycle arrest indicating that this truncated Ime2 kinase is highly active. We have earlier shown that high levels of Ime2, produced in a strain containing 5 copies of GAL-IME2 induced a cell cycle arrest in dividing cells (Bolte et al. 2002). If Ime2 $\Delta 405-645$ is also functional, one would expect a similar arrest. For that reason wild-type cells containing five copies of the complete GAL-IME2 (S396) or GAL-IME2 $4405-645$ on a $C E N$-plasmid (S001 with pME2595) were pregrown for two days on raffinose medium, before they were transferred to galactose or glucose medium. Indeed both constructs were able to arrest the cultures as unbudded cells (Fig. 6A). To determine the time course of accumulation of unbudded cells, the same experiment was performed in liquid cultures. Samples were taken every two hours and the amount of unbudded cells was determined by microscopy. Cells arrested faster and more effectively, when the deletion construct was expressed. After two hours in galactose medium 56\% unbudded cells were observed in the culture containing the stabilised Ime2 in contrast to $37 \%$ in the control culture (Fig. 6B). The truncated Ime2 on a centromeric plasmid efficiently caused a cell cycle arrest similar to the arrest caused by the full-length protein. Cells arrested as unbudded cells with short spindles. These results show that the trucated, stabilised Ime2 protein is highly active when expressed in the mitotic cell cycle. 
A WT
GAL-IME2 $2405-645-H A$
WT GAL-IME2-HA

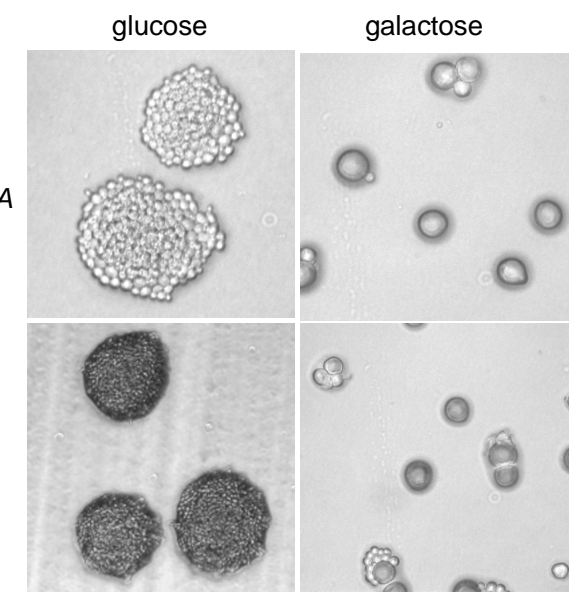

B

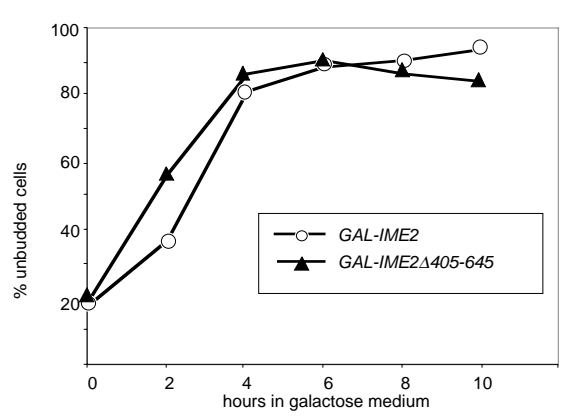

\section{Fig. 6}

Ectopic expression of the stabilised, truncated IME2 $\triangle 405-645-H A$ arrests wild-type cells as unbudded cells, simliar to expression of the full-length $I M E 2$. A) Cells carrying either the GAL-IME2 $405-645-H A$ construct or five copies of the GAL-IME2 construct (S396) were pregrown for two days on raffinose medium before they were striked on galactose or glucose medium. Cells were photographed after one day. B) Wild-type strain carrying either the GAL-IME2 $4405-645-H A$ construct on a centromeric plasmid or five copies of the GAL-IME2 construct (S396) was pregrown in liquid culture with raffinose as carbon source. Galactose was added to express the $G A L$-construct. The timecourse of cell cycle arrest triggered by $I M E 2$ expression was determined by microscopy.

\section{Ectopic expression of the truncated IME2 $\triangle 405-645-H A$ stabilises the cyclin Clb2. We} have previously shown that expression of IME2 in G1 arrested cells inhibits proteolysis of Clb2 (Bolte et al. 2002). To test wether the truncated Ime2 also effects APC/C-mediated proteolysis, cells containing both $G A L-C L B 2$ and $G A L-I M E 2$-(deletion)-constructs (S456 and S023 transformed with the deletion construct plasmids) were arrested in G1-phase with alpha-factor pheromone. Simultaneous expression of both genes was induced by galactose. Co-expression of GAL-CLB2 and GAL-IME2 $4405-645-H A$ or GAL-IME2 $4405-533-H A$ respetively, led to an accumulation of $\mathrm{Clb} 2$ protein. In the case of the complete stabilised Ime2 this effect was stronger than observed for GAL-IME2-HA (Fig. 7).

In conclusion, ectopic expression of the GAL-IME2 $\triangle 405-645-H A$ in G1 arrested cells seems to inhibit APC/C mediated proteolysis of the cyclin Clb2 more efficiently than fulllength Ime2. 


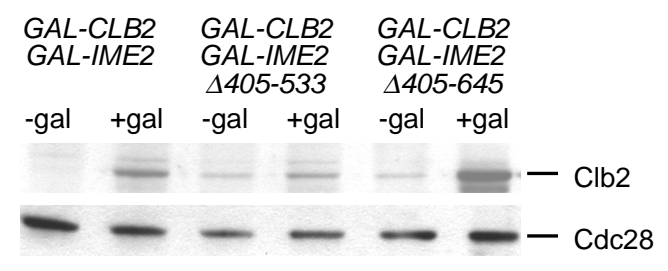

Fig. 7

Ectopic expression of IME2, IME2 $\triangle 405-533$ or IME2 $\triangle 405-645$ leads to accumulation of Clb2 in G1 arrested cells. A strain containing GAL-CLB2 and GAL-IME2 constructs (S456) was arrested in G1 with alpha-factor for $2 \mathrm{~h}$. Galactose was added and cells were incubated for $2 \mathrm{~h}$. Samples were taken before (-gal) and after galactose addition (+gal). Clb2 was detected by immunoblotting with anti-Clb2 antibody. A strain containing GAL-CLB2 construct (S023) was transformed with the plasmids carrying the Ime2-deletion constructs. After selection on minimal medium lacking tryptophan, transformants were treated like S456.

\section{The stabilised Ime2 interferes with spore formation.}

To test the influence of stabilised Ime2 on the meiotic cell cycle, the stable IME2 $\triangle 405-645$ was expressed under control of its own promoter. Therefore, IME2 was replaced by a IME2 4 405-645-HA-KanMX6 module in the W303 wild-type strain. Integration was verified by Western analysis. The effect of the truncated Ime 2 protein on progression through sporulation was tested in strains heterozygous and homozygous for the truncated kinase. Therefore, cells were pregrown in YEPD overnight and then transferred into sporulation medium (VB). Sporulation was monitored by microscopy and percentage of asci was determined every day. As control a diploid wild-type strain containing the fulllength IME2 was used. The wild-type sporulated within 48 hours. Approximately $40 \%$ of the cells formed four spored asci, called tetrades (Fig. 8A,B). In contrast, the strains containing the truncated Ime2 kinase formed asci containing three or two instead of four spores, indicating that the truncated Ime 2 interferes with proper spore formation (Fig. 8A, B). In the heterozygous IME2/IME2 $\triangle 405-645$ strain $13 \%$ of the cells formed proper tetrades, but nearly the same amount of cells produced triades or dyades containing three or two spores. In the homozygous strain the situation is even worth, because no tetrades were produced, $1 \%$ of the cells formed triads and $4 \%$ form dyads. These data indicate that the deleted C-terminal region is essential for proper progression through the meiotic cell cyle. Since the heterozygous strain also displays defects in sporulation, it is likely caused by a dominant effect of Ime $2 \Delta 405-645$, probably by a failure to inactivate Ime 2 by proteolysis. 


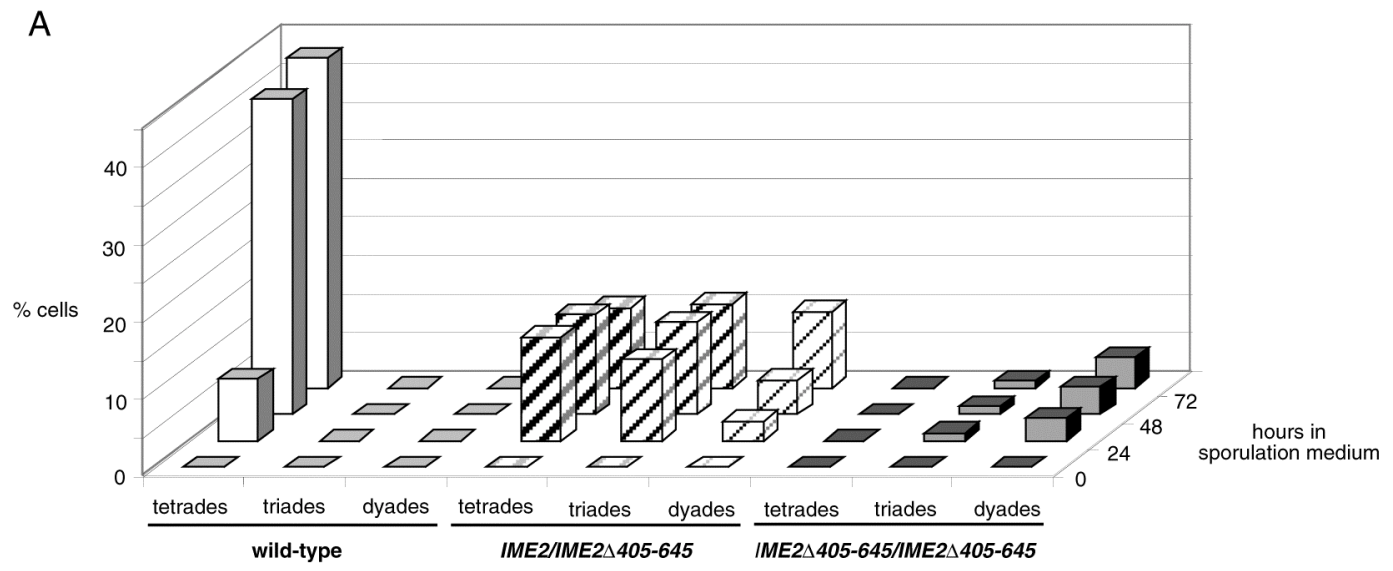

B

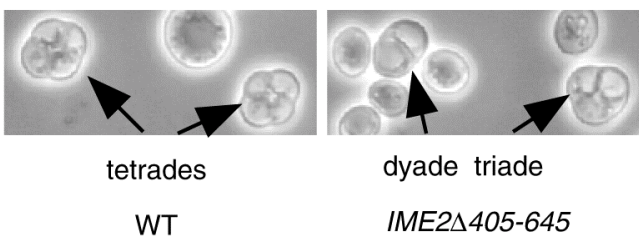

Fig. 8

Expression of the truncated, stabilised IME2 leads to formation of asci containing less than four spores. W303 strains homo- or heterzygous for the truncated IME2 $4405-645-H A$ were pre-grown overnight in YEPD medium and then transferred into VB-sporulation medium. A) Percentage of cells containing four, three or two spores was determined by microscopy after 24,48 and 72 hours. As control a wild-type strain containing the full-length Ime2 protein was used. B) Asci were photographed after 72 hours in sporulation medium. Tetrades, triades and dyades were indicated by arrows. 


\section{Discussion}

Investigation of Ime2 protein levels and kinase activity during meiosis. The analysis of Ime2-MYC9 protein levels in a synchronous sporulation culture of the highly efficient sporulating SK1 strain revealed a significant fluctuation during the meiotic cell cycle progression. Ime 2 protein accumulates for the first time when cells are grown in acetate medium in absence of glucose. These findings are consistent with the transcriptional regulation of IME2 mediated by $I M E 1$, whose expression is under control of the carbon source. Expression of IME1 is repressed by glucose but activated by acetate (Sagee et al. 1998). Therefore, expression of IME2 is also regulated indirectly by the carbon source. As soon as cells are transferred to sporulation medium the amount of Ime2-MYC9 protein starts to rise and peaks after approximately 2 hours. Between 4 and 6 hours in sporulation medium the amount of Ime 2 protein is reduced but still detectable. At this time cells containing two nuclei appear and transition from meiosis I to meiosis II is initiated. Afterwards the protein level increases again and remains on a high level even after completion of sporulation. Recently published data indicate, in addition to functions for Ime2 in early meiosis, an essential role for Ime2 in late meiosis (Benjamin et al. 2003). Accordingly, Ime2 is required for meiotic M-phase and spore formation and this fits with the presence of Ime 2 during the whole sporulation process.

Our results concerning Ime 2 protein levels during sporulation are also consistent with the findings from Benjamin and co-workers (2003). They found that Ime2 exhibits basal levels of kinase activity all over progression through sporulation, but they also determined a fluctuation in the intensity of kinase activity. Two peaks of kinase activity were determined. First peak was observed 2 hours after transfer to sporulation medium. Kinase activity declines afterwards and the second peak occur around 6 hours, before activity decreases again.

Whether the fluctuation in Ime2 protein level is due to regulation of expression or to regulation of Ime2 stability during sporulation remains to be determined. The expression pattern published in the Standford yeast genome database argues against a transcriptional control, once expressed under sporulation conditions expression of IME2 remains more or less constant on a high level until the end of meiosis.

The stability of Ime 2 is regulated by its $\mathbf{C}$-terminal region. Ime 2 was shown to be a very unstable protein (Bolte et al. 2002; Guttmann-Raviv et al. 2002). To identify the region responsible for its rapid degradation, a systematic deletion set was created 
consisting of ten truncated proteins lacking approximately 60 - 70 aa and two additional larger deletions in the C-terminal region. Most of the truncated Ime2 proteins are degraded as fast as the full-length protein. Even deletion of the PEST-rich region, which was suggested to be involved in rapid degradation of Ime2, does not lead to stabilisation of the protein. Only deletions in the $\mathrm{C}$-terminal region of the protein result in significant stabilisation. Complete stabilisation is only obtained by deletion of the last 241 aa at the $3^{\prime}$ end. Taken together the $\mathrm{C}$-terminus plays an important role in Ime 2 regulation as proposed earlier (Kominami et al. 1993). Up to know we can conclude that the instability region of the C-terminus consists of more than 45 aa but less than the 241 aa deleted here.

Since complete stabilisation can be obtained only by a large deletion at the C-terminal region, we suggest that the $\mathrm{C}$-terminal region contains two or more redundant degradation signals. By constructing additional deletions for this region it should be possible to narrow down the degradation signal.

How far the truncated Ime 2 proteins can be phosphorylated and if the phosphorylation influences Ime2 stability remains unclear. If Ime2, similar to Ime1, can be phosphorylated at the C-terminal region and thereby be targeted for degradation, Ime 2 may regulate itself in two distinct ways. First, it can activate its own transcription by a positive feed-back loop (Kassir et al. 2003) and second, Ime2 could promote its own degradation by autophosphorylation. It was shown that Ime 2 could exist in different phosphorylation forms (Benjamin et al. 2003). Late in meiosis Ime2 gets hyperphosphorylated, in contrast to early stages in meiosis when Ime 2 is not phosphorylated. A slight band shift due to phosphorylation of Ime2 in late meiosis can also be observed in Western blot analysis (Fig. 1), even if a clear separation of the different bands was not achieved.

Cdc28 seems to be required for some modifications of Ime2 (Benjamin et al. 2003) and dispensable for others. Sequence analysis revealed that Ime 2 possesses six potential Cdc28 phosphorylation sites. In the stabilised protein two out of six phosphorylation sites are deleted. Therefore, it could be possible that regulation by $\mathrm{Cdc} 28$ is disabled and the truncated protein cannot become hyperphosphorylated and thereby not marked for degradation.

Activity of the truncated Ime2 proteins. Deletion constructs lacking regions in the Nterminal and middle part of Ime2 prevent Ime2 activity, suggesting that the deleted regions are essential for functionality. These results are consistent with the proposal that the Nterminus of the Ime 2 protein is responsible for kinase activity, due to the conserved kinase 
domain, whereas the C-terminus is involved in regulation of activity (Kominami et al. 1993).

The stabilised Ime2 lacking the last 241 aa produced at low levels from a centromeric plasmid has the same impact on cell cycle progression and Clb2 cyclin degradation as five genomicly integrated copies of the full-length $I M E 2$ in vegetative growing cells. Degradation of the cyclin Clb2 is impaired and a cell cycle arrest occurs. Using the stabilised protein even enhances the effect of ectopic IME2 expression on mitotic cell cycle. The fact that a few copies of GAL-IME2 $\triangle 405-645$ are sufficient to cause the same effects as five copies of GAL-IME2 indicates that the truncated kinase is hyperactive.

In previous works $\mathrm{C}$-terminaly truncated Ime 2 constructs were found to be hyperactive concerning their in vitro kinase activity (Kominami et al. 1993). Our results suggest that this hyperactivity is due to elevated protein levels. Another explanation of the elevated effect on mitotic cell cycle progression could be the inhibition of the posttranslational control of Ime 2 kinase activity. Downregulation of Ime2 kinase activity in the presence of glucose is mediated by direct binding of Gpa2, which is part of the G-protein coupled glucose sensor to the C-terminal region of Ime2 (Donzeau and Bandlow 1999). It would be considerable that additional unknown factors involved in regulation of kinase activity during meiosis also mediate their regulation signal to the $\mathrm{C}$-terminus. This would explain the strong effect of truncated Ime2 on meiotic cell cycle progression. W303 strains heteroor homozygous for the stabilised Ime 2 construct fail to form proper asci containing four spores. Instead triads or dyads with three or two spores are produced. Sporulation efficiency is significantly reduced in these strains in comparison to the wild-type.

Our favourite explanation is that the phenotype is due to stabilisation of Ime2, resulting in high Ime2 kinase activity throughout meiosis. The production of 2 spores suggests that meiosis I can take place in a normal fashion, whereas meiosis II seems to be impaired. As demonstrated in our previous experiments, Ime 2 is able to phosphorylate the APC/C regulator Cdh1 and thereby inhibits activation of the APC/C in vegetative cells. Perhaps activation of the $\mathrm{APC} / \mathrm{C}^{\mathrm{Cdh} 1}$ is inhibited in the presence of the truncated Ime2, because Cdh1 is phosphorylated permanently. The role of Ime2 in APC/C regulation during meiosis remains to be clarified.

Another possibility is that the recognition of the meiotic Ime2 substrates like Ndt80 is disturbed. Ndt80 is phosphorylated by Ime2 in late meiosis. Ime2-deficient cells show a meiosis II defect, which was supposed to be a result of inadequate transcription of one or 
more middle genes when Ndt80 is improperly phosphorylated (Benjamin et al. 2003). Taken together, the C-terminal sequence seems to be essential for regulating Ime 2 activity in meiosis. Factors required for Ime2 degradation are still unknown, but these are likely to have an important function in regulating the activity of this central co-ordinator of meiosis. 


\section{References}

Amon, A. 2001. Together until separin do us part. Nat Cell Biol 3: E12-4.

Bäumer, M., G.H. Braus, and S. Irniger. 2000. Two different modes of cyclin clb2 proteolysis during mitosis in Saccharomyces cerevisiae. FEBS Lett 468: 142-8.

Benjamin, K.R., C. Zhang, K.M. Shokat, and I. Herskowitz. 2003. Control of landmark events in meiosis by the CDK Cdc28 and the meiosis-specific kinase Ime2. Genes Dev 17: 1524-39.

Bolte, M., P. Dieckhoff, C. Krause, G.H. Braus, and S. Irniger. 2003. Synergistic inhibition of APC/C by glucose and activated Ras proteins can be mediated by each of the Tpk1-3 proteins in Saccharomyces cerevisiae. Microbiology 149: 1205-16.

Bolte, M., P. Steigemann, G.H. Braus, and S. Irniger. 2002. Inhibition of APC-mediated proteolysis by the meiosis-specific protein kinase Ime2. Proc Natl Acad Sci U S A 99: 4385-90.

Cooper, K.F., M.J. Mallory, D.B. Egeland, M. Jarnik, and R. Strich. 2000. Ama1p is a meiosis-specific regulator of the anaphase promoting complex/cyclosome in yeast. Proc Natl Acad Sci U S A 97: 14548-53.

Dirick, L., L. Goetsch, G. Ammerer, and B. Byers. 1998. Regulation of meiotic S phase by Ime 2 and a Clb5,6-associated kinase in Saccharomyces cerevisiae. Science 281: 1854-7.

Donzeau, M. and W. Bandlow. 1999. The yeast trimeric guanine nucleotide-binding protein alpha subunit, Gpa2p, controls the meiosis-specific kinase Ime2p activity in response to nutrients. Mol Cell Biol 19: 6110-9.

Gietz, R.D. and A. Sugino. 1988. New yeast-Escherichia coli shuttle vectors constructed with in vitro mutagenized yeast genes lacking six-base pair restriction sites. Gene 74: 527-34.

Guttmann-Raviv, N., S. Martin, and Y. Kassir. 2002. Ime2, a meiosis-specific kinase in yeast, is required for destabilization of its transcriptional activator, Ime1. Mol Cell Biol 22: 2047-56.

Kassir, Y., N. Adir, E. Boger-Nadjar, N.G. Raviv, I. Rubin-Bejerano, S. Sagee, and G. Shenhar. 2003. Transcriptional regulation of meiosis in budding yeast. Int Rev Cytol 224: 111-71.

Knop, M., K. Siegers, G. Pereira, W. Zachariae, B. Winsor, K. Nasmyth, and E. Schiebel. 1999. Epitope tagging of yeast genes using a PCR-based strategy: more tags and improved practical routines. Yeast 15: 963-72.

Kominami, K., Y. Sakata, M. Sakai, and I. Yamashita. 1993. Protein kinase activity associated with the IME2 gene product, a meiotic inducer in the yeast Saccharomyces cerevisiae. Biosci Biotechnol Biochem 57: 1731-5.

Lee, B. and A. Amon. 2001. Meiosis: how to create a specialized cell cycle. Curr Opin Cell Biol 13: 770-7.

Peters, J.M. 2002. The anaphase-promoting complex: proteolysis in mitosis and beyond. Mol Cell 9: 931-43.

Pringle, J.R. 1991. Staining of bud scars and other cell wall chitin with calcofluor. Methods Enzymol 194: 732-5.

Rechsteiner, M. and S.W. Rogers. 1996. PEST sequences and regulation by proteolysis. Trends Biochem Sci 21: 267-71.

Rogers, S., R. Wells, and M. Rechsteiner. 1986. Amino acid sequences common to rapidly degraded proteins: the PEST hypothesis. Science 234: 364-8. 
Sagee, S., A. Sherman, G. Shenhar, K. Robzyk, N. Ben-Doy, G. Simchen, and Y. Kassir. 1998. Multiple and distinct activation and repression sequences mediate the regulated transcription of $I M E 1$, a transcriptional activator of meiosis-specific genes in Saccharomyces cerevisiae. Mol Cell Biol 18: 1985-95.

Salah, S.M. and K. Nasmyth. 2000. Destruction of the securin Pds1p occurs at the onset of anaphase during both meiotic divisions in yeast. Chromosoma 109: 27-34.

Schwab, M., A.S. Lutum, and W. Seufert. 1997. Yeast Hct1 is a regulator of Clb2 cyclin proteolysis. Cell 90: 683-93.

Shirayama, M., A. Toth, M. Galova, and K. Nasmyth. 1999. APC(Cdc20) promotes exit from mitosis by destroying the anaphase inhibitor Pds1 and cyclin Clb5 [see comments]. Nature 402: 203-7.

Tyers, M., G. Tokiwa, R. Nash, and B. Futcher. 1992. The Cln3-Cdc28 kinase complex of S. cerevisiae is regulated by proteolysis and phosphorylation. Embo J 11: 1773-84.

Visintin, R., S. Prinz, and A. Amon. 1997. CDC20 and $C D H 1$ : a family of substratespecific activators of APC- dependent proteolysis. Science 278: 460-3.

Xu, L., M. Ajimura, R. Padmore, C. Klein, and N. Kleckner. 1995. NDT80, a meiosisspecific gene required for exit from pachytene in Saccharomyces cerevisiae. Mol Cell Biol 15: 6572-81.

Yeong, F.M., H.H. Lim, C.G. Padmashree, and U. Surana. 2000. Exit from mitosis in budding yeast: biphasic inactivation of the $\mathrm{Cdc} 28-\mathrm{Clb} 2$ mitotic kinase and the role of Cdc20. Mol Cell 5: 501-11.

Zachariae, W., M. Schwab, K. Nasmyth, and W. Seufert. 1998. Control of cyclin ubiquitination by CDK-regulated binding of Hct1 to the anaphase promoting complex. Science 282: 1721-4. 


\section{Chapter 5}

\section{Conclusions and Outlook}

The understanding how critical events during the mitotic and meiotic cell cycle are regulated is a prerequisite for analysis of cells in which the control of the cell cycle is impaired. Abnormal cell cycle regulation in humans may finally result in dramatic genetic impacts as trisomy 21 and the resulting Down syndrom or may result in transformed cells and subsequently to diseases as cancer. Many critical events in cell cycle regulation are highly conserved from yeast to mammals, therefore findings in Saccharomyces cerevisiae could lead to a better understanding of cell cycle control also in higher organisms. In yeast, progression through mitosis and meiosis is mediated by ubiquitin-dependent proteolysis triggered by an ubiquitin-ligase, anaphase promoting complex/cyclosome (APC/C). This work contributes to the understanding of the regulation of the APC/C in the budding yeast S. cerevisiae. The main focus was on APC/C regulation mediated by two protein kinases: the protein kinase $\underline{\mathrm{A}}$ (PKA) during the mitotic cell cycle and the meiosis-specific protein kinase Ime2 during the meiotic cell cycle.

\section{Integration of environmental signals to inhibit $\mathrm{APC} / \mathrm{C}$ activity is mediated by the protein kinase A (PKA) in the mitotic cell cycle.}

In previous works it was found that the cAMP/protein kinase $\underline{A}$ (PKA) signalling pathway influences the anaphase promoting complex (APC/C) in budding yeast (Anghileri et al. 1999; Irniger et al. 2000). Activation of this pathway, which can be mediated either by glucose or constitutively activated Ras proteins, leads to inhibition of the APC/C.

The cAMP signal mediated by PKA is a key regulator for many processes, like invasive/filamentous growth, response to different nutrient conditions, and stress resistance (Thevelein and de Winde 1999). High PKA activity promotes growth, proliferation, and glycolysis but inhibits gluconeogenesis and lowers the stress resistance. It was shown that the three genes encoding PKA in budding yeast, TPK1-3, possess redundant function for viability but specific functions for pseudohyphal growth and iron uptake (Robertson and Fink 1998; Robertson et al. 2000). In this work, the role of the single $T P K$ gene in APC/C inhibition was analysed. We found that each of the three genes, TPK1-3, in S. cerevisiae is sufficient for inhibition of APC/C activity in response to glucose or activated Ras protein 
(Bolte et al. 2003). Ras protein can activate two different regulation cascades, firstly the cAMP/PKA pathway and secondly the MAP kinase (mitogen activating protein kinase) pathway. We showed that the Ras signal is mediated exclusively by PKA and not by MAPK, whereas invasive growth is under control of both networks (Mösch et al. 1999). The mechanism by which the protein kinase A inhibits APC/C activity in $S$. cerevisiae remains unknown. In fission yeast PKA activity inhibits formation and ubiquitination activity of the anaphase promoting complex (Yamashita et al. 1996). A first hint for the mechanism of regulation of APC/C by PKA was found in mammals. The APC/C regulator protein $\mathrm{Cdc} 20$ is unable to bind to mammalian APC/C when pre-incubated with active PKA. PKA phosphorylates some APC/C core subunits and thereby inhibits its activation by preventing the binding of Cdc20 (Kotani et al. 1998).

In this work the first evidence for Cdc20 as potential target of the cAMP/PKA pathway in yeast was provided. Experiments showed that in budding yeast high levels of Cdc20 partially suppress the inhibitory effect of constitutively active Ras2 protein (Bolte et al. 2003).

Taken together, these results lead to a more detailed model of regulation of the activity of the APC/C by glucose and activated Ras proteins (see Fig. 1). 


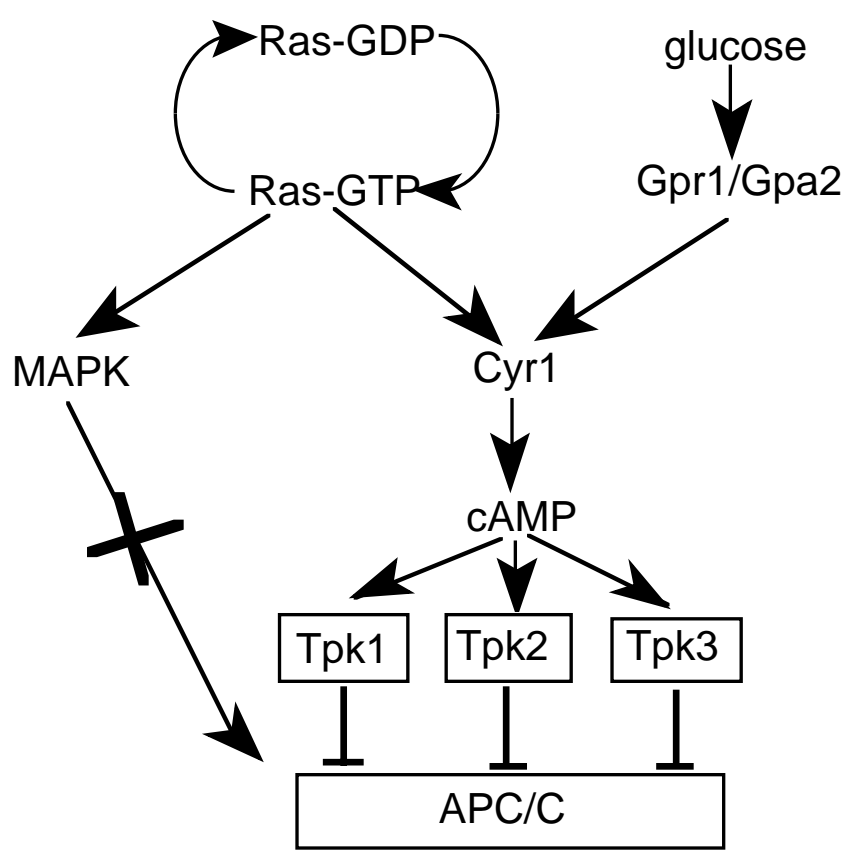

Fig. 1 Model of APC/C regulation by protein kinase A in yeast

The activity of the anaphase promoting complex/cyclosome (APC/C) is inhibited by active protein kinase $\underline{A}$ (PKA), encoded by three genes TPK1-3 in budding yeast. Both known activators of the cAMP/PKA pathway lead to inactivation of the APC/C. Glucose binds to the G-protein coupled receptor system consisting of Gpr1 and Gpa2, which activates the adenylate cyclase Cyr1. cAMP synthesis by Cyr1 can be promoted at the same time by activated Ras proteins. An increase in cAMP levels results in activation of the protein kinase A. Each of the three Tpk proteins is able to mediate the cAMP signal to the APC/C, in contrast to other cell cycle processes where one specific Tpk protein is essential for signal transduction to the target proteins. The Ras signal is mediated exclusively by the cAMP/PKA pathway to the APC/C and not by the mitogen activated protein kinase (MAPK) pathway, which can also be stimulated by active Ras proteins.

What role does glucose and activated Ras proteins play in APC/C regulation? By regulation of $\mathrm{APC} / \mathrm{C}$ activity in response to nutrient conditions, the yeast cell can coordinate cell growth and cell division with nutrient supply.

On rich medium cAMP level in the cell is elevated due to activation of the adenylate cyclase Cyr1. High cAMP levels cause a G1-delay resulting in an enlarged critical cell size before budding initiation. The delay is achieved by inhibition of G1-cyclin transcription, thereby inhibiting entry into S-phase (Baroni et al. 1994).

Not only in G1-, but also in G2/M-phase cell cycle progression can be delayed in response to nutrient conditions. As a consequence of nitrogen starvation in the presence of a fermentable carbon source budding yeast starts to grow as pseudohyphae. In the 
pseudohyphal form exit from mitosis and cell division occurs when the daughter cell has obtained the same size as the mother cell (Kron et al. 1994). Therefore, cell division has to be delayed until the daughter cell has reached a sufficient size. The signal for this G2-delay seems to be a consequence of Ras signalling, because Ras signalling is necessary for pseudohyphae formation (Mösch et al. 1996). PKA-mediated inhibition of APC/C activity could be a mechanism for a delay in mitosis during pseudohyphal growth.

Under good nutrient conditions the progression through the cell cycle is delayed by inhibition of the APC/C, which enables the cells to grow to larger size before cell division. The elongated "Gap"-phases ensure that as long as enough nutrient are in the medium, the cell consume these nutrients to form biomass. This mechanism could contribute to enhance survival under bad nutrient conditions. This would be consistent with the finding, that on rich medium daughter cells were born at larger cell size compared to daughter cells in poor medium (Alberghina et al. 1998).

The cAMP/PKA pathway seems to have a conserved role in growth and division coordination in mitosis, because intracellular cAMP levels always decrease significantly before cell division in budding yeast (Smith et al. 1990). In mammalian somatic cells PKA activity is significantly reduced before anaphase (Kotani et al. 1998).

Parts of the PKA pathway are involved even in the initiation of meiosis (Honigberg and Purnapatre 2003). Extracellular glucose is sensed by a G-coupled receptor Gpr1, which in turn activates a G-protein complex containing Gpa2. GTP-Gpa2 causes activation of PKA. Active PKA inhibits expression of IME1 and IME2, and therefore entrance into meiosis. In addition Gpa2 can bind directly to Ime2 and inhibit its kinase activity during meiosis (Donzeau and Bandlow 1999). In summary the PKA pathway in combination with the $\mathrm{APC} / \mathrm{C}$ represents a universal tool to integrate environmental signals in cell cycle regulation during mitosis as well as during meiosis.

\section{The meiosis-specific protein kinase Ime2 as a novel regulator of the APC/C.}

$\mathrm{APC} / \mathrm{C}$ regulation during the meiotic cell cycle is poorly understood. Therefore, the identification of the meiosis-specific kinase $I M E 2$ in a screen for new negative regulators of the APC/C-dependent proteolysis revealed the opportunity to get new insights into the role of the APC/C during the meiotic cell cycle.

Ime 2 is part of a regulation cascade that governs entry into the sporulation program in the budding yeast $S$. cerevisiae. Ime 2 is essential for early and middle gene expression during 
meiosis. Besides the kinase was found to be necessary for expression and activation of the meiotic transcription activator Ndt80.

Ectopic expression of $I M E 2$ in G1-arrested cells in mitosis stabilises diverse APC/C ${ }^{\mathrm{Cdh} 1}$ substrates, including $\mathrm{Clb} 2, \mathrm{Clb} 3, \mathrm{Cdc} 5$ and delays slightly degradation of the $\mathrm{APC} / \mathrm{C}^{\mathrm{Cdc} 20}$ substrate Pds1. By investigating the mechanism of APC/C inhibition mediated by Ime2 we found that Ime 2 is able to phosphorylate the regulator protein Cdh1 (Bolte et al. 2002).

In additional experiments we examined by immunoprecipitation whether phosphorylation of Cdh1 by Ime 2 prevents its interaction with APC/C. A strain containing a MYC-tagged component of the APC/C core complex, Cdc23-MYC, and an HA-tagged Cdh1 expressed from the weak GALL-promoter, was arrested in G1-phase. After 2 hours of induction of the $G A L$-constructs cells were harvested and crude extracts were prepared. Coimmunoprecipitation experiments using MYC-antibodys showed that HA-Cdh1 can be copurified with Cdc23-MYC, but in the presence of a GAL-IME2 construct no Cdh1 can be detected in the immunoprecipitates (Fig. 2). This result implies that Ime2 inhibits $\mathrm{APC} / \mathrm{C}^{\mathrm{Cdh} 1}$ by preventing the interaction between the regulator protein and the complex due to phosphorylation of $\mathrm{Cdh} 1$. Since IME2 is only expressed in meiosis our data implicate a role for Ime 2 in inactivating the $\mathrm{APC} / \mathrm{C}^{\mathrm{Cdh} 1}$ at the end of G1-phase. In meiosis Ime2 may take over the role of cyclin dependent kinase $\mathrm{Cdc} 28$, which inactivates $\mathrm{APC} / \mathrm{C}^{\mathrm{Cdh} 1}$ in the mitotic cell cycle.

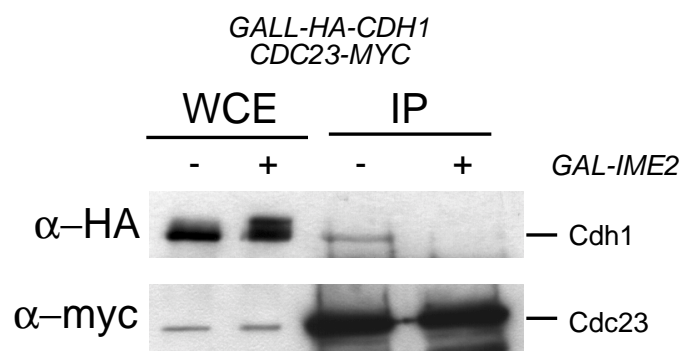

Fig. 2 The kinase Ime 2 can regulate APC/C $\mathrm{C}^{\mathrm{Cdh} 1}$ activity by phosphorylation.

Ectopic expression of IME2 leads to phosphorylation of Cdh1 and thereby prevents its interaction with the APC/C. A wild-type strain (S512) and a GAL-IME2 strain (S511) both carrying GALL-HA-CDH1 and CDC23-MYC constructs were arrested in G1 with alpha-factor. Galactose was added to express the GALconstructs. HA-tagged Cdh1 was detected in whole cell extracts (WCE) and after immunoprecipitation with anti-MYC antibodies (IP). As a control MYC-tagged Cdc23 was also detected before and after immunoprecipitation. 
Ime 2 shares some more similarities with cyclin dependent kinases. First, Ime2 and cyclin dependent kinases share significant sequence similarities. Ime 2 shows $47 \%$ similarity and $31 \%$ identity to human cyclin dependent kinase, $C D K 2$, and $45 \%$ similarity and $27 \%$ identity to yeast cyclin dependent kinase CDC28 (Kominami et al. 1993; Mitchell 1994). Second, both kinases, the G1-specific Cdc28/Cln and Ime2 are responsible for degradation of the cyclin dependent kinase inhibitor Sic1, Cdc28/Cln during mitosis and Ime2 during meiosis (Dirick et al. 1998). As a third similarity this work identified the ability of both kinases to downregulate activity of $\mathrm{APC} / \mathrm{C}^{\mathrm{Cdh} 1}$. Despite of these similarities there are also significant differences between these kinases. Ectopic expression of IME2 in $\alpha$-factor arrested cells or cells lacking G1-cyclins leads to an arrest with unduplicated DNA, indicating that Ime2 can not replace Cdc28/Cln in initiation of DNA replication. During mitosis Cdc28/Cln promotes budding, but ectopic expression of IME2 in cycling cultures leads to accumulation of unbudded cells with replicated DNA. The inhibition of bud formation in mitotic cells suggests a similar role for Ime2 in the meiotic cell cycle. In contrast to $\mathrm{Cdc} 28$, whose activity is regulated by the binding of cyclins, no cyclins are known for Ime2. Binding of cyclins to human cyclin dependent kinase, $C D K 2$, requires two regions: PSTAIRE and the T-loop (Jeffrey et al. 1995). Ime2 does not contain a PSTAIRE-motif, but does include a T-loop region with 52,3\% identity to the T-loop region of human Cdk2. Up to now there have been no reports on proteins binding to that region of Ime2. Ime2 seems to be active upon expression, independently of binding to cyclins.

A model for the regulation of mitotic and meiotic G1-S-phase transitions is illustrated in Fig. 3. 


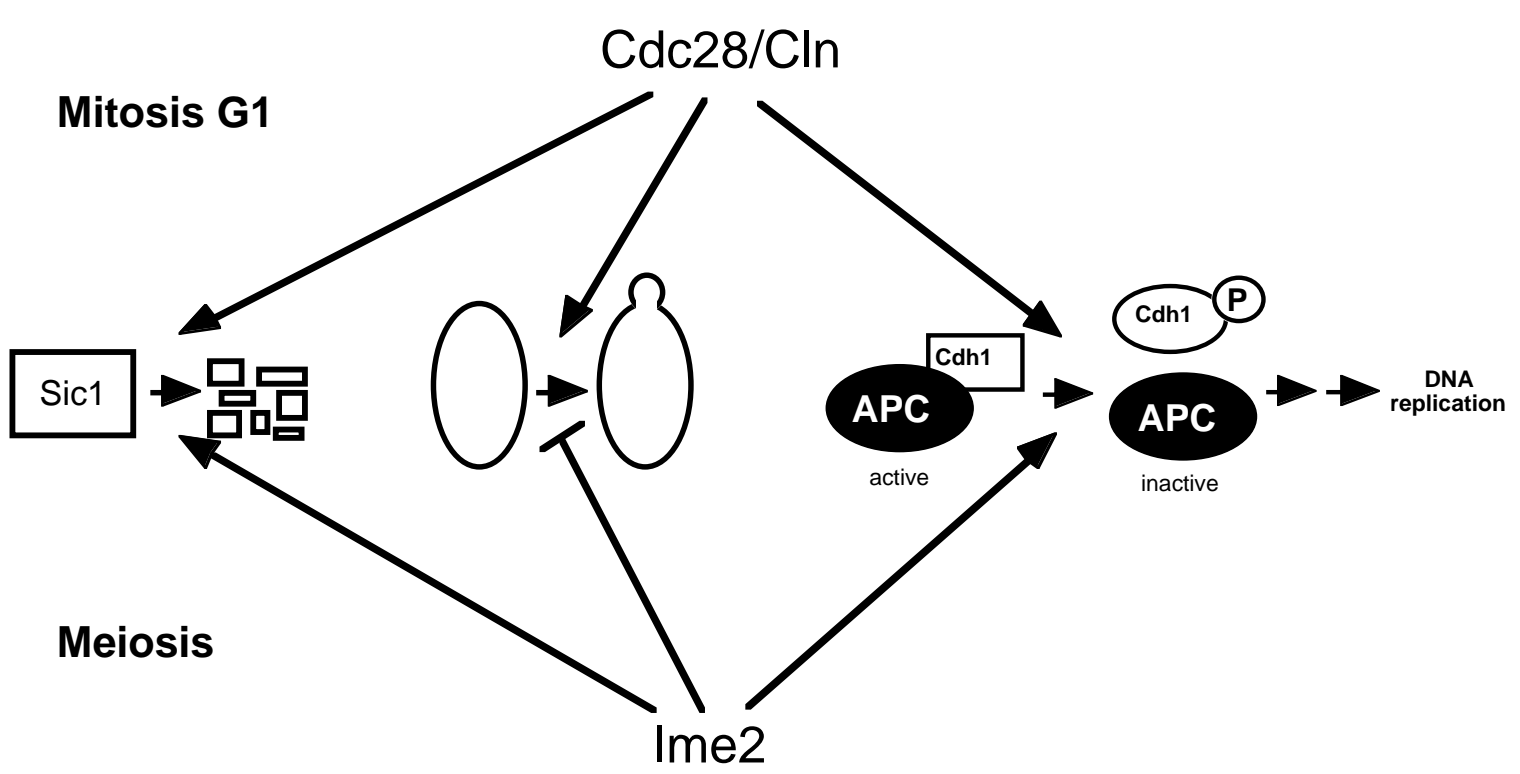

Fig. 3 Comparison of regulation of the G1-S-phase transition during mitosis and meiosis. In mitosis critical events for entry into a new replication cycle like degradation of the cyclin dependent kinase inhibitor Sic1, initiation of bud formation and inactivation of the $\mathrm{APC} / \mathrm{C}^{\mathrm{Cdh} 1}$ complex were triggered by the cyclin dependent kinase Cdc28 in association with G1-cyclins (Cdc28/Cln). During meiosis Ime2 fullfills these functions. In contrast to $\mathrm{Cdc} 28 / \mathrm{Cln}$, Ime 2 does not promote bud formation but inhibits this process.

The aim of future work will focus on the function and regulation of proteolytic degradation mediated by the APC/C during meiosis. The exact mechanism by which the protein kinase Ime2 inhibits APC/C dependent proteolysis during meiosis has to be determined. Is Ime2 able to phosphorylate the regulator protein Cdh1 under sporulation conditions and thereby prevent Cdh1 interaction with the APC/C? At which stage of the meiotic cell cycle is inhibition of the APC/C mediated by Ime2? The last question could be addressed by the use of an analog-sensitive version of the kinase. Substitution of a single conserved amino acid creates an analog-sensitive kinase that is uniquely sensitive to inhibition by cellpermeable purin analogs (Bishop et al. 2000). The addition of the inhibitor at different time points during meiosis efficiently inhibits Ime2 activity (Benjamin et al. 2003). Thus, this modified Ime2 should allow us to test wether Ime2 indeed phosphorylates Cdh1 during meiosis.

What is known about Ime2 homologues and orthologues in other organisms? Two orthologues of Ime2, mde3 and pit1, have been identified in Schizosaccharomyces pombe they were essential for timing of meiotic division and spore formation (Abe and Shimoda 2000). The „, male germ cell- associated kinase“, Mak, is a homologue of Ime2 in mammals, which is found specifically in primary spermatocyctes during late meiotic G2- 
phase (Jinno et al. 1993; Shinkai et al. 2002). Further homologues were indentified in Neurospora crassa, Drosophila melanogaster, Anopheles gambiae, Rattus norvegicus, Mus musculus, and the plant Arabidopsis thaliana (BLASTsearch). The existence of Ime2 orthologues and homologues in many different species, suggests a conserved role of Ime 2 in regulation of meiotic cell cycle progression in eukaryotic organsims.

\section{Regulation of Ime2 stability.}

Ime 2 is an unstable protein, when expressed in cycling cells (Bolte et al. 2002) and in meiosis (Guttmann-Raviv et al. 2002). Its proteolysis seems to be independent of the ubiquitination ligase complexes SCF and APC/C (Bolte et al. 2002). Ime 2 is present throughout the meiotic cell cycle, but kinase activity and protein level are regulated (Benjamin et al. 2003) (see Fig. 1, chapter 4). Factors involved in this regulation process remain still unknown. Since Ime 2 activity is not regulated by cyclin binding, it is conceivable that activity could be controlled by its own instability. To gain more information about Ime2 stability we have constructed a deletion set in order to identify regions responsible either for rapid degradation or functionality of Ime2. The experimental data indicate that the $\mathrm{N}$-terminal part of the protein is necessary for kinase activity, whereas the C-terminal part of the protein contains degradation signals as proposed by Kominami et al. (1993). Deletion of the last 241 aa results in a drastically stabilised Ime2 protein, which is still fully active when expressed ectopically in vegetative growing cells. The truncated protein can, like the full-length version, inhibit APC/C activity when expressed in the mitotic cell cycle. Ectopic expression stabilises the cyclin $\mathrm{Clb} 2$ and results in an efficient cell cycle arrest.

Overexpression of IME2 lacking its C-terminus was known to successfully override the pre-requisite of nutrient limitation for initiation of sporulation (Kominami et al. 1993). Normally the accumulation of Ime 2 protein and thereby entry into the meiotic cell cycle is inhibited by its rapid degradation under non-starvation conditions. Kominami could also show that the truncated Ime2 exhibits higher kinase activity in vitro as the wild-type protein. Our data suggest that these effects are due to its increased stability. It was shown that the posttranslational control of Ime 2 activity is also impaired when the C-terminus of the protein is deleted. This is due to the fact, that the nutrient signal sensed by the Gprotein is transmitted to the C-terminus. GTP-bound Gpa2 binds specifically to Ime 2 and thereby inhibits the kinase activity (Donzeau and Bandlow 1999). 
We have shown that W303 wild-type strains heterozygous for the truncated Ime 2 under control of its own promoter form abnormal asci containing two or three instead of four spores under sporulation conditions. In strains homozygous for the truncated Ime 2 this effect is enhanced. Moreover sporulation efficiency is significantly reduced in comparison to the wild-type strain expressing the full-length IME2. This shows that a controlled decrease in Ime2 protein level during sporulation is essential for proper progression through sporulation. In summary, Ime 2 and its controlled degradation fullfill an important role in triggering the decision to initiate and regulate progression through meiotic differentiation in S. cerevisiae. Comparable to fluctuating Cdc28 activity levels essential for progression through mitosis, a fluctuating Ime2 level seems to be necessary for meiotic progression.

It has to be clarified in the future how the activity and the stability of Ime 2 are regulated during the meiotic cell cycle, resulting in two peaks of activity. Is Ime 2 activity regulated by other factors, comparable to regulation of cyclin dependent kinase activity by cyclins? In general Ime 2 is active without association with other proteins. This is supported by the ability of recombinant Ime2 isolated from Escherichia coli to phosphorylate histone $\mathrm{H} 1$ in vitro. But for phosphorylation of the native substrate Gpa2, Ime2 has to be isolated from yeast (Donzeau and Bandlow 1999), indicating that at least for some substrates, Ime2 needs to be modified by an additional factor. Therefore it would be interesting during the course of future work to perform a screen for regulators of Ime 2 itself.

Furthermore we are interested in the degradation of Ime 2 itself. Is its proteolysis mediated by ubiquitination and performed by the $26 \mathrm{~S}$ proteasome? Which sequence signals in the Cterminal region target Ime 2 for its rapid degradation? Do additional factors exist which promote or inhibit degradation of Ime2? The effect of the truncated stabilised Ime 2 on progression through sporulation and on Ime2 activity pattern during meiosis of the high efficient sporulating SK1 strain has to be analysed. This should allow us to determine which processes in meiosis are inhibited by the stabilised Ime2. 


\section{The meiosis-specific APC/C regulator protein, Ama1.}

Up to now only the degradation of one APC/C substrate, Pds1, was investigated in detail during meiosis (Lee and Amon 2001). Analysis of APC/C dependent proteolysis of other substrates, could clarify the role of $\mathrm{APC} / \mathrm{C}$ for co-ordination of meiotic cell cycle progression. Therefore, investigation of the different functions displayed by the three WD proteins Cdh1, Cdc20 and Ama1, involved in regulation of APC/C activity and substrate specificity, should lead to a better understanding of how the cell manages to prevent a intervening S-phase after the first meiotic division.

AMA1 is only expressed and spliced during meiosis and represents an additional meiosisspecific regulator protein of the APC/C. Since during mitosis two regulator proteins Cdh1 and $\mathrm{Cdc} 20$ are sufficient for regulation of APC/C substrate specifity, we asked whether Ama1 can take over some functions of the other regulator proteins when expressed during mitosis? When Cooper et al. (2000) identified the new meiosis-specific regulator Ama1, they proposed that activation of $\mathrm{APC} / \mathrm{C}^{\mathrm{Amal}}$ depends on phosphorylation. Two candidateactivating kinases are $\mathrm{Cdc} 28$ and Ime2. In silico analysis revealed that Ama1 contains two full cyclin dependent kinase (CDK) consensus sites (S/T-P-X-K/R) and five minimal CDK consensus sites (S/T-P), that make Ama1 a potential Cdc28 target protein. In a recently published screen for targets of Cdk substrates in budding yeast among 695 proteins no phosphorylation of Ama1 by Cdc28 could be determined (Ubersax et al. 2003). This argues against Cdc28 as the modifier of Ama1.

To analyse the role of Ama1, a meiosis-specific WD repeat protein related to Cdc20 and $\mathrm{Cdh} 1$, some initial experiments have been performed. A 1,7 kb fragment containing the $A M A 1$ gene was amplified from a $S$. cerevisiae $G A L-c D N A$ library, and cloned into the $C E N$-plasmid pRS313 (Sikorski and Hieter 1989; Mumberg et al. 1994) between the GALpromoter and the $C Y C 1$ terminator (pME2655). A $B g l I I$ restriction site was introduced behind the start codon of AMAl. Nine copies of the MYC-tag were cloned as a $B g l$ IIfragment into this site, resulting in the CEN-plasmid pRS316I-GAL-MYC9-AMA1-CYC1 (pME2657).

Ama1 protein levels were determined in different cell cycle arrests. Strains carrying a $C E N$-plasmid containing the MYC-tagged Ama1 expressed from the GAL-promoter were arrested in different stages of the cell cycle: with alpha-factor in G1-phase, with nocodazol in M-phase or with hydroxyurea in S-phase, then galactose was added to express the $G A L$ constructs. The level of Ama1 was constant in all phases of the cell cycle. In addition to 
Ama1 itself a slower migrating band which seemed to be a modified version of Ama1 occured in the immunoblott analysis. The quantity of modified Ama1 decreased significantly in G1-phase (Fig. 4A). The factors involved in modification of Ama1 remain unknown, but modification of Ama1 occurs in a cell cycle regulated manner.

In order to find out whether Ama1 is phosphorylated by Ime 2 we used a strain containing GAL-MYC9-AMA1. Cultures were grown in minimal medium lacking uracil. To check whether the slower migrating band corresponds to Ama1, a control using the untagged version of Ama1was performed. As expected, no signal was obtained after galactose addition to the wild-type carrying the GAL-AMA1 construct (Fig. 4B, lane1). So the shifted band is specific and belongs to Ama1. In G1 arrested cells expressing the GAL-MYC9$A M A$ only a small amount of Ama1 produced slower migrating bands, (Fig.4B, lane 3, 4). G1 arrested cells containing both GAL-MYC9-AMA and the GAL-IME2 construct showed the same result (Fig.4B, lane 5, 6), indicating that Ime2 does not lead to phosphorylation of Ama1 in G1 arrested cells.

To address the question whether Ama1 can fullfill some functions of Cdh1 in mitosis we tested if ectopic expression of AMAl in mitosis can suppress the G1-defect of $\Delta c d h 1$ mutants. A $\Delta c d h 1$ mutant is viable, but defective in $\mathrm{Clb} 2$ degradation and impaired in the response to alpha-factor treatment. A wild-type and a $\Delta c d h 1$ mutant were transformed with a $C E N$-plasmid containing either the GAL-AMA1 construct, or the empty vector YCplac33 (URA3 marker). Samples were collected before and after induction of the GAL-promoter and in absence and presence of alpha-factor. In cycling cultures ectopic expression of AMA1 did not influence cell cycle progression significantly neither in wild-type nor in $\Delta c d h 1$ mutant cells. In the presence of alpha-factor wild-type strains arrested to $99 \%$ as unbudded cells no matter which plasmid was transformed. In $\Delta c d h 1$ mutant cultures carrying the empty vector $24 \%$ of the cells remained as budded cells, whereas expression of AMA1 resulted in a slight but reproduceable reduction to $14 \%$ budded cells (Fig.4D). It seems that ectopic expression of $A M A 1$ leads to a partial suppression of the G1-defect of $\Delta c d h 1$ mutants.

In an initial experiment we have also analysed the stability of Ama1 in $G A L$-promoter shutoff experiments. A wild-type strain carrying the MYC-tagged Ama1 expressed from the $G A L$-promoter on a $C E N$-plasmid was used. Amal was degraded within 40 minutes after transfer to glucose medium. Interestingly the modified form producing slower migrating bands remained stable and was detectable up to 80 minutes after promoter 
shutoff (Fig. 4D). These preliminary results indicate that Ama1 is like Cdc20 a highly unstable protein. In further experiments it will be interesting to determine whether Ama1 protein level fluctuates during meiosis.

A

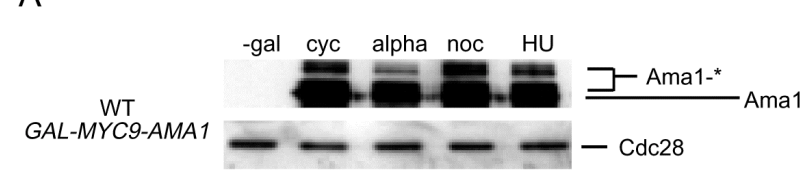

C

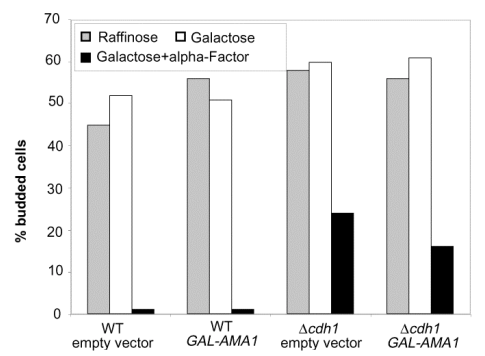

$\mathrm{B}$

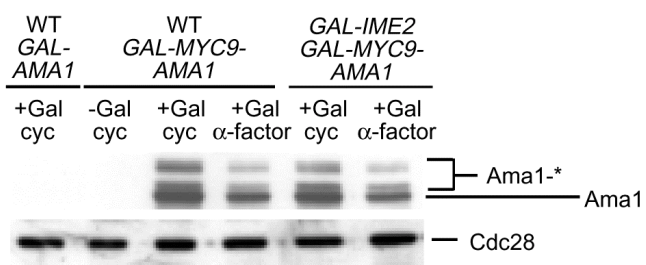

D

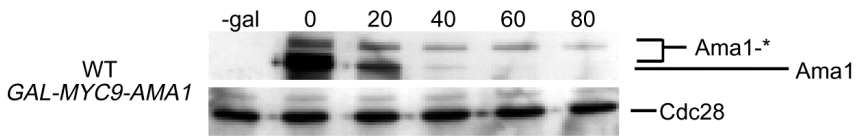

Fig. 4

A) Modification of Ama1 is cell cyle regulated. Wild-type strain carrying a $C E N$-plasmid containing the MYC-tagged Ama1 expressed from the GAL-promoter was arrested in different phases of the cell cycle: with alpha-factor (alpha) in G1-phase, nocodazol (noc) in M-phase or hydroxyurea (HU) in S-phase, then galactose was added to express the $G A L$-construct. B) Ime2 is not able to phosphorylate Ama1. A wild-type strain and a strain containing the GAL-IME2 (S396) construct were transformed with a $C E N$-plasmid carrying GAL-MYC9-AMA1. Transformants were selected on minimal medium lacking uracil. Galactose was added to induce the $G A L$-constructs and samples were collected in the absence and presence of alpha-factor. In order to prove that the slower migrating bands are no unspecific signals but belong to the expression of $G A L$ MYC9-AMA1 a wild-type carrying GAL-AMAl was used. C) A wild-type strain and a $c d h 1$-deletion strain were transformed with a $C E N$-plasmid containing the GAL-AMAl construct. As a control the empty vector was used. Samples were collected before and after induction of the $G A L$-promoter and in absence and presence of alpha-factor. The percentage of budded cells was determined by microscopy. D) Ama1 is rapidly degraded in mitosis, but the modified form seems to be stabilised. Stability of Ama1 expressed from the $G A L$-promoter on a centromeric plasmid was analysed in a $G A L$-promoter shutoff experiment. Samples were collected before addition of galactose (-gal) and at the indicated time points after $G A L$-promoter shut off.

It should be the aim of future work to find out by which mechanism Ama1 is degraded and what kind of modification is able to protect Amal from degradation. For analysis of the modification a proteomic approach could be useful, in which the immunoprecipitated protein is separated on a 2D-polyacrylamide gel and analysed by mass spectrometry. It should be analysed whether Ama1 is modified during meiosis and whether modification of Amal is cell cycle regulated during sporulation like phosphorylation of Ime2. How does 
the modification of Ama1 influence APC/C activity? Is modification of Ama1 necessary for its association with the APC/C or inhibits this modification the activation of the APC/C? To clarify the question which substrates are degraded by $\mathrm{APC} / \mathrm{C}^{\mathrm{Ama} 1}$ during meiosis, the stability of tagged APC/C substrates should be analysed in amal deletion strains. 


\section{References}

Abe, H. and C. Shimoda. 2000. Autoregulated expression of Schizosaccharomyces pombe meiosis-specific transcription factor Mei4 and a genome-wide search for its target genes. Genetics 154: 1497-508.

Alberghina, L., C. Smeraldi, B.M. Ranzi, and D. Porro. 1998. Control by nutrients of growth and cell cycle progression in budding yeast, analyzed by double-tag flow cytometry. J Bacteriol 180: 3864-72.

Anghileri, P., P. Branduardi, F. Sternieri, P. Monti, R. Visintin, A. Bevilacqua, L. Alberghina, E. Martegani, and M.D. Baroni. 1999. Chromosome separation and exit from mitosis in budding yeast: dependence on growth revealed by cAMPmediated inhibition. Exp Cell Res 250: 510-23.

Baroni, M.D., P. Monti, and L. Alberghina. 1994. Repression of growth-regulated G1 cyclin expression by cyclic AMP in budding yeast. Nature 371: 339-42.

Benjamin, K.R., C. Zhang, K.M. Shokat, and I. Herskowitz. 2003. Control of landmark events in meiosis by the CDK Cdc28 and the meiosis-specific kinase Ime2. Genes Dev 17: 1524-39.

Bishop, A.C., J.A. Ubersax, D.T. Petsch, D.P. Matheos, N.S. Gray, J. Blethrow, E. Shimizu, J.Z. Tsien, P.G. Schultz, M.D. Rose, J.L. Wood, D.O. Morgan, and K.M. Shokat. 2000. A chemical switch for inhibitor-sensitive alleles of any protein kinase. Nature 407: 395-401.

Bolte, M., P. Dieckhoff, C. Krause, G.H. Braus, and S. Irniger. 2003. Synergistic inhibition of APC/C by glucose and activated Ras proteins can be mediated by each of the Tpk1-3 proteins in Saccharomyces cerevisiae. Microbiology 149: 1205-16.

Bolte, M., P. Steigemann, G.H. Braus, and S. Irniger. 2002. Inhibition of APC-mediated proteolysis by the meiosis-specific protein kinase Ime2. Proc Natl Acad Sci U S A 99: 4385-90.

Cooper, K.F., M.J. Mallory, D.B. Egeland, M. Jarnik, and R. Strich. 2000. Ama1p is a meiosis-specific regulator of the anaphase promoting complex/cyclosome in yeast. Proc Natl Acad Sci U S A 97: 14548-53.

Dirick, L., L. Goetsch, G. Ammerer, and B. Byers. 1998. Regulation of meiotic S phase by Ime 2 and a Clb5,6-associated kinase in Saccharomyces cerevisiae. Science 281: 1854-7.

Donzeau, M. and W. Bandlow. 1999. The yeast trimeric guanine nucleotide-binding protein alpha subunit, Gpa2p, controls the meiosis-specific kinase Ime2p activity in response to nutrients. Mol Cell Biol 19: 6110-9.

Guttmann-Raviv, N., S. Martin, and Y. Kassir. 2002. Ime2, a meiosis-specific kinase in yeast, is required for destabilization of its transcriptional activator, Ime1. Mol Cell Biol 22: 2047-56.

Honigberg, S.M. and K. Purnapatre. 2003. Signal pathway integration in the switch from the mitotic cell cycle to meiosis in yeast. $J$ Cell Sci 116: 2137-47.

Irniger, S., M. Bäumer, and G.H. Braus. 2000. Glucose and ras activity influence the ubiquitin ligases APC/C and SCF in Saccharomyces cerevisiae. Genetics 154: 1509-21.

Jeffrey, P.D., A.A. Russo, K. Polyak, E. Gibbs, J. Hurwitz, J. Massague, and N.P. Pavletich. 1995. Mechanism of CDK activation revealed by the structure of a cyclinA-CDK2 complex. Nature 376: 313-20.

Jinno, A., K. Tanaka, H. Matsushime, T. Haneji, and M. Shibuya. 1993. Testis-specific mak protein kinase is expressed specifically in the meiotic phase in 
spermatogenesis and is associated with a 210-kilodalton cellular phosphoprotein. Mol Cell Biol 13: 4146-56.

Kominami, K., Y. Sakata, M. Sakai, and I. Yamashita. 1993. Protein kinase activity associated with the IME2 gene product, a meiotic inducer in the yeast Saccharomyces cerevisiae. Biosci Biotechnol Biochem 57: 1731-5.

Kotani, S., S. Tugendreich, M. Fujii, P.M. Jorgensen, N. Watanabe, C. Hoog, P. Hieter, and K. Todokoro. 1998. PKA and MPF-activated polo-like kinase regulate anaphase-promoting complex activity and mitosis progression. Mol Cell 1: 371-80.

Kron, S.J., C.A. Styles, and G.R. Fink. 1994. Symmetric cell division in pseudohyphae of the yeast Saccharomyces cerevisiae. Mol Biol Cell 5: 1003-22.

Lee, B. and A. Amon. 2001. Meiosis: how to create a specialized cell cycle. Curr Opin Cell Biol 13: 770-7.

Mitchell, A.P. 1994. Control of meiotic gene expression in Saccharomyces cerevisiae. Microbiol Rev 58: 56-70.

Mösch, H.U., E. Kübler, S. Krappmann, G.R. Fink, and G.H. Braus. 1999. Crosstalk between the Ras2p-controlled mitogen-activated protein kinase and cAMP pathways during invasive growth of Saccharomyces cerevisiae. Mol Biol Cell 10: 1325-35.

Mösch, H.U., R.L. Roberts, and G.R. Fink. 1996. Ras2 signals via the Cdc42/Ste20/mitogen-activated protein kinase module to induce filamentous growth in Saccharomyces cerevisiae. Proc Natl Acad Sci U S A 93: 5352-6.

Mumberg, D., R. Muller, and M. Funk. 1994. Regulatable promoters of Saccharomyces cerevisiae: comparison of transcriptional activity and their use for heterologous expression. Nucleic Acids Res 22: 5767-8.

Robertson, L.S., H.C. Causton, R.A. Young, and G.R. Fink. 2000. The yeast A kinases differentially regulate iron uptake and respiratory function. Proc Natl Acad Sci U S A 97: 5984-8.

Robertson, L.S. and G.R. Fink. 1998. The three yeast A kinases have specific signaling functions in pseudohyphal growth. Proc Natl Acad Sci U S A 95: 13783-7.

Shinkai, Y., H. Satoh, N. Takeda, M. Fukuda, E. Chiba, T. Kato, T. Kuramochi, and Y. Araki. 2002. A testicular germ cell-associated serine-threonine kinase, MAK, is dispensable for sperm formation. Mol Cell Biol 22: 3276-80.

Sikorski, R.S. and P. Hieter. 1989. A system of shuttle vectors and yeast host strains designed for efficient manipulation of DNA in Saccharomyces cerevisiae. Genetics 122: 19-27.

Smith, M.E., J.R. Dickinson, and A.E. Wheals. 1990. Intracellular and extracellular levels of cyclic AMP during the cell cycle of Saccharomyces cerevisiae. Yeast 6: 53-60.

Thevelein, J.M. and J.H. de Winde. 1999. Novel sensing mechanisms and targets for the cAMP-protein kinase A pathway in the yeast Saccharomyces cerevisiae. Mol Microbiol 33: 904-18.

Ubersax, J.A., E.L. Woodbury, P.N. Quang, M. Paraz, J.D. Blethrow, K. Shah, K.M. Shokat, and D.O. Morgan. 2003. Targets of the cyclin-dependent kinase Cdk1. Nature 425: 859-64.

Yamashita, Y.M., Y. Nakaseko, I. Samejima, K. Kumada, H. Yamada, D. Michaelson, and M. Yanagida. 1996. 20S cyclosome complex formation and proteolytic activity inhibited by the cAMP/PKA pathway. Nature 384: 276-9. 


\section{Danksagung}

Mein herzlicher Dank gilt meinem Doktorvater Prof. Dr. Gerhard H. Braus für die Ermöglichung dieser Arbeit in seiner Abteilung, sowie die Übernahme des Referats.

Mein besonderer Dank gebührt Dr. Stefan Irniger, der mich in das Arbeiten mit eukaryontischen Mikroorganismen eingeführt hat, und mir während meiner gesamten Doktorarbeit stets mit Rat und Tat zur Seite stand. Seine exzellente Betreuung hat mir die Arbeit sehr erleichtert. Danken möchte ich ihm auch für die gewissenhafte Durchsicht des Manuskriptes, den richtigen Riecher bei der Auswahl der Journals für meine Publikationen, sowie seine hervorragenden Ideen für weiterführende Experimente.

Wibke Meyer hat während meiner Doktorarbeit mit ihrer exzellenten Diplomarbeit entscheidend zur weiteren Analyse des Ime2 Proteins beigetragen.

Ein herzliches Dankeschön für die Übernahme des Korreferats und die Unterstützung bei sämtlichen Mac-spezifischen Computerproblemen geht an Prof. Dr. Hans-Ulrich Mösch.

Mein Dank gilt auch meinen ehemaligen und derzeitigen Kollegen im Labor: Patrick Dieckhoff, Wibke Meyer, Yasemin Sancak, Jürg Stebler, Jessica Jabin, Fathi Sari und Ingrid Bahr für die stets gute Arbeitsatmosphäre.

Patrick Steigemann und Cindy Krause haben mit ihren Diplomarbeiten eine erhebliche Vorarbeit geleistet, auf die ich aufbauen konnte.

Danken möchte ich auch Silke Busch, Patrick Dieckhoff, Sven Krappmann, Krystyna Nahlik und Oliver Valerius für das Korrekturlesen des Manuskriptes. Vielen Dank auch allen anderen Mitgliedern der Arbeitsgruppe Braus, die dazu beigetragen haben, daß ich mich hier immer sehr wohl gefühlt habe.

Meinen Eltern und meinen Geschwistern möchte ich für alles, was sie bisher für mich getan haben, ganz herzlich danken. Während den Jahre des Studiums bin ich stets in jeder Hinsicht von ihnen unterstützt worden.

Abschliessend ein riesiges Dankeschön an meinen Freund Alexander Heinrich, der mit mir durch alle Höhen und Tiefen meines Studiums und meiner Promotion gegangen ist. Er hat mir vor allem in Stressituationen die nötige Kraft zum Durchhalten gegeben. 


\section{Curriculum Vitae}

\section{Melanie Bolte}

Geburtsdatum: $\quad 26.04 .1976$

Geburtsort:

Hann. Münden

$1982-1986$

Grundschule Reinhardshagen

1986-1988

Förderstufe Reinhardshagen

1988-1995

Grotefend Gymnasium Münden

1995-2000

Studium der Biologie an der Georg-August-Universität zu Göttingen

Oktober 1999

Diplom in Biologie

Hauptfach: Mikrobiologie

Nebenfächer: Biochemie und organische Chemie

$1999-2000$

Diplomarbeit am Institut für Mikrobiologie und Genetik,

Georg-August-Universität zu Göttingen, bei PD Dr. B. Averhoff in

der Abteilung von Prof. Dr. G. Gottschalk

Thema: ,, Typ-IV-Pili und natürliche Transformation:

Molekularbiologische und physiologische Charakterisierung einer unbeweglichen Acinetobacter sp. BD413-Mutante“

Februar 2001 bis

Dezember 2003

Doktorarbeit am Institut für Mikrobiologie und Genetik, Georg-August-Universität zu Göttingen, bei Prof. Dr. G. H. Braus

Thema: „Regulation of the anaphase promoting complex (APC/C) in the mitotic and meiotic cell cycle of Saccharomyces cerevisiae“ 